\title{
POTENCIAL DE DESARROLLO DE PLANTACIONES DENDROENERGÉTICAS EN LA ARGENTINA
}




\section{POTENCIAL DE DESARROLLO DE PLANTACIONES DENDROENERGÉTICAS EN LA ARGENTINA}

Proyecto para la promoción de la energía

derivada de biomasa (UTF/ARG/020/ARG) 
FAO. 2020. Potencial de desarrollo de plantaciones dendroenergéticas en la Argentina. Colección Documentos Técnicos N. ${ }^{\circ}$ 18. Buenos Aires. https://doi..org/10.4060/ca8031es

Las denominaciones empleadas en este producto informativo y la forma en que aparecen presentados los datos que contiene no implican, por parte de la Organización de las Naciones Unidas para la Alimentación y la Agricultura (FAO), juicio alguno sobre la condición jurídica o nivel de desarrollo de países, territorios, ciudades o zonas, o de sus autoridades, ni respecto de la delimitación de sus fronteras o límites. La mención de empresas o productos de fabricantes en particular, estén o no patentados, no implica que la FAO los apruebe o recomiende de preferencia a otros de naturaleza similar que no se mencionan.

Las opiniones expresadas en este producto informativo son las de su(s) autor(es), y no reflejan necesariamente los puntos de vista o políticas de la FAO.

ISBN 978-92-5-132261-1

(C) FAO, 2020

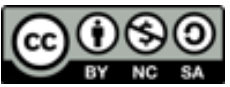

Algunos derechos reservados. Este obra está bajo una licencia de Creative Commons Reconocimiento-NoComercial-Compartirlgual 3.0 Organizaciones intergubernamentales.; https://creativecommons.org/licenses/by-nc-sa/3.0/igo/deed.es).

De acuerdo con las condiciones de la licencia, se permite copiar, redistribuir y adaptar la obra para fines no comerciales, siempre que se cite correctamente, como se indica a continuación. En ningún uso que se haga de esta obra debe darse a entender que la FAO refrenda una organización, productos o servicios específicos. No está permitido utilizar el logotipo de la FAO. En caso de adaptación, debe concederse a la obra resultante la misma licencia o una licencia equivalente de Creative Commons. Si la obra se traduce, debe añadirse el siguiente descargo de responsabilidad junto a la referencia requerida: "La presente traducción no es obra de Organización de las Naciones Unidas para la Alimentación y la Agricultura (FAO). La FAO no se hace responsable del contenido ni de la exactitud de la traducción. La edición original en inglés será el texto autorizado".

Toda mediación relativa a las controversias que se deriven con respecto a la licencia se llevará a cabo de conformidad con las Reglas de Mediación de la Comisión de las Naciones Unidas para el Derecho Mercantil Internacional (CNUDMI) en vigor.

Materiales de terceros. Si se desea reutilizar material contenido en esta obra que sea propiedad de terceros, por ejemplo, cuadros, gráficos o imágenes, corresponde al usuario determinar si se necesita autorización para tal reutilización y obtener la autorización del titular del derecho de autor. El riesgo de que se deriven reclamaciones de la infracción de los derechos de uso de un elemento que sea propiedad de terceros recae exclusivamente sobre el usuario.

Ventas, derechos y licencias. Los productos informativos de la FAO están disponibles en la página web de la Organización (http://www.fao.org/publications/es) y pueden adquirirse dirigiéndose a publications-sales@fao.org. Las solicitudes de uso comercial deben enviarse a través de la siguiente página web: www.fao.org/contact-us/licence-request.

Las consultas sobre derechos y licencias deben remitirse a: copyright@fao.org. 
Este documento fue realizado en el marco del Proyecto para la promoción de la energía derivada de biomasa (UTF/ARG/020/ARG), iniciativa de los siguientes ministerios:

\section{Ministerio de Agricultura, Ganadería y Pesca}

Luis Miguel Etchevehere

Ministro de Agricultura, Ganadería

y Pesca de la Nación

Andrés Murchison

Secretario de Alimentos y Bioeconomía

Miguel Almada

Director de Bioenergía

\section{Ministerio de Hacienda}

Hernán Lacunza

Ministro de Hacienda

Gustavo Lopetegui

Secretario de Gobierno de Energía

Sebastián A. Kind

Subsecretario de Energías Renovables

Maximiliano Morrone

Director Nacional de Promoción

de Energías Renovables

\section{Organización de las Naciones Unidas para la Alimentación y la Agricultura}

Hivy Ortiz Chour

Oficial Forestal Principal

Oficina Regional América Latina
Francisco Yofre

Oficial de Programas

Oficina Argentina

Karina Casellas

Ana María Lupi

Demián Olemberg

Javier Gyenge

Roberto Fernández

Hugo E. Fassola

Constantino Zaderenko

Fabiana Navarro de Rau

Autores

Guillermo Parodi

Coordinación y supervisión técnica

Verónica González

Coordinación Colección

Sofía Damasseno

Colaboración Colección

Alejandra Groba

Edición y corrección

Mariana Piuma

Diseño e ilustraciones 


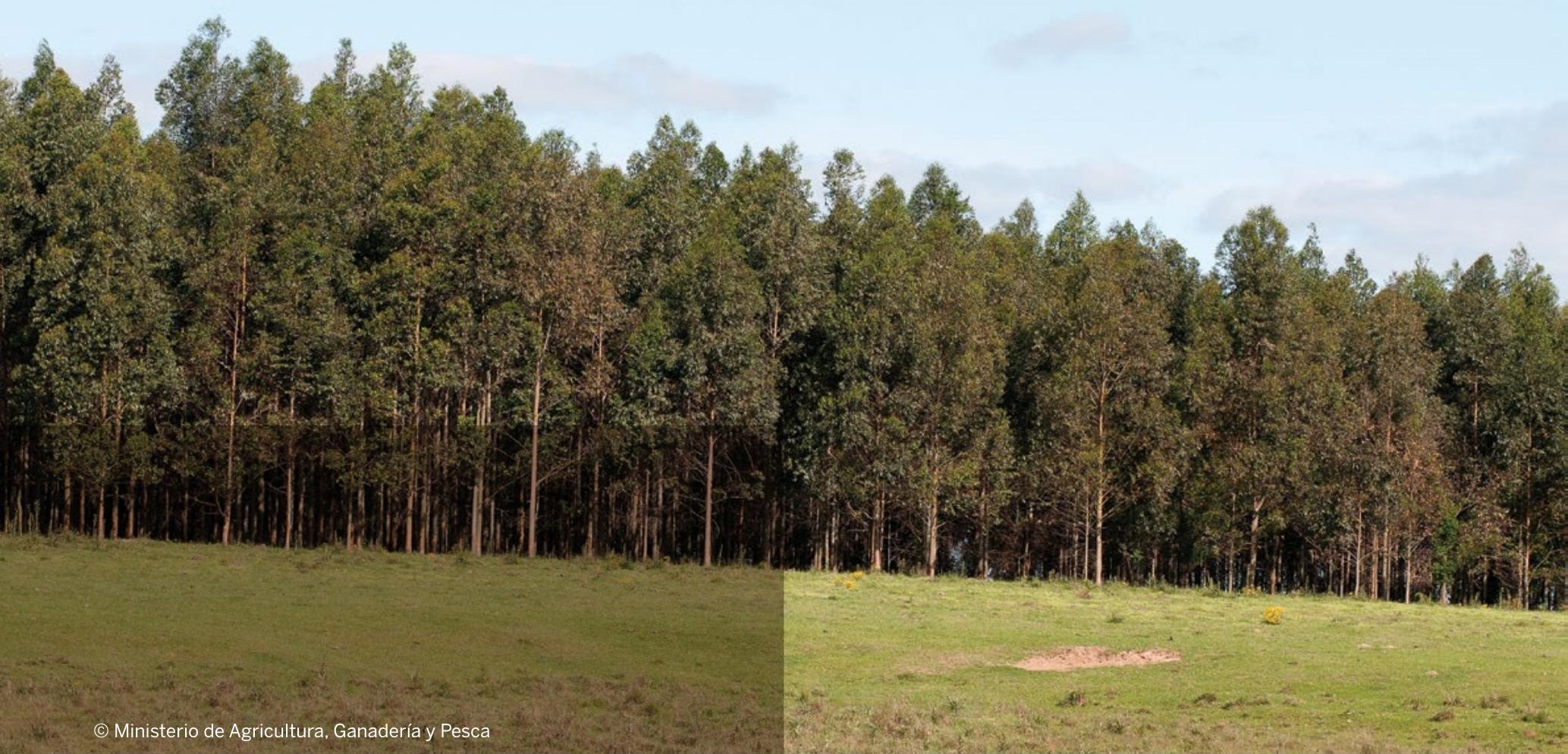


Prólogo

Agradecimientos

Siglas y acrónimos

Unidades de medida

Resumen ejecutivo

1

Introducción

C.

\section{Análisis de aspectos regulatorios y}

socioeconómicos

Energías renovables no convencionales en la

Argentina: el caso de la biomasa

Usos de las principales fuentes de biomasa

Escenarios potenciales

Marco regulatorio: incentivos y vacíos

(y falencias) normativas

Ley 27191

Dendroenergía y sistemas dendroenergéticos

Forestación dendroenergética: estímulos,

costos y sustentabilidad

Potencial demanda de mano de obra

\}.

Áreas potencialmente aptas para especies dendroenergéticas y productividad de cada una

Materiales y métodos

Mapas de aptitud para plantaciones

dendroenergéticas en la Argentina

Región Mesopotamia

28

Región Central

Región NOA

Región Pampeana
1

ix

xi

xiii

xiii

O

Conclusiones

73
כ.

Modelo técnico-económico de generación de energía y análisis de rentabilidad

Modelo de generación dendroenergética

Rentabilidad de la producción biomasa en función del costo de transformación en usinas

\section{Bibliografía}


Cuadro 1 Mano de obra demandada en plantaciones forestales dendroenergéticas

Cuadro 2 Clases de aptitud de las especies forestales propuestas, por región

Cuadro 3 Crecimiento en volumen para diferentes especies y regiones según la aptitud de las tierras

Cuadro 4 Superficie potencialmente apta para plantaciones

Cuadro 5

Superficie potencial para plantaciones dendroenergéticas en la Argentina, según aptitud de las especies en cada región

Cuadro 6 Superficie potencialmente apta para Eucalyptus grandis y Pinus taeda en la Región Mesopotamia

Cuadro 7 Superficie potencialmente apta para Eucalyptus grandis, E. camaldulensis, E. tereticornis y E. viminalis en la Región Central

Cuadro 8 Superficie potencialmente apta para las especies Eucalyptus grandis y E. camaldulensis en la Región NOA

Cuadro 9 Superficie potencialmente apta para Eucalyptus dunnii, E. camaldulensis, E. viminalis, Populus spp. y Salix spp. en la Región Pampeana

Cuadro 10 Resultado económico de modelos productivos Costos de las tareas de extracción de la biomasa del campo Costos fijos y variables del transporte por camión de biomasa combustible en usinas de 0,5, 1,0 y 2,0 MW 
Mapa 1 Áreas potencialmente aptas para plantaciones dendroenergéticas en la Argentina, según criterios propuestos por el INTA en 2016

Mapa 2 Áreas potencialmente aptas para Eucalyptus grandis en la Región Mesopotamia 32

Mapa 3 Áreas potencialmente aptas para Pinus taeda en la Región Mesopotamia

Mapa 4 Áreas potencialmente aptas para Eucalyptus grandis en la Región Central 34

Mapa 5 Áreas potencialmente aptas para Eucalyptus camaldulensis en la Región Central 35

Mapa 6 Áreas potencialmente aptas para Eucalyptus tereticornis en la Región Central

Mapa 7 Áreas potencialmente aptas para Eucalyptus viminalis en la Región Central

Mapa 8 Áreas potencialmente aptas para Eucalyptus grandis en la Región NOA

Mapa 9 Áreas potencialmente aptas para Eucalyptus camaldulensis en la Región NOA

Mapa 10 Áreas potencialmente aptas para Eucalyptus dunnii en la Región Pampeana

Mapa 11 Áreas potencialmente aptas para Eucalyptus camaldulensis en la Región Pampeana

Mapa 12 Áreas potencialmente aptas para Eucalyptus viminalis en la Región Pampeana

Mapa 13 Áreas potencialmente aptas para Populus spp. en la Región Pampeana

Mapa 14 Áreas potencialmente aptas para Salix spp. en la Región Pampeana

\section{Gráficos}

Gráfico 1 Composición de la oferta interna de energía primaria en la Argentina, en porcentaje

Gráfico 2 Participación promedio de las ERNC en la Argentina

Gráfico 3 Pasos para la obtención del mapa de áreas potencialmente aptas para plantaciones dendroenergéticas

Gráfico 4 Precios mínimos en cada región según tasa de descuento

Gráfico 5 Sensibilidad del precio ante cambios en el valor de variables clave en la estructura de costos 


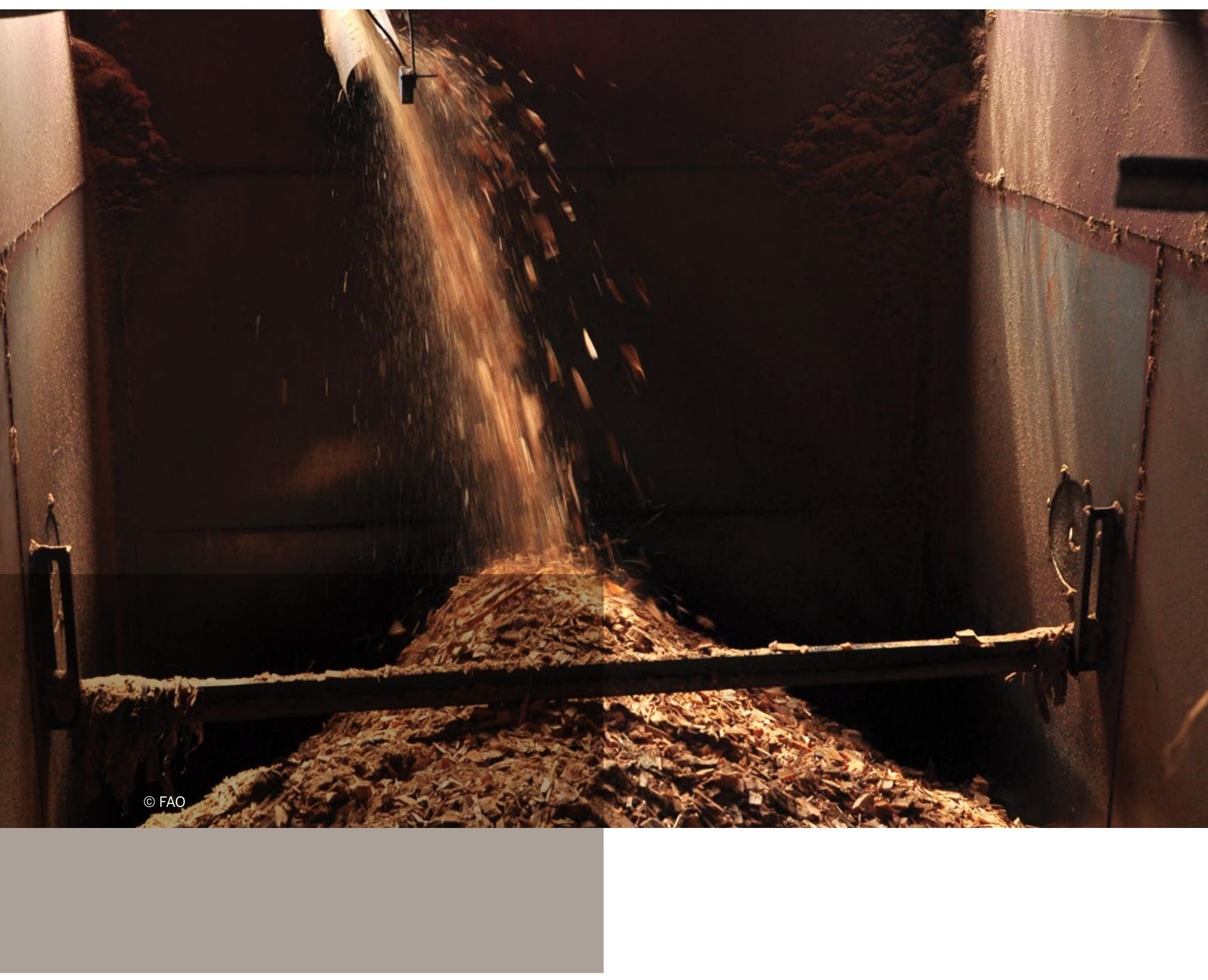




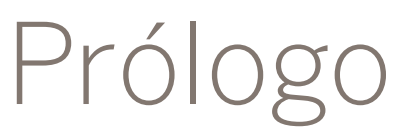

La matriz energética argentina está conformada, en su gran mayoría, por combustibles fósiles. Esta situación presenta desafíos y oportunidades para el desarrollo de las energías renovables, ya que la gran disponibilidad de recursos biomásicos en todo el territorio nacional constituye una alternativa eficaz frente al difícil contexto energético local e internacional. En este escenario, en 2015, la República Argentina promulgó la Ley 27191, Régimen de fomento nacional para el uso de fuentes renovables de energía destinada a la producción de energía eléctrica -que modificó la Ley 26190-, con el objetivo de fomentar la participación de las fuentes renovables hasta que estas alcancen un $20 \%$ del consumo de la energía eléctrica nacional en 2025, otorgando a la biomasa una gran relevancia.

La biomasa es una de las fuentes de energía renovable más confiables, es constante y se puede almacenar, lo que facilita la generación térmica y eléctrica. En virtud de sus extraordinarias condiciones agroecológicas, y las ventajas comparativas y competitivas de su sector agroindustrial, la Argentina es un gran productor de biomasa con potencial energético.

La energía derivada de biomasa respeta y protege el ambiente, genera nuevos puestos de trabajo, integra comunidades energéticamente vulnerables, reduce la emisión de gases de efecto invernadero, convierte residuos en recursos, moviliza inversiones y promueve el agregado de valor y nuevos negocios.

No obstante, aún existen algunas barreras y desafíos de orden institucional, legal, económico, técnico y sociocultural que deben superarse para incrementar, de acuerdo con su potencial, la proporción de bioenergía en la matriz energética nacional.

En este marco, en 2012, se creó el Proyecto para la promoción de la energía derivada de biomasa - UTF/ARG/O20/ARG (PROBIOMASA), una iniciativa que llevan adelante el Ministerio de Agricultura, Ganadería y Pesca, y la Secretaría de Gobierno de Energía del Ministerio de Hacienda, con la asistencia técnica y administrativa de la Organización de las Naciones Unidas para la Alimentación y la Agricultura (FAO).

El Proyecto tiene como objetivo principal incrementar la producción de energía térmica y eléctrica derivada de biomasa a nivel local, provincial y nacional, para asegurar un creciente suministro de energía limpia, confiable y competitiva y, a la vez, abrir nuevas oportunidades agroforestales, estimular el desarrollo regional y contribuir a mitigar el cambio climático. 
Para lograr ese propósito, el Proyecto se estructura en tres componentes principales con objetivos específicos:

- Estrategias bioenergéticas: asesorar y asistir, legal, técnica y financieramente, a proyectos bioenergéticos y tomadores de decisión para aumentar la participación de la energía derivada de biomasa en la matriz energética.

- Fortalecimiento institucional: articular con instituciones de nivel nacional, provincial y local a fin de evaluar los recursos biomásicos disponibles para la generación de energía aplicando la metodología WISDOM (Woodfuels Integrated Supply/Demand Overview Mapping, Mapeo de Oferta y Demanda Integrada de Dendrocombustibles).

- Sensibilización y extensión: informar y capacitar a los actores políticos, empresarios, investigadores y público en general acerca de las oportunidades y ventajas que ofrece la energía derivada de biomasa.

Esta Colección de Documentos Técnicos pone a disposición del público estudios, guías y recomendaciones sobre aspectos específicos de la generación de energía derivada de biomasa, elaborados por consultoras y consultores del Proyecto e instituciones parte, con el propósito de contribuir tanto al desarrollo de negocios como al diseño, formulación y ejecución de políticas públicas que promuevan el crecimiento del sector bioenergético en la Argentina. 


\section{Agradecimientos}

Para la elaboración del presente documento se contó con la colaboración de organismos nacionales y provinciales, productores y técnicos, particularmente de la Secretaría de Gobierno de Ambiente y Desarrollo Sustentable de la Nación, que facilitó los formatos digitales del Ordenamiento Territorial de Bosques Nativos (OTBN) y las Áreas Naturales Protegidas (ANP) de las provincias involucradas en la zonificación, y de la Subsecretaría de Desarrollo Foresto Industrial de la Nación.

Se agradece particularmente a los investigadores y técnicos que trabajaron a la par de los autores y sin quienes este documento no habría sido posible: Daniel Lema y Marcelo Germán Posada en el Capítulo 2; Leonardo Tenti Vuegen y Juan Gaitán en el Capítulo 3; Javier Álvarez, Jorge Aparicio, Marcos Atanasio, Ezequiel Balducci, Federico Caniza, María Fernanda Barrios, Francisco Cardozo, Teresa Cerrillo, Silvia Cortizo, Ernesto Crechi, Carlos De la Peña, Diego Domínguez Daguer, María Elena Fernández, Ezequiel Fernández Tschieder, Paula Ferrere, Mario Flores, María de los Ángeles García, María Elena Gauchat, Leonel Harrand, Sebastian Kees, Aldo Keller, Federico Letourneau, Matías Martínez, Ciro Mastrandrea, Silvana Monteverde, Javier Oberschelp, Norberto Pahr, Pablo Pathauer, Pablo Peri, Lorena Pernochi, Fernando Speranza, Natalia Tesón, Alejandra Von Wallis y Esteban Zupan en el Capítulo 4; y Patricia Egolf e Ignacio Benito Amaro en el Capítulo 5.

Por último, cabe un reconocimiento especial a Sofía Blumenthal, por su apoyo fundamental en los aspectos administrativos de este trabajo. 


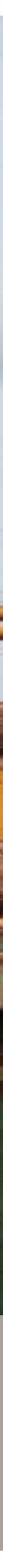




\section{Siglas y acrónimos}

$\begin{array}{ll}\text { ACV } & \text { Análisis del ciclo de vida } \\ \text { ARS } & \text { Pesos argentinos } \\ \text { BAU } & \text { Business as usual - negocios de rutina } \\ \text { EDI } & \text { Electrodesionización } \\ \text { EEA } & \text { Estación Experimental Agropecuaria } \\ \text { ERNC } & \text { Energías renovables no convencionales } \\ \text { CACME } & \text { Comité Argentino del Consejo Mundial de Energía } \\ \text { CAMMESA } & \text { Compañía Administradora del Mercado } \\ & \text { Mayorista Eléctrico } \\ \text { GD } & \text { Generación distribuida } \\ \text { INTA } & \text { Instituto Nacional de Tecnología Agropecuaria } \\ \text { MAyDS } & \text { ex Ministerio de Ambiente y Desarrollo Sustentable } \\ \text { MEM } & \text { Mercado Eléctrico Mayorista } \\ \text { MINCYT } & \text { ex Ministerio de Ciencia y Tecnología } \\ \text { MINEM } & \text { ex Ministerio de Energía y Minería } \\ \text { NO } & \text { Noroeste } \\ \text { NOA } & \text { Noroeste argentino } \\ \text { OCDE } & \text { Organización para la Cooperación y el Desarrollo } \\ & \text { Económicos } \\ \text { OTBN } & \text { Ordenamiento Territorial de Bosques Nativos } \\ \text { SIG } & \text { Sistema de Información Geográfica } \\ \text { TIR } & \text { Tasa interna de retorno } \\ \text { USD } & \text { Dólares estadounidenses } \\ \text { USDA } & \text { Departamento de Agricultura de Estados Unidos } \\ \text { VAD } & \text { Valor agregado de distribución }\end{array}$

Unidades de medida

$\begin{array}{ll}{ }^{\circ} \mathrm{C} & \text { grado centígrado } \\ \mathrm{CHbs} & \text { contenido de humedad en base seca } \\ \mathrm{Cm}^{2} & \text { centímetro cuadrado } \\ \mathrm{ha} & \text { hectárea } \\ \mathrm{HP} & \text { caballo de vapor } \\ \mathrm{kcal} & \text { kilocaloría } \\ \mathrm{kg} & \text { kilogramo } \\ \mathrm{km} & \text { kilómetro } \\ \mathrm{kWh} & \text { kilovatio hora } \\ \mathrm{m}{ }^{2} & \text { metro cuadrado } \\ \mathrm{m}^{3} & \text { metro cúbico } \\ \mathrm{mm} & \text { milímetro } \\ \mathrm{MWh} & \text { megavatio hora } \\ \mathrm{psi} & \text { libra por pulgada } \\ \mathrm{t} & \text { tonelada } \\ \mathrm{t} / \mathrm{hab} & \text { toneladas por habitante }\end{array}$




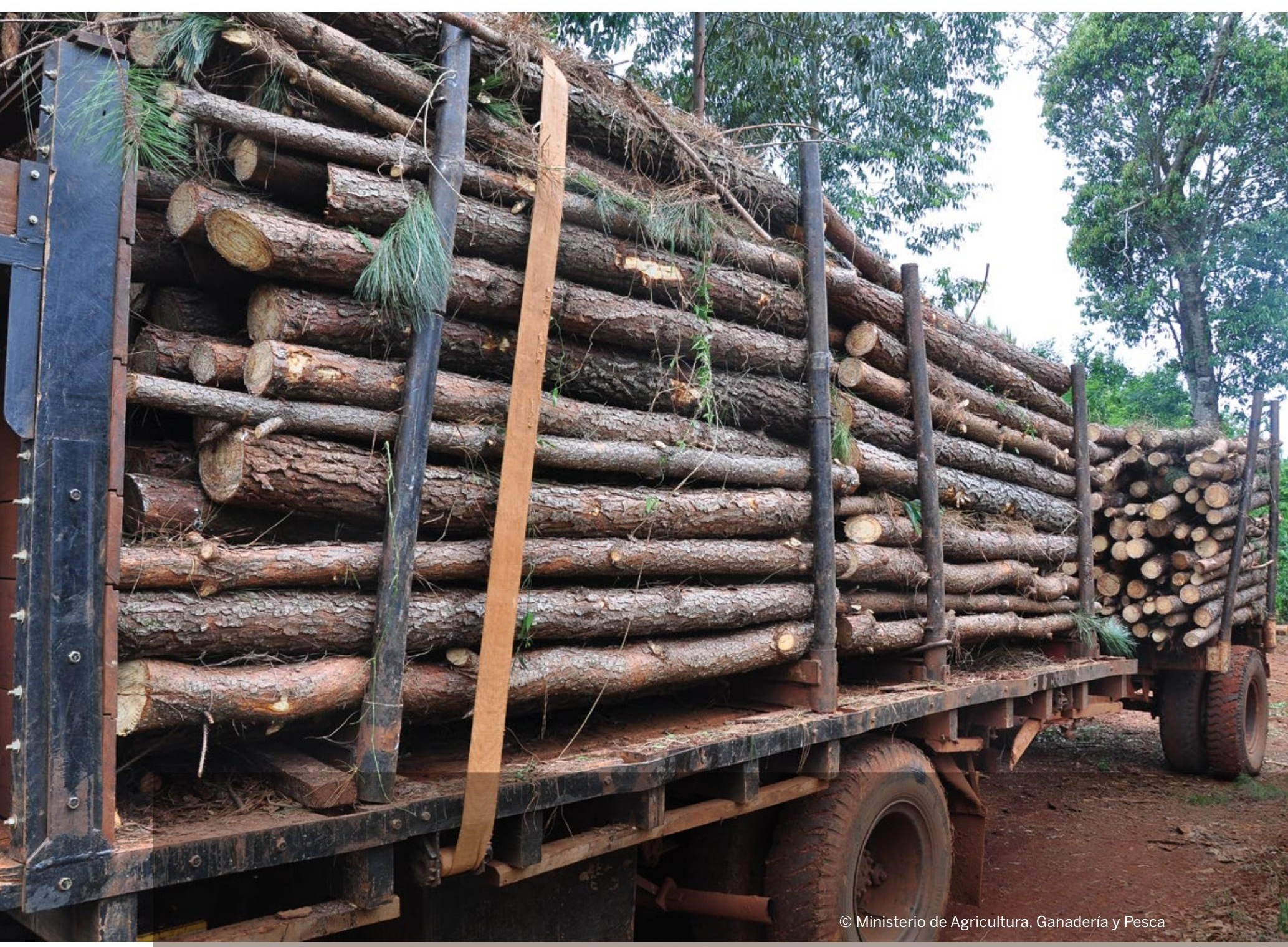




\section{Resumen ejecutivo}

Este documento pretende contribuir a que se conozcan y puedan dimensionar aspectos claves del potencial de desarrollo de plantaciones dendroenergéticas en la Argentina, sobre la base de conocimiento científico acerca de la silvicultura de bosques cultivados, su relación con el ambiente, el análisis de los aspectos económicos y el desarrollo de proyectos de generación de energía a partir de biomasa.

A nivel nacional, se detectaron cerca de 15252878 hectáreas potencialmente aptas para plantaciones dendroenergéticas, de las que 2544057 se encuentran en la región Central; 5375 463, en la Mesopotamia; 325 104, en el NOA, y 7008254 en la región Pampeana.

El análisis económico indica que el precio mínimo esperado es muy variable debido a diferentes factores que influyen en la estructura de costos de cada modelo, como la duración del proyecto productivo, los rendimientos esperables, la mano de obra, el costo del combustible y las condiciones financieras.

Este documento presenta también el desarrollo de un caso completo de generación de energía a partir de plantaciones dendroenergéticas, modelizado técnica y económicamente, a fin de evaluar sus condiciones de viabilidad. Este modelo, desarrollado para el noroeste de Misiones a partir de rollos de eucaliptos y usinas de 0,5, 1,0 y 2,0 MW, muestra que el máximo precio de compra de materia prima, aun para el proyecto de menor costo de transformación energética, no llega a compensar el costo de producción de biomasa.

Se destaca el impacto positivo de la cogeneración, que brinda a los proyectos dendroenergéticos una alta complementariedad en regiones del país donde los requerimientos de calor y/o vapor de la industria forestal o agroforestal deben satisfacerse. 


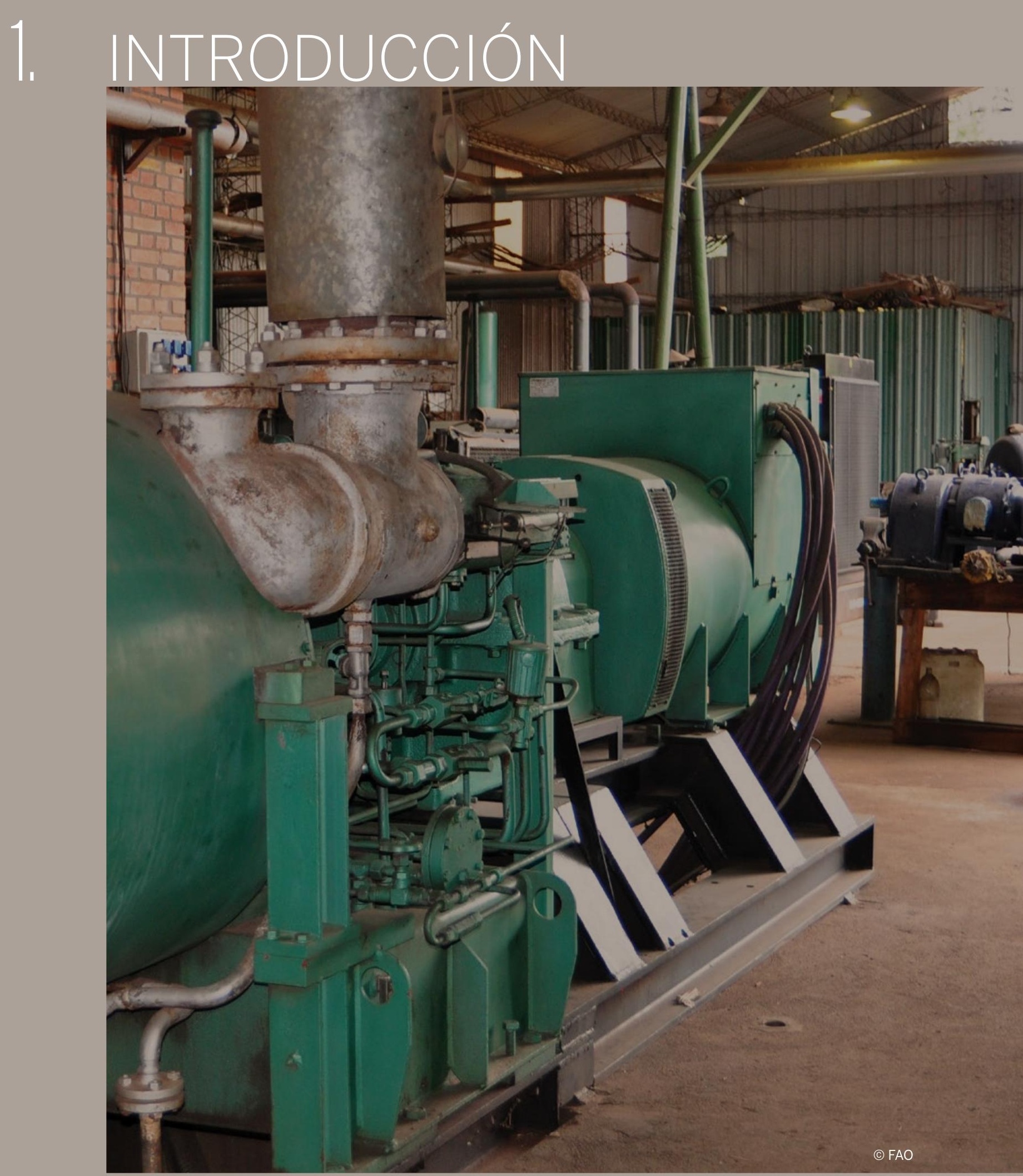


Este libro aborda el desarrollo de la dendroenergía desde distintos enfoques: un análisis del marco regulatorio, una cartografía de posibles áreas de plantaciones, $y$ modelos técnico-económicos de forestaciones y de generación de energía de biomasa forestal.
Este documento surge como respuesta a una demanda del Proyecto para la promoción de la energía derivada de biomasa (PROBIOMASA) y fue elaborado en el marco de una carta de acuerdo entre la FAO y el Instituto Nacional de Tecnología Agropecuaria (INTA). La información generada da continuidad a un análisis realizado en 2015, en el que se plantearon los aspectos silvícolas de las plantaciones dendroenergéticas.

Para la elaboración del presente documento, se contemplaron cuatro objetivos, cada uno de los cuales contó con sus equipos de trabajo aunque en interacción con los demás: regionalizar la áreas potencialmente elegibles para plantaciones dendroenergéticas; elaborar modelos técnico-económicos de esta actividad; desarrollar modelos alternativos de transformación energética a partir de biomasa forestal; y analizar las regulaciones que se relacionan directa o indirectamente con la actividad de forestación dendroenergética.

Este documento presenta los informes de trabajo correspondientes a esos cuatro grandes temas, editados y compilados.
En primer lugar se desarrollan los aspectos normativos y regulatorios que involucran a la actividad generadora de energía a partir de fuentes no convencionales en general, en cuyo seno se asienta la dendroenergía, y, por ende, involucra a las plantaciones desarrolladas con ese objetivo. A continuación se exponen los resultados alcanzados luego del proceso de definición de criterios de elegibilidad de tierras con destino a aquellas plantaciones, las especies consideradas y los requerimientos y tolerancias para su cultivo, y como producto de ese trabajo se presenta la cartografía elaborada. En el siguiente capítulo se presenta la construcción de los modelos técnico-económicos que permiten analizar la viabilidad de las plantaciones dendroenergéticas, según la regionalización configurada en el marco del proyecto. En la última parte se desarrolla un modelo de transformación, a partir de biomasa de plantaciones dendroenergéticas, en energía eléctrica y térmica, idealmente asentado en la provincia de Misiones. 


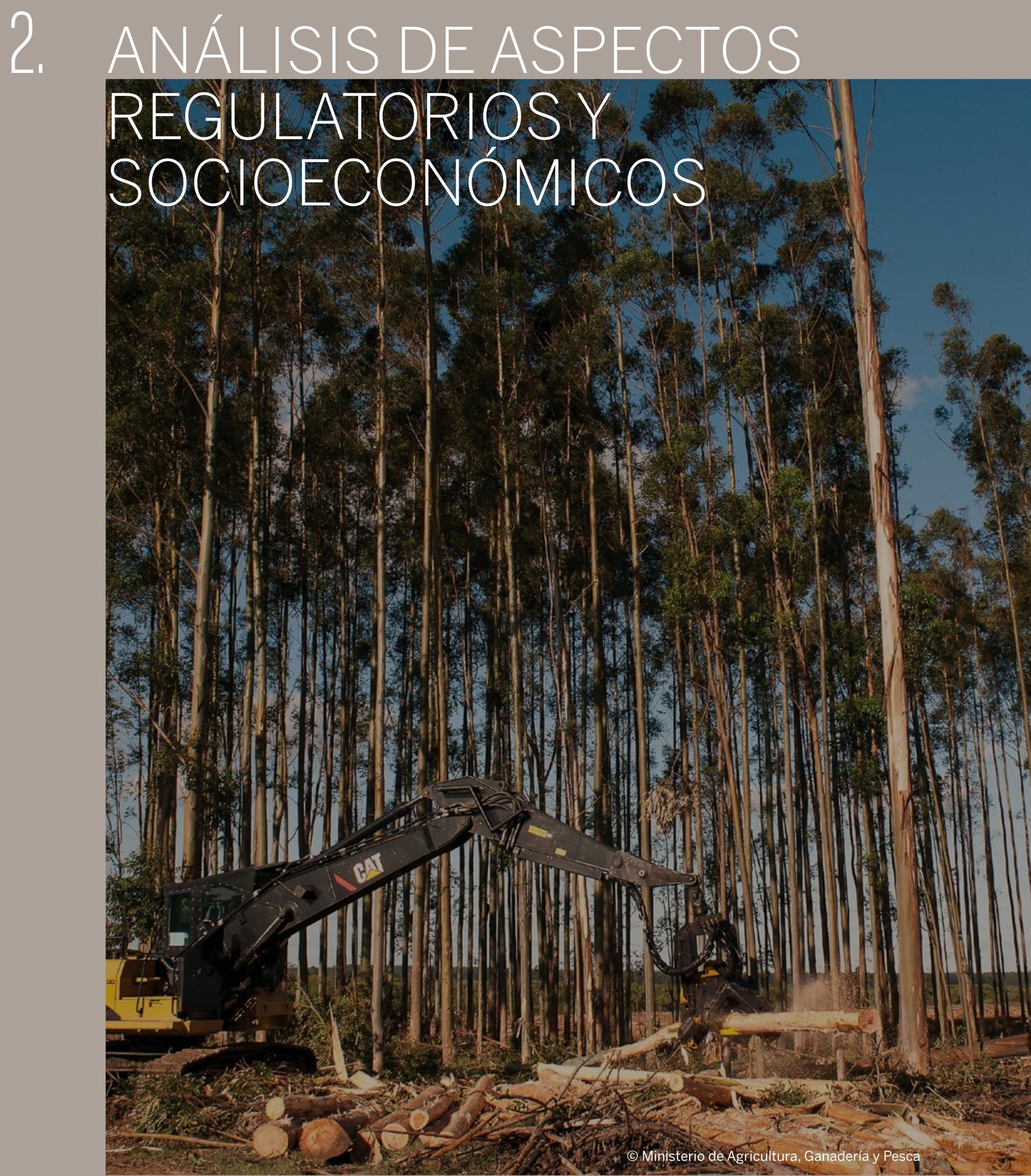


En lo que va del siglo, se afianzaron

dos procesos en la matriz energética

argentina: el aumento de la energía

de biomasa, en particular de aceites

y alcoholes vegetales, y la caída de

reservas de combustibles fósiles, que conforman el $87 \%$ del consumo.

En lo que respecta a la dendroenergía, gran parte de los estudios relevados para el presente trabajo hacen hincapié en su planificación y desarrollo a partir de la utilización de residuos tanto forestales como de la industria maderera. En pocos análisis se contempla la implantación de bosques específicamente orientados a su explotación para la generación de energía. Esos estudios tampoco ahondan en la articulación de este tipo de generación con una estrategia de mayor alcance, como es la diversificación de la matriz energética. Y varios trabajos plantean un modelo de generación orientado, primordialmente, al autoconsumo, de modo que las empresas puedan suplir la compra de energía al sistema interconectado.

Es innegable que, en el contexto de una matriz energética en la que el peso de los combustibles fósiles es muy relevante, todo esfuerzo por sustituir eficientemente el consumo de energía de ese origen es importante. Si se plantea como objetivo de política pública sectorial (energética) la diversificación de esa matriz, con la meta de un piso mínimo de energía de fuentes renovables no convencionales, la dendroenergía aparece como una de ellas. Este punto es en particular relevante, dado que el desarrollo de plantaciones como insumo para la provisión de energía depende, entre muchos factores, de los marcos regulatorios del mercado energético y los incentivos subyacentes en las regulaciones y marcos institucionales.

En el documento de referencia para la reunión del $34 .^{\circ}$ período de la $\mathrm{FAO}$, que abordó el tema de los bosques y la generación de energía (y que se convirtió en uno de los documentos centrales para el análisis de este tema hasta el presente), se señala taxativamente que la política forestal debería estar 
Potencial de desarrollo de plantaciones dendroenergéticas en la Argentina

integrada y coordinada con la política de energía. Así, este trabajo centra la indagación y el análisis en la cuestión de la generación de energías por fuentes renovables no convencionales y en uno de sus aspectos clave, la generación distribuida. Asimismo, hace referencias particulares a los encuadres jurídicos que, por carácter transitivo, conforman parte del entramado legal y de estímulo de la dendroenergía.

También se presenta de modo general la configuración y dinámica de los sistemas dendroenergéticos, exponiendo las características estructurales y funcionales de sus dimensiones. Y se analizan las plantaciones forestales dendroenergéticas desde la óptica de su viabilidad, con el sistema de incentivos imperante y de posible requerimiento, y los costos integrales que conllevan la dendroenergía en general y las plantaciones foresto-energéticas en particular, a la par que se plantea la cuestión de las sostenibilidad de tales forestaciones, para lo que se propone un esquema de abordaje a partir de un set de indicadores.

\section{Energías renovables no convencionales en}

\section{la Argentina: el caso de la biomasa}

La matriz energética argentina exhibe una alta dependencia de los combustibles fósiles: el $87 \%$ de la energía consumida es de ese origen (MINEM, 2016). Ese porcentaje sobrepasa la media de la matriz de América Latina, así como la media mundial.

A lo largo del presente siglo, dos procesos relevantes se han ido afianzando en la estructura de la matriz energética argentina. Por un lado, el incremento sostenido de la participación de la energía de biomasa, en particular los aceites y alcoholes vegetales, aunque todavía marginal en el conjunto. Por el otro, el marcado descenso en los niveles de reservas de combustibles fósiles disponibles en el país (con alrededor de siete años de reserva de gas y diez años de petróleo). Este último proceso implicó que la Argentina pasara de ser un exportador neto de gas a adoptar un perfil importador, en un lapso de diez años. Y esto, sumado a la política en materia energética implementada a partir de 2003 , centrada en mantener artificialmente bajos los precios de consumo de energía a través de una compleja estructura de subsidios, llevó a que el tema energético ocupe un papel central en cualquier análisis de la situación económica del país ${ }^{1}$.

Hacia 2010 se abrió una perspectiva para la continuación de esa matriz energética, evaluada positivamente por diversos sectores, con la posibilidad de producción de shale oil y shale gas. La confirmación de la existencia de reservas muy grandes de esos combustibles en la Patagonia (principalmente, en el yacimiento de Vaca Muerta) generó optimismo sobre el retorno al autoabastecimiento energético. Sin embargo, los análisis más meditados mostraron que la puesta en valor de tales reservas implica inversiones muy elevadas, largo plazo de concreción y alto riesgo ambiental. Así, entonces, la necesidad (y el desafío) de diversificar la matriz energética argentina continúa pendiente, y debería inclinarse hacia las llamadas energías renovables no convencionales (ERNC), no solo por motivos económicos, sino también ambientales.

La actual matriz energética argentina genera importantes emisiones de dióxido de carbono, lo que contribuye al proceso de calentamiento global. Si bien su relevancia en este proceso es mucho menor que la de otros países de mayor dimensión económica (China, por ejemplo), debe ser tenida en consideración: el aporte de emisiones per capita, que ascienden a cerca de 4,4 toneladas por habitante (t/hab.), supera en más de $60 \%$ el promedio de América Latina, y sobrepasa a las economías más grandes de la región, Brasil (1,9 t/hab.) y México (4 t/hab.) (Villalonga, 2013).

Frente a este panorama, y en un contexto mundial tendiente a diseñar e implementar acciones que mitiguen las causas del denominado calentamiento global, centradas en las emisiones de dióxido de carbono, la Argentina comenzó a instrumentar medidas para cambiar la composición de la matriz energética nacional, con un papel más relevante de las ERNC.

\footnotetext{
${ }^{1}$ Entre 2010 y 2015, las importaciones de combustibles fósiles representaron entre el 40 y el $46 \%$ del total de liquidaciones de divisas originadas en las exportaciones agropecuarias y agroindustriales.
} 
Gráfico 1. Composición de la oferta interna de energía primaria en la Argentina, en porcentaje

\begin{aligned} $53,6 \% &$ Gas natural de pozo \\ \hline $31,9 \% &$ Petróleo \\ \hline $4,1 \% &$ Energía hidráulica \\ \hline $2,0 \% &$ Energía nuclear \\ \hline $1,3 \% &$ Carbón mineral \\ \hline $0,2 \% &$ Energía eólica \\ \hline $0,0 \% &$ Energía solar \\ \hline $6,1 \% &$ Bioenergías \\ $50,5 \% &$ Aceites vegetales \\ $17,0 \% &$ Leña \\ $17,0 \% &$ Bagazo \\ $9,5 \% &$ Alcoholes vegetales \\ $6,0 \% &$ Otros primarios \end{aligned}

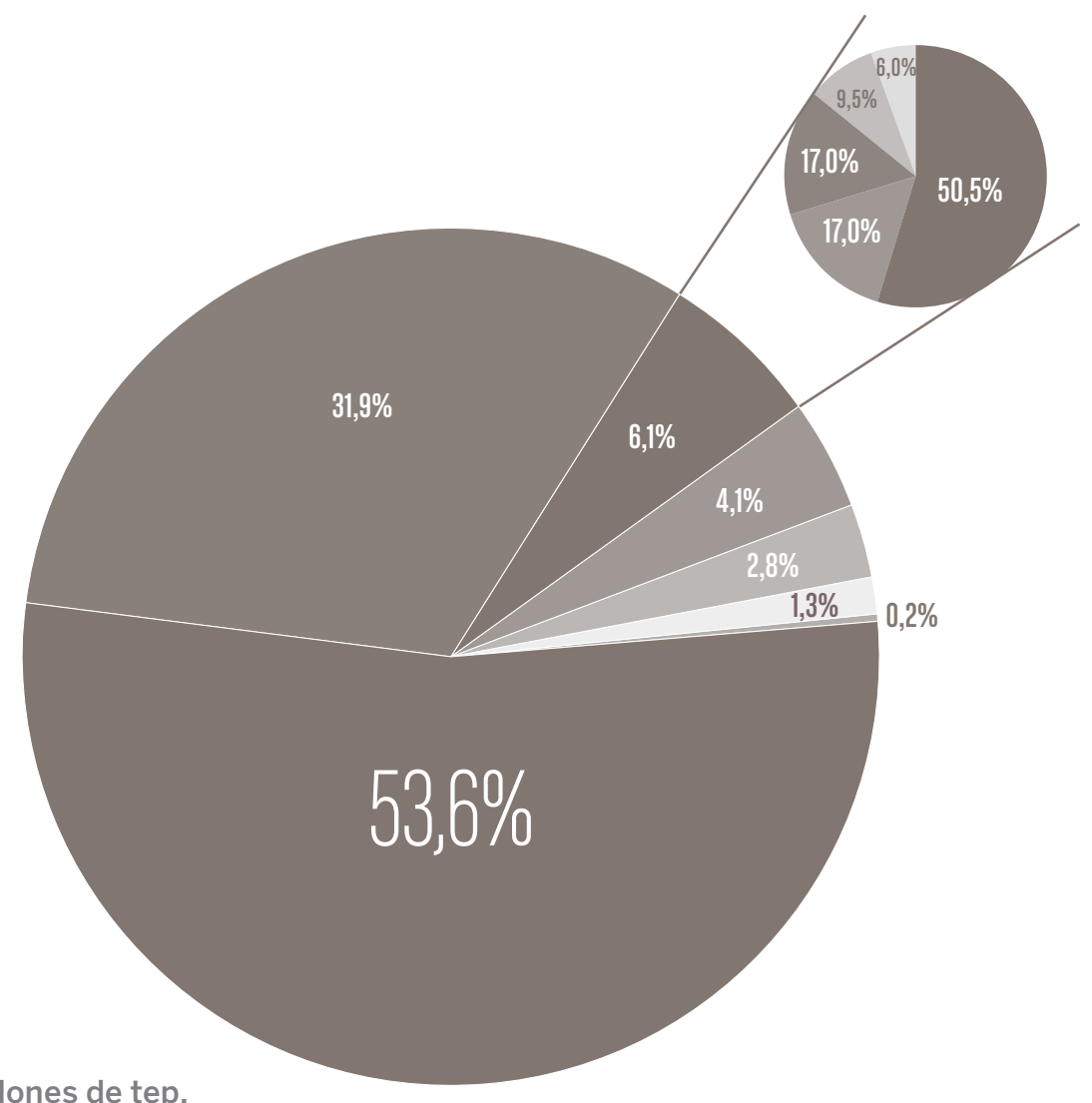

Total energía primaria 2016: 80,06 millones de tep.

Fuente: MINEM (2016).

Las ERNC no se consumen ni agotan en sus procesos de transformación y aprovechamiento, a la par que generan impactos ambientales significativamente menores que los de las energías no renovables. Las principales (pero no las únicas) son la energía eólica, la solar fotovoltaica, la hidroeléctrica generada en centrales de pequeña escala y la originada en la biomasa.

A lo largo del siglo XXI, las ERNC han incrementado su participación en la matriz energética global. Sin embargo, ese crecimiento no fue lineal ni homogéneo, debido a un conjunto de factores que impulsaron, en determinadas regiones o países y en diferentes momentos, la expansión y/o retracción de cada tipo. En base a las principales previsiones elaboradas por distintos países y organismos no gubernamentales (Altomonte, 2016), es posible esbozar un eventual devenir de estas fuentes energéticas:

- Se prevé una expansión sustantiva de la utilización de ERNC para generación eléctrica.

- China, que tiene el principal consumo de carbón mineral del mundo, lo disminuirá a la mitad en un lapso de 30 años, a favor de fuentes de energía renovable. 
Potencial de desarrollo de plantaciones dendroenergéticas en la Argentina

- A nivel global, el peso de las energías nuclear e hidroeléctrica continuará en disminución dentro del conjunto global, con variaciones; ese declive, que dejará espacio a las ERNC, será más intenso en los países miembros de la Organización para la Cooperación y el Desarrollo Económicos (OCDE), mientras que en los otros países se verificará muy amortiguado.

- No obstante, China incrementará su generación de energía nuclear e hidroeléctrica, con lo que la disminución mencionada se verificará muy tenuemente a nivel mundial.

- Continuará la tendencia decreciente en los costos de generación de las ERNC, en particular en la solar fotovoltaica.

- La mencionada tendencia irá en paralelo con el incremento de los costos de generación de las energías fósiles (gas y carbón mineral), debido a la aplicación de los cargos por emisión de carbono que se plantea implementar.

En relación con este informe, se debe prestar atención al desarrollo alcanzado por la generación energética a partir de biomasa. Esta está conformada por todo material de origen biológico salvo aquel que ha sido englobado en formaciones geológicas, sufriendo un proceso de mineralización. Esta definición -originada en el Comité Europeo de Estandarización- es pertinente para el presente estudio, puesto que excluye los combustibles fósiles, que en su origen sí fueron biomasa.

La biomasa contiene energía solar almacenada a través de la fotosíntesis, proceso por el cual algunos organismos vivos (como las plantas) convierten los compuestos inorgánicos que asimilan (como el dióxido de carbono) en compuestos orgánicos. De este modo, la energía de biomasa se puede extraer de una amplia gama de recursos, desde la paja residual de una cosecha hasta las aguas residuales urbanas, pasando por plantaciones agrícolas o forestales ad hoc, subproductos y residuos de la industria forestal, y otros.

El empleo de biomasa como recurso energético implica una serie de ventajas medioambientales y económicas (IDAE, 2007b), entre las que se destacan:
- Disminución de las emisiones de azufre.

- Disminución de las emisiones de partículas.

- Reducción de emisiones de contaminantes como el cobalto o el óxido de nitrógeno.

- Generación de un ciclo neutro de dióxido de carbono, sin contribución al efecto invernadero.

- Reducción de los riesgos y de los gastos de mantenimiento derivados de la dotación de equipos generadores de gases tóxicos en las instalaciones humanas.

- Reducción de riesgos de incendios forestales y de plagas de insectos.

- Aprovechamiento de residuos agrícolas y forestales, evitando su quema en el terreno.

- Posibilidad de utilizar tierras de barbecho para realizar cultivos energéticos.

- Desacople de los costos energéticos de las fluctuaciones de precios de combustibles importados.

- Generación de nuevas oportunidades económicas para las áreas rurales.

Es necesario indicar también que los proyectos bioenergéticos deben incorporar el análisis de potenciales impactos negativos, a efectos de evitarlos (INTA, 2016).

Cada recurso utilizable para la producción energética a partir de biomasa requiere un análisis particular, tanto a nivel de disponibilidad como de extracción, transporte y distribución. A continuación, se reseñan las características básicas de utilización de las principales fuentes de biomasa relacionadas con la generación dendroenergética:

\section{Usos de las principales fuentes de biomasa}

Residuos forestales: Se originan en los tratamientos y aprovechamientos de las masas vegetales, tanto para su defensa y mejora, como para la obtención de materias primas para el sector forestal (maderas, resinas y otras). Los residuos generados en la limpieza, poda o corte de los montes pueden utilizarse para usos energéticos 
dadas sus excelentes características como combustibles.

Con maquinaria apropiada, es posible astillar o empacar ese material para obtener un producto más manejable y de tamaño homogéneo, y así abaratar su transporte desde las áreas productivas. Sin embargo, estos residuos presentan inconvenientes (dispersión, difícil accesibilidad, heterogeneidad de tamaños y composición, impurezas mezcladas, elevada humedad) que dificultan la generalización de su uso para energía, a la vez que compiten por ellos otros demandantes, como las empresas madereras y las papeleras.

Residuos agrícolas leñosos: Las podas de plantaciones frutales y de viñedos constituyen otra importante fuente potencial. Como en el caso anterior, es necesario dimensionar y homogeneizar el empacado para facilitar su transporte. Debido a su estacionalidad, esta fuente debe considerarse en función de la disponibilidad de un centro de acopio y distribución de biomasa.

Residuos agrícolas herbáceos: Son aquellos obtenidos de la cosecha de algunos cultivos, genéricamente englobados en la categoría de "pajas" o "cañotes". Como en el caso anterior, su producción estacional implica enmarcarlos en una estrategia que pivotee sobre un centro de acopio y distribución de biomasa.

Residuos de industrias forestales y agroalimentarias: Las astillas, cortezas o aserrín de la industria de la madera, y los carozos, cáscaras y otros residuos de la industria agroalimentaria son parte de los biocombustibles sólidos industriales. En estos casos, la estacionalidad en el aprovisionamiento está amortiguada, y no depende tanto de ciclos vitales, sino de procesos industriales y su dinámica económica.

Cultivos y plantaciones energéticas: Se trata de cultivos vegetales y plantaciones forestales destinados específicamente a la producción de biomasa para uso energético. Contando con la dotación apropiada de maquinarias y equipos, se puede establecer un circuito productivo, de acopio y de distribución que amortigüe los ciclos vitales de esa biomasa, y la canalice eficaz y eficientemente a la generación de energía.
A partir de las biomasas descriptas es factible generar calor y electricidad, con variaciones en la complejidad técnica y la escala de operaciones en cada caso. La producción térmica a partir de biomasa incluye desde la quema de leña a nivel hogareño para calefaccionar o cocinar, hasta la instalación y alimentación de grandes calderas industriales con residuos agroforestales, la mayor parte de las veces autogenerados por la industria propietaria de tales calderas, calor que suele destinarse al ciclo productivo que lleva adelante la empresa.

En cuanto a la producción eléctrica a partir de biomasa, debido al bajo poder calorífico de esta, a su alto porcentaje de humedad y a su gran contenido de volátiles, requiere de sistemas más complejos: centrales térmicas específicas, con grandes calderas, con volúmenes de hogar mayores que si utilizaran combustible convencional, y que implican inversiones elevadas, a la par que requieren un aceitado mecanismo de abastecimiento continuo de biomasa. Esta generación eléctrica a partir de biomasa tiene escasa difusión en el mundo, y se concentra, en general, en instalaciones ubicadas en las propias industrias que tienen asegurado el combustible con su propia producción (residuos del proceso productivo), principalmente, la industria papelera.

Las innovaciones tecnológicas relacionadas con esta generación se han abocado, a lo largo de la última década, fundamentalmente, al desarrollo de la gasificación de biomasa y posterior conversión en electricidad a través de motogeneradores u otros sistemas de combustión del gas de síntesis producido.

En cuanto a las ERNC en general (englobando a las generadas a partir de biomasa forestal), su potencialidad de desarrollo para la generación eléctrica ocupa un lugar destacado, en línea con la tendencia tecnológica global hacia un mayor uso de energía eléctrica, incluyendo el transporte, en procura de reemplazar combustibles fósiles. Sin embargo, más allá de la tendencia creciente, su participación es aún marginal.

\section{Escenarios potenciales}

De acuerdo con la información disponible sobre la Argentina, se observa que, respecto del total de la demanda expresada en el Mercado Eléctrico 
Potencial de desarrollo de plantaciones dendroenergéticas en la Argentina

Mayorista (MEM), la electricidad generada por las ERNC representa solo el $1,4 \%$ del total. En su interior, las distintas fuentes se distribuyen como muestra el Gráfico 2.

El cambio de gestión de gobierno a fin de 2015 implicó, a nivel energético, un proceso de reacomodamiento gradual de la estructura de tarifas, a la par que se puso el acento en la expansión de las energías renovables en el marco de la Ley 27191, sancionada meses antes pero reglamentada a fin de marzo de 2016.

Esa normativa establece metas de incremento de la participación de las ERNC en el conjunto de la provisión eléctrica nacional, que debería pasar del $8 \%$ del total en 2017 (si bien solo es fiscalizable a partir de 2019) al 20\% en 2025. Estas metas implican multiplicar por 17 la capacidad de generación de ERNC en una década, objetivo evaluado como ambicioso por parte de distintos agentes del sector (IDEAR Desarrollo, 2016).

No obstante, en un ejercicio de prospectiva energética realizado por organizaciones no gubernamentales y cámaras empresarias poco antes de la sanción de la Ley 27191, se planteaban escenarios posibles para el desarrollo de las ERNC mucho más optimistas ${ }^{2}$. De acuerdo con lo ejercitado para esos escenarios, algunos participantes consideraron que, en condiciones BAU (business as usual), la participación de las ERNC podría llegar a representar el $57 \%$ del MEM, mientras que en escenarios URE (uso racional de la energía) esa participación podría elevarse al $67 \%$, aunque en ambos escenarios el promedio fue menor: $33 \%$ y $35 \%$, respectivamente.

En lo que atañe específicamente a la energía generada por biomasa (incluyendo la de origen forestal), los escenarios fueron heterogéneos: en algunos representó solo el 0,3\% del total de ERNC, y en otros el $33 \%$, con un promedio de todos los escenarios del $9,7 \%{ }^{3}$.

\footnotetext{
2 http://www.escenariosenergeticos.org/
}

${ }^{3}$ Cabe señalar que en esos análisis se planteó la utilización de residuos de la industria maderera y no se consideró la biomasa eventualmente originada en plantaciones forestales ad hoc.

Gráfico 2. Participación promedio de las ERNC en la Argentina

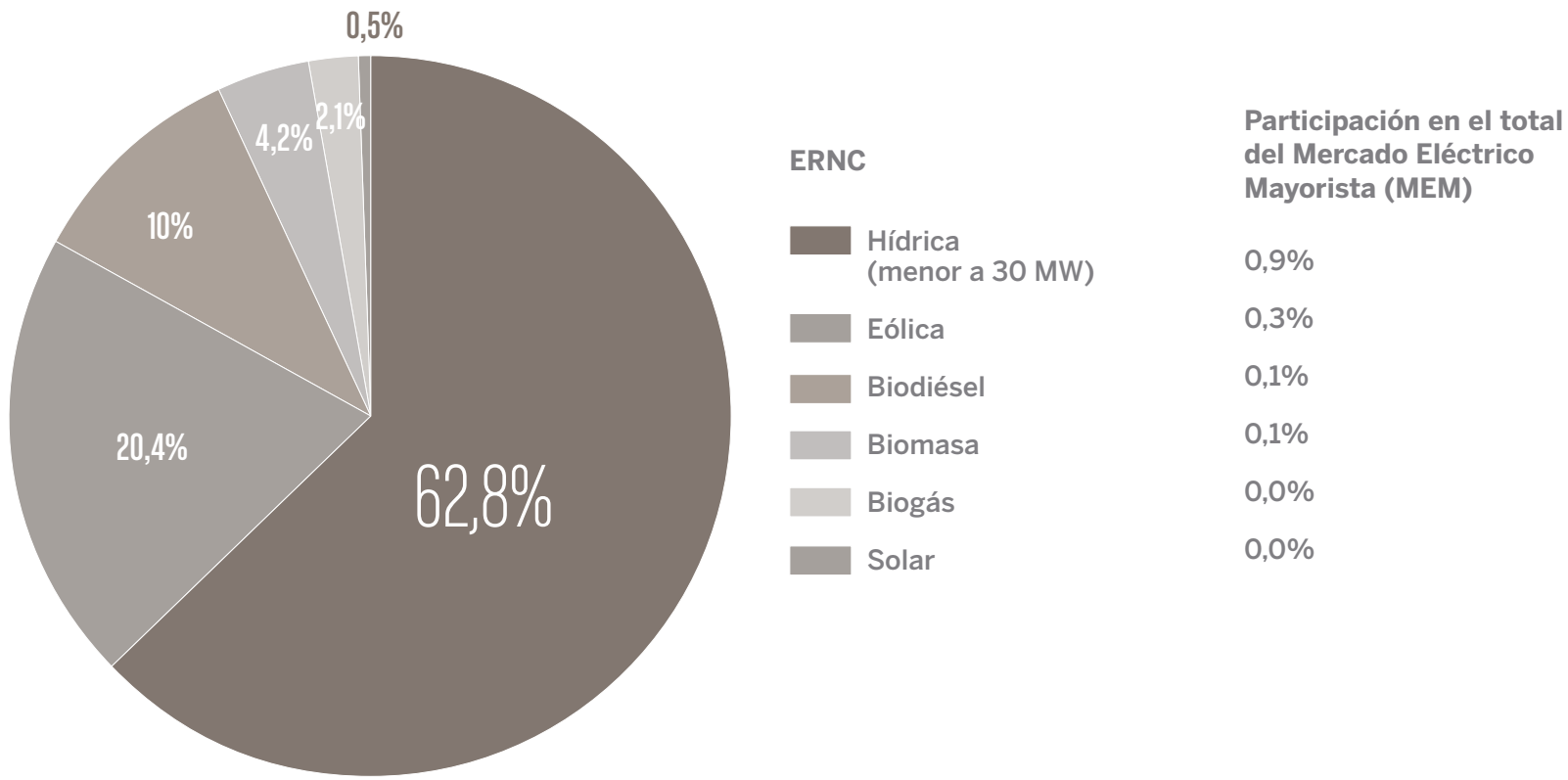

Fuente: Elaborado por los autores de acuerdo con los informes anuales de CAMESA de 2012-2015. 
En síntesis, las ERNC tienen un elevado potencial de desarrollo en la Argentina, en sintonía con su dinámica mundial, pero actualmente ocupan un lugar reducido en la composición de la oferta energética nacional (y eléctrica, en particular). Los pasos legislativos dados en los últimos años intentan estimular su desarrollo, a fin de que el porcentaje global de ERNC utilizado aumente en el mediano plazo, para lo cual se requieren inversiones de magnitud, además de un marco regulatorio que funcione como incentivo.

\section{Marco regulatorio: incentivos y vacíos (y falencias) normativas}

En este apartado se aborda la cuestión del esquema jurídico que regla el desenvolvimiento de las ERNC y, en particular, se hace hincapié en el tema de la generación distribuida, factor central si se busca impulsar el uso de estas energías más allá del mero autoconsumo. Todos estos aspectos tienen una relevancia particular para encuadrar el análisis de la viabilidad de las plantaciones dendroenergéticas.

Pese a los distintos programas de estímulo que se han diseñado y ejecutado a lo largo del presente siglo, el desenvolvimiento de las ERNC se ha visto ralentizado por un conjunto de barreras de distinta índole que pueden sintetizarse en los siguientes grupos (Zoratti y Guzmán, 2015b; Bertero, 2015; Secretaría de Energía de la Nación, 2009; Aguilar, 2014; Marco et al., 2017).

Barreras político-institucionales: De acuerdo con un relevamiento oficial efectuado entre agentes relevantes del sector energético argentino antes de la sanción de la Ley 27191, estos consideraban que las autoridades de las áreas con incumbencia en la cuestión de las ERNC carecían de capacidad de coordinación para unificar criterios y generar sinergias entre sus esfuerzos investigativos, estimuladores y normativos. Esto originaba, en la visión de esos agentes, competencias, solapamientos e ineficacias. A la vez, el papel del organismo que en teoría debería dirigir el proyecto de expansión de la generación a partir de ERNC (la Secretaría de Energía de la Nación) se veía desdibujado.

La sanción de la Ley 27191, su reglamentación y, particularmente, la elevación a rango ministerial de aquella Secretaría parecieron despejar el escenario político-institucional, al menos, formalmente. La profundización de vínculos interinstitucionales facilita, al menos en teoría, la configuración de un escenario institucional más sólido y proclive a implementar un entramado de políticas de estímulo a las ERNC, pivoteando sobre la mencionada ley.

Barreras económico-financieras: Hasta principio de 2016 la cuestión tarifaria y las dificultades para asegurar la disponibilidad de las eventuales ganancias constituyeron los dos grandes obstáculos económico-financieros que dificultaron la realización de inversiones en generación a partir de ERNC.

A su vez, las herramientas de financiamiento existentes hasta ese momento (la llamada "remuneración adicional" por unidad de energía generada, y el Fondo Nacional de Energías Renovables) no se habían implementado, a la par que los proyectos del programa GENREN (Generación Renovable) que fueron licitados redundaron en avances sumamente limitados, al igual que los llamados "contratos de abastecimiento".

Barreras regulatorias: La sucesión de leyes sancionadas desde 1998 (25019, 26190 y 27191), así como el denso entramado de regulaciones complementarias (1281/06, 220/07, 280/08, $712 / 09$ y $108 / 11$, entre otras) no lograron generar un marco normativo que facilitara el desenvolvimiento de las ERNC.

Al contrario, la sanción de herramientas de estímulo a tales fuentes de energía que no fueron puestas en marcha, no funcionaron correctamente o no fueron implementadas por completo dieron lugar a la formación de un escenario poco propicio para la inversión privada en el sector. Esto se intenta corregir a partir de la reglamentación de la Ley 27191 y la implementación del programa RenovAr desde 2016.

Por otro lado, varias provincias del país han sancionado sus propios marcos normativos para el estímulo y desenvolvimiento de las ERNC; si bien no todos son equiparables entre sí, son tributarios de la legislación nacional, en tanto que derivaron de la adhesión provincial a la ley nacional vigente en el momento de la sanción (la mayoría adherente a la Ley 26190).

Barreras técnicas: Según los relevamientos oficiales y privados, anteriores y posteriores a la 
Potencial de desarrollo de plantaciones dendroenergéticas en la Argentina

sanción de la Ley 27191, los principales agentes del sector consideran que no existen limitantes técnicas de relevancia para la generación a partir de ERNC, al menos, las que tienen mayor participación en el espectro de generación eléctrica, indicadas anteriormente.

Las innovaciones técnicas en fase de desarrollo se centran, básicamente, en las llamadas "tecnologías de segunda generación", para implementar particularmente en proyectos de generación a partir de biomasa. En cambio, en energía solar y energía eólica los desarrollos técnicos parecen haber alcanzado un nivel de equilibrio, concentrándose, básicamente, en la reducción de costos.

Barreras socioculturales: La información sobre las distintas fuentes de ERNC y sus impactos positivos, tanto a nivel ambiental como económico, es de amplia difusión y está libremente al alcance de los distintos públicos (especializados, usuarios, entre otros).

Con distintos grados de eficacia, el mismo Estado nacional ha implementado acciones de difusión y sensibilización desde hace algo más de una década, que han contribuido al conocimiento público de las razones por las cuales es conveniente el desarrollo de las ERNC. En paralelo, organizaciones privadas han efectuado campañas en el mismo sentido.

Desde el punto de vista sociocultural, entonces, no parecen existir barreras para el uso de las ERNC. Tales barreras son de índole comercial: el costo relativo de la energía renovable frente al de la energía de combustibles fósiles inclina la elección hacia estas últimas.

Como se ha señalado, varias de las barreras mencionadas han sido abordadas con la reglamentación de la Ley 27191, que implica un cambio cuantitativo y cualitativo en el posible devenir de las ERNC en el país.

\section{Ley 27191}

Modificatoria de la ley vigente anteriormente (26190), la Ley 27191 y su decreto reglamentario $531 / 17$, como las resoluciones ministeriales 71 y $72 / 16$, ratifican la necesidad de incrementar la participación de las ERNC en la matriz energética argentina, llevando -como se mencionó- la meta al 20\% de participación en 2025.

Una de las novedades de esta norma es que establece que todos los grandes usuarios de energía eléctrica, que demanden más de 300 kW, deberán cumplir esa meta. Es decir, ya no se la plantea como una meta global para toda la matriz, sino que además se estipula que ese segmento del consumo debe alcanzarla individualmente. Para cumplir con la ley, esos grandes usuarios podrán autogenerar o comprar esa electricidad originada en ERNC, tanto a un distribuidor como a la Compañía Administradora del Mercado Mayorista Eléctrico (CAMMESA), a un precio máximo de 113 USD/MWh.

Tan relevante como lo anterior es que la Ley 27191 contempla un conjunto de beneficios fiscales y financieros que deberían incentivar las inversiones en la generación eléctrica a partir de ERNC. Ellos son:

- Régimen de beneficios impositivos sobre IVA y Ganancias: se extiende la aplicación de la devolución anticipada de IVA y amortización acelerada en el Impuesto a las Ganancias para la ejecución de obras civiles, adquisición de bienes de capital y demás inversiones para nuevas plantas o ampliación de las existentes. Tales beneficios no son excluyentes entre sí, a la par que rigen tanto para la compra de bienes muebles nacionales como extranjeros. La devolución de IVA podrá efectivizarse un período fiscal después de concretada la inversión, y en el cómputo de las amortizaciones podrá optarse por un mínimo de dos cuotas anuales.

- Certificado fiscal: para los proyectos de inversión que acrediten un $60 \%$ de integración de componente nacional en las instalaciones electromecánicas, excluida la obra civil (excepto que no exista producción nacional, aunque igualmente debe tener un mínimo de 30\% de componente nacional), los beneficiarios obtendrán un certificado fiscal que podrán utilizar para el pago de impuestos nacionales. El certificado será equivalente al 20\% del valor del componente nacional de las instalaciones electromecánicas. 
- Derechos de importación: exención de derechos de importación para bienes de capital y partes o piezas para equipos destinados a proyectos de generación a partir de fuentes renovables. Este beneficio regirá para la importación de piezas para utilizar en la fabricación de equipos destinados a la generación eléctrica que no sean producidos localmente.

- Fondo Fiduciario para el Desarrollo de Energías Renovables (FODER): se crea el fideicomiso para facilitar el acceso al financiamiento para proyectos de energía renovable. Entre los destinos de los fondos se destacan: otorgar préstamos o realizar aportes de capital; otorgar avales y garantías para respaldar contratos de compraventa de energía suscritos por CAMMESA; subsidiar tasa de interés de préstamos para proyectos de energías renovables; aportes para fondos que financien estos proyectos.

Como se señaló, los grandes usuarios deben cumplir individualmente la meta de consumo de energía renovable. Para ello, podrán adquirir la energía a CAMMESA (sobreentendiéndose que el MEM se abastecerá cuanto menos del $8 \%$ de ERNC), sometiéndose a sus condiciones contractuales (con el límite mencionado de 113 USD/MWh) o a un generador privado, o, incluso, desarrollar sus propios proyectos de autogeneración que, llegada determinada escala, pueden convertirse también en generación para vender energía.

En este punto cabe mencionar el tema de la generación distribuida (GD) que se produce a partir de ERNC desarrolladas a pequeña y mediana escala, en general en ciclos de cogeneración (calorelectricidad). No se trata de un sistema autónomo, sino conectado a la red de distribución (no de alto voltaje).

La GD agrega un nuevo agente al esquema de generación, transporte, distribución y consumo de electricidad: el prosumidor, es decir, el consumidor de electricidad generada a partir de fuentes de ERNC que, a la vez, es productor y vendedor de la misma. Esto implica que los flujos de energía son bidireccionales, de modo que, para administrarlos, deben colocarse estaciones de monitoreo de la demanda en determinados puntos de la red, con sensores que permitan medir cada flujo y establecer las fallas que existan. La gestión de esa red implica coordinar el consumo con la generación, que en el caso de las ERNC es intermitente (con excepciones en los casos de geotermia, hidráulica y biomasa cuya generación puede llegar a ser constante).

La GD permite aprovechar el potencial de las fuentes renovables de baja y mediana escala, como es la biomasa, lo que disminuye la demanda de generación desde los grandes centros de producción (centrales térmicas o hidroeléctricas), y hace más eficiente el sistema de distribución, al equilibrar demandas y disminuir pérdidas por transmisión a grandes distancias. La GD está ligada a una política de uso racional de la energía y es esencial a la hora de diseñar un escenario energético con peso creciente de las ERNC.

Dendroenergía y sistemas dendroenergéticos Como se indicó, el análisis de las plantaciones dendroenergéticas debe ser encarado no solo desde una perspectiva forestal, sino también energética. En ese sentido, cobran relevancia algunas preguntas: ¿existe un marco regulatorio claro de cogeneración de energía? ¿Es adecuado el esquema de incentivos actual para la generación de energía por biomasa? ¿Es factible desarrollar inversiones forestoenergéticas con una orientación que exceda el autoconsumo? Si las respuestas son positivas, entonces se puede indagar sobre la viabilidad económica y social de las plantaciones en sí, pero no siguiendo el camino inverso.

Aquí se abordará específicamente la cuestión de las plantaciones forestoenergéticas desde el punto de vista del encuadre normativo y de incentivos para la generación de energía renovable que existe en la Argentina.

La biomasa para uso energético debe ser técnica y económicamente accesible (Broto Cartagena, 2015). Estas dos condiciones son fundamentales para entender la viabilidad del negocio bioenergético.

Que la biomasa sea accesible técnicamente implica que puede ser transportada y almacenada, alimentar dispositivos y ser consumida en ellos para 
Potencial de desarrollo de plantaciones dendroenergéticas en la Argentina

generación de energía con medios existentes y disponibles y con eficiencia suficiente. La eficacia en el manejo y la eficiencia en el uso requieren, como mínimo, propiedades constantes y conocidas. Es pues necesaria la caracterización y, en general, una transformación de la biomasa, y en ocasiones el desarrollo o modificación de medios y equipos. Si los procesos necesarios para la introducción del producto en el mercado no existen, deben desarrollarse nuevos medios y equipos, lo cual a su vez crea nuevas oportunidades de negocio.

En tanto, la accesibilidad económica requiere que el biocombustible tenga un costo menor que otros combustibles por unidad de energía generada. Este concepto está ligado a la eficiencia en el proceso y, por supuesto, al precio en relación con las propiedades que presenta. En este aspecto, la caracterización es también necesaria. Si no se conocen las propiedades de la biomasa, es imposible determinar el costo de la energía.

La accesibilidad energética es, así, un concepto también relativo y en constante evolución por la variación no sólo de los costos de producción y del mercado de los biocombustibles sólidos, sino principalmente de los precios de la energía y, por ende, de los combustibles fósiles (Broto Cartagena, 2015).

Solo una vez cumplidos los requisitos de accesibilidad planteados anteriormente se pueden analizar las ventajas de la biomasa como recurso energético. En muchos casos, si bien la biomasa es técnicamente accesible, no lo es económicamente por variables exógenas (precio de bienes sustitutos) o regulaciones que incrementan los costos de producción.

Un tipo particular de bioenergía es la dendroenergía, que se genera, directa o indirectamente, a partir de biomasa leñosa, es decir, la materia lignocelulósica de árboles, arbustos y matorrales (dendrocombustibles).

Cuando todas las unidades y operaciones involucradas en el proceso de producción, preparación, transporte, comercio y conversión de dendrocombustibles a energía útil están integradas, es factible hablar de la existencia de sistemas dendroenergéticos.
Estos sistemas exponen diversas aplicaciones y agentes intervinientes según sea su implementación: producción de biocombustibles para la generación de calor en hornos y calderas; gasificación de biomasa para la generación de energía eléctrica; producción de biocombustibles líquidos para el transporte, entre otras.

En tanto que ERNC, la dendroenergía debe ser sostenible. Por consiguiente, su análisis debe contemplar un amplio conjunto de dimensiones interrelacionadas, que constituyen un sistema integrado. A continuación, se describen las principales dimensiones para considerar.

Producción de biomasa: Un sistema dendroenergético requiere que el suministro de materia prima sea tal que logre mantener la planta de conversión en operación de acuerdo con la demanda específica del producto. Así, entonces, la biomasa dendroenergética debe ser de alto rendimiento, con períodos de rotación cortos, y adaptarse bien al sitio en que se localiza el sistema.

La provisión de esta biomasa puede derivar de forestaciones de larga rotación, de industrias forestales, o de plantaciones forestales de corta rotación.

Las plantaciones de larga rotación tienen potencial de producción de biomasa dendroenergética pero como subproducto, en tanto que su orientación primordial está en la producción de madera para la industria. Las operaciones de aprovechamiento, raleo o tala que se realizan en estas plantaciones dan origen a residuos utilizables como dendrocombustibles.

La industria forestal, por su parte, también genera residuos adecuados para convertirse en dendrocombustibles, sea en forma directa (quema de aserrín, por ejemplo) o una vez transformados y acondicionados (en pellets, chips, fardos o rollos, por ejemplo).

Las plantaciones forestales de corta rotación constituyen otra estrategia de aprovisionamiento de dendrocombustibles (una reseña de esta cuestión en Patiño Díez y Smith, 2008).

El desarrollo de una estrategia de plantaciones de corta rotación conlleva la necesidad de contar con un espectro de especies adecuadas a las características climáticas y edáficas del área, como 
así también a la disponibilidad de tierras. A este respecto, distintos documentos de organismos internacionales remarcan la necesidad de que dicha disponibilidad no se construya sobre el desplazamiento de cultivos anuales destinados a alimentación humana (FAO, 2007, 2008 y 2010).

Asimismo, ese desarrollo estratégico debe contar con información sobre la energía contenida en la biomasa que puede ser técnica y económicamente aprovechada, que depende de diferentes factores, como la productividad de las tierras forestadas, la elección de las especies para implantar, la densidad de plantación, los manejos forestales aplicados, las medidas de conservación del suelo, del agua y la biodiversidad, y otros.

Logística y transporte: Esta dimensión de los sistemas dendroenergéticos es la que se ubica entre la producción de biomasa y el proceso de conversión. En ella se incluyen el preprocesamiento, el almacenamiento y el transporte de la materia prima, todo lo cual tiene incidencia directa en los aspectos energéticos, económicos y ambientales del sistema dendroenergético integrado. Del mismo modo, los sitios de forestación y tala, las condiciones de almacenamiento, los métodos de transporte de la biomasa, y las distancias y costos de ese transporte, dan los perfiles propios de esta dimensión.

Los elevados costos y consumos de energía que implica transportar la madera con destino dendroenergético han impulsado la necesidad de atenuarlos mediante la reducción de esa materia prima a pequeñas piezas y posterior compactación (pellets, fardos, chips y rollos).

Conversión energética: Para convertir la biomasa sólida en otras formas de energía adecuadas para proveer servicios energéticos, como calor o electricidad, existen rutas físicas y químicas (Lozanoff et al., 2007; Patiño Díez y Smith, 2008). Se identifican también procesos biológicos de conversión, como la fermentación alcohólica y la digestión anaeróbica, aunque presentan poco interés para la conversión de recursos dendroenergéticos.

En la planificación de la forestación dendroenergética resulta importante, además de considerar las especies que se implantarán, evaluar el sistema de conversión al que se apelará, en tanto que la combinación de ambos factores es lo que determina la energía útil obtenible, y por ende, establece el nivel de sostenibilidad económica de la iniciativa.

Los dendrocombustibles pueden ser convertidos a energía útil a través de un rango de tecnologías como motores, calderas, refinerías, turbinas, celdas de combustibles y otras. Los desarrollos en varias de ellas están muy avanzados, pero su implementación masiva no depende de obstáculos técnicos, sino de la ecuación de costos: deben generar energía a un costo competitivo frente a la proveniente de combustibles fósiles.

Aplicación de los dendrocombustibles: Esta dimensión engloba los usos eventuales a los que se pueden destinar los dendrocombustibles; básicamente, son la combustión directa para la generación de calor y de electricidad, y la producción de combustibles para alimentar usinas; en menor medida, se cuenta también la producción de biocombustibles para motores basados en biomasa (metanol, etanol y dimetiléter).

También debe contarse al gas obtenido de la gasificación de la biomasa leñosa, adecuado para motores diésel, para motores fijos y para generar electricidad.

En la planificación de todo sistema dendroenergético que implique forestación ad hoc, esta dimensión adquiere una relevancia especial, en tanto que la selección de especies, la definición de estrategias logísticas y la opción de tecnologías de conversión dependerán, en última instancia, del uso que se le desee dar a la energía generada.

Aspectos socioambientales: Desde el punto de vista social y ambiental, la generación dendroenergética tiene aspectos positivos y negativos. Entre los primeros se cuentan el efecto en los equilibrios de carbono causado por la sustitución de combustibles fósiles, la generación de empleo en zonas rurales, la diversificación de la matriz energética y la menor emisión de metales pesados en la generación de energía eléctrica. Entre los negativos se ubica el costo ambiental de la recolección de la biomasa dendroenergética, aun cuando se trate de bosques implantados. 
El potencial de la dendroenergía para provocar cambios en los equilibrios de carbono depende de la fuente del combustible de madera a la que se apele. Si se origina en bosques implantados (sin importar si son específicamente energéticos o de larga rotación orientados a la producción de madera para la industria), ese balance será, prima facie, positivo, al igual que si se utilizan residuos forestales o industriales. En cambio, si los procesos de conversión trabajan en forma ineficiente, emitiendo gran cantidad de dióxido de carbono, el balance final será negativo.

Sin embargo, el desarrollo dendroenergético -sea cual fuese su materia prima, forestal ad hoc o residuos- presenta un grado de complejidad mayor para identificar efectos positivos y negativos al interior de la dimensión aquí abordada. A continuación, se lista un conjunto de eventuales efectos de la dendroenergía de acuerdo con la FAO (2008). Siempre esbozando escenarios potenciales, los beneficios en este ámbito serían:

- diversificación de la producción agrícola;

- estímulo del desarrollo económico rural y contribución a la reducción de la pobreza;

- aumento de los precios de las producciones y mayores ingresos para los agricultores;

- desarrollo de infraestructuras y aumento del empleo en zonas rurales;

- reducción de las emisiones de gases de efecto invernadero;

- nuevos ingresos generados por el uso de la madera, sus subproductos, sus residuos y los créditos de carbono;

- reducción de la dependencia energética y diversificación de los suministros de energía para uso doméstico, en particular, en ámbitos rurales;

- disponibilidad de energías limpias y a precios accesibles para empresas medianas y pequeñas del ámbito rural.

En cuanto a los potenciales impactos negativos, se identificaron:
- menor disponibilidad local de alimentos cuando las tierras agrícolas pasan a ser empleadas para plantaciones energéticas;

- aumento en los precios de los productos agrícolas para los consumidores finales;

- aumento de la deforestación, reducción de la biodiversidad y aumento de las emisiones de gases de efecto invernadero a causa de la demanda de tierras para cultivos energéticos;

- aumento en el número de sustancias contaminantes;

- modificaciones de los requisitos con que deben cumplir los vehículos y las infraestructuras utilizadas para las operaciones relacionadas con los combustibles;

- aumento de los costos de los combustibles;

- mayores riesgos de degradación de las tierras forestales por la intensificación en el uso del suelo;

- desplazamiento de los pequeños agricultores y concentración de la tenencia de la tierra y de los ingresos;

- menor calidad y fertilidad de los suelos ocasionada por las prácticas intensivas exigidas por los cultivos bioenergéticos;

- riesgos sanitarios para el sistema forestal actual.

La amplitud y variedad de los efectos potenciales mencionados permite señalar que, en realidad y hasta el presente, no es posible definir con precisión cuáles son los impactos positivos y negativos que generan los desarrollos dendroenergéticos, si bien, como sostiene la misma FAO, puede entreverse que las externalidades positivas se concentran en los países desarrollados, mientras que las negativas tienden a convergir en los países con menor nivel de desarrollo (FAO, 2005).

Como se ha podido observar, la cuestión dendroenergética involucra una gran diversidad de factores que influyen ante cualquier consideración respecto de este tipo de energía. De ahí que sea necesario un abordaje sistémico, que tenga 
en cuenta las dinámicas existentes en su interior y con el medio que la rodea. De tal enfoque se derivan los siguientes lineamientos generales para su estímulo y direccionamiento:

- Las políticas forestales y las energéticas deben ser complementarias, e ir de la mano de la política de desarrollo rural a fin de alcanzar los beneficios que puede ofrecer la dendroenergía.

- Dado el nivel de precios relativos entre energía de biomasa y energía fósil, es necesario que exista un sistema de incentivos público a la dendroenergía para que esta pueda competir en el mercado. Muchos de los factores que le quitan competitividad están vinculados a la infraestructura de transporte y logística (que incrementa los costos hasta hacerlos inviables en algunas regiones), y la pequeña escala de las explotaciones forestales. Sin embargo, los esquemas de incentivos deben tener en cuenta los efectos que un uso mayor de la dendroenergía puede causar en otras partes del sector forestal.

- Las políticas y proyectos a favor del desarrollo dendroenergético deberán basarse en un análisis completo de todos sus costos y beneficios económicos, sociales y ambientales.

- Deberá prestarse atención a las posibles externalidades negativas del uso de la dendroenergía (como emisiones de óxidos de nitrógeno y partículas). Son necesarios estudios científicos que demuestren la eficacia de las intervenciones y los impactos (positivos y negativos) sobre los sistemas forestales, de tal manera que puedan generarse criterios e indicadores válidos de sostenibilidad. Sin embargo, la falta de conocimiento sobre ciertos procesos ecológicos no debería ser un impedimento para su desarrollo, ya que lo que sí existe son abundantes evidencias científicas acerca de los efectos negativos de la falta de aprovechamiento de la multifuncionalidad de los bosques.

- Se debe impulsar un desarrollo dendroenergético que combine la producción forestal y la transformación industrial de la madera en paralelo a la generación energética. Y, al mismo tiempo, un programa de comunicación eficaz de los beneficios de la dendroenergía, y una coordinación eficiente entre todos los actores del sector.

\section{Forestación dendroenergética: estímulos, costos y sustentabilidad}

Si bien la madera de las plantaciones forestales con destino energético es una de las fuentes para la producción de energía de biomasa forestal, en general, los estudios sectoriales en la materia hacen hincapié en que el desarrollo dendroenergético tiene su eje principal en la utilización de los residuos de la industria maderera. Por ejemplo, uno de los trabajos recientes más importantes sobre la producción dendroenergética en la Argentina se desenvuelve, básicamente, sobre su desarrollo a partir del uso de residuos de la industria forestal (Uasuf y Hilbert, 2012). Del mismo modo, análisis prospectivos realizados en el marco de la planificación estratégica en ciencia y tecnología del país, centrados en el sector forestal, exponen como línea de desarrollo de la dendroenergía el aprovechamiento de residuos forestales, y solo marginalmente mencionan la posibilidad de apelar a cultivos forestoenergéticos (Sharry, 2013; Federico, 2012). Incluso desde el punto de vista de la forestación, un documento oficial reciente expone un cuadro general de la producción forestal implantada y define los parámetros generales de su gestión sostenible, sin hacer referencia a las plantaciones dendroenergéticas (UCAR, 2015).

El esquema de incentivos para el desarrollo de cultivos forestales para producción de electricidad debe asentarse, precisamente, en el ámbito energético, es decir, en el conjunto de normas y políticas que estimulen la generación a partir de ERNC coordinadas entre las administraciones nacional y provinciales, para dar seguridad jurídica a los agentes del sector y aliviar la burocratización administrativa.

En otras palabras, incentivar la generación por ERNC y la generación distribuida constituye el paso previo, necesario e ineludible para el desenvolvimiento dendroenergético en su vertiente de utilización de la madera obtenida de bosques implantados. Sin esos incentivos en pleno 
Potencial de desarrollo de plantaciones dendroenergéticas en la Argentina

funcionamiento, carece de sentido estimular las plantaciones forestales energéticas.

Ahora bien, aun cuando se afiance el sistema de incentivos mencionados, el impulso al desarrollo dendroenergético argentino debe tomar en consideración las prevenciones ambientales del reciente documento del INTA sobre el potencial de desarroIlo de las plantaciones forestoenergéticas. Ese minucioso análisis recomienda focalizar la atención en "el balance entre los impactos positivos y negativos, en términos de agotamiento de nutrientes del suelo, erosión, consumo de agua, pérdida de biodiversidad, contaminación del aire y pérdida de productividad" (INTA, 2016).

En ese documento se insta a que las plantaciones forestales dendroenergéticas se enfoquen más allá del análisis costo-beneficio económico, y que incluyan los costos ambientales, lo que permitiría sopesar con mayor precisión la rentabilidad real de estas plantaciones. Sin embargo, el mismo documento señala que la información "respecto de especies y materiales genéticos elegibles, modelos silviculturales y productividad esperable en términos de biomasa aérea, así como los impactos potenciales sobre los recursos, aplicables a plantaciones con destino dendroenergético, es prácticamente inexistente en la Argentina".

Finalmente, el estudio indica que "las plantaciones dendroenergéticas presentan características propias de los usos intensivos de la tierra y, al igual que ellos, un significativo potencial para provocar impactos negativos".

Esta faceta del análisis lleva a incorporar la cuestión de los costos (monetarios y ambientales) que acarrea la promoción de las plantaciones forestales con destino energético, en relación con las herramientas de incentivo a la forestación y, más atrás, de estímulo a la generación eléctrica a partir de ERNC. Es decir, al contemplar integralmente los costos que apareja la dendroenergía a partir de plantaciones ad hoc cambia la ecuación de rentabilidad, no solo de la propia inversión dendroenergética, sino también el retorno de la inversión que realiza el Estado a través de los mecanismos de incentivos monetarios a la difusión de esas plantaciones.
Considerar los costos integrales de la generación energética basada en productos forestales implantados específicamente implica una estructura como la siguiente (compartida, claro está, con otras formas de generación):

- costo del combustible;

- costo de operación y mantenimiento;

- inversión de capital, incluyendo planificación y sitio de trabajo;

- tasa de descuento;

- costo de emisiones de dióxido de carbono;

- costos ambientales;

- otros costos no claramente cuantificables (externalidades).

Y esta estructura es aplicable también -con las adecuaciones del caso- a la sola fase de la implantación de bosques con fines dendroenergéticos.

Algunos de los impactos de la implantación de bosques para dendroenergía son detectables y mensurables, mientras que otros no (o no con algún grado de certeza). Una estructura de costos que no incluya todos los impactos genera algún tipo de externalidad (o falla del mercado). La no valorización de tales externalidades lleva a una asignación no óptima de los recursos involucrados en el proceso productivo. Específicamente, en la generación de energía, la inadecuada consideración de las externalidades puede distorsionar severamente la evaluación, lo cual puede conducir a una elección de tecnologías de generación contaminantes.

Para corregir tales fallas del mercado deben internalizarse esos costos externos, incorporándolos al precio a través de distintos mecanismos. Con ese fin, es necesario expresar los costos en las mismas unidades que el precio, cuantificándolos en valores monetarios. Un camino posible es apelar al método del análisis del ciclo de vida (ACV), que consiste en cuantificar todos los flujos de materia y energía asociados con el proceso productivo, desde su inicio hasta su término. En el caso de la generación de energía, implica recorrer desde la extracción del combustible que se utilice hasta la 
deposición de los residuos finales, pasando por el transporte de aquel combustible, la preparación del proyecto y la construcción, operación, mantenimiento y desmantelamiento de la planta. En el caso particular de las plantaciones dendroenergéticas, ese recorrido tiene su réplica en los costos de implantación, manejo, tala y transporte de la biomasa involucrada.

Esas fases mencionadas dentro de la generación de biomasa dendroenergética aparejan consecuencias contaminantes resumibles en grandes conjuntos:

- emisiones atmosféricas de dióxido de carbono, dióxido de nitrógeno, dióxido de azufre y partículas;

- vertidos líquidos de químicos de uso agrícola de potencial contaminante (plaguicidas, fungicidas y otros);

- ocupación de terrenos antes no forestados, lo que genera impacto visual y procesos de degradación (edáfica, hídrica y de biodiversidad).

Una vez cuantificados físicamente los impactos producidos por las distintas tecnologías utilizadas y no recogidos en sus precios, se debe avanzar hacia su cuantificación monetaria. Para ello se puede apelar a distintos métodos (Zoratti y Guzmán, 2015a):

- el método llamado updown, que utiliza datos agregados, se basa en un enfoque global, calculando las emisiones totales del sector energético y los impactos causados por la contaminación ambiental, que consigna a cada agente generador en función de sus emisiones específicas;

- el método Bernow-Marron, que propone una cuantificación basada en los costos de control, es decir, el daño causado por un contaminante se valora como el costo necesario para reducir la emisión de ese contaminante hasta el nivel establecido por la legislación;

- el método derivado del proyecto Extern E, que se basa en la cuantificación de los daños producidos y analiza la sucesión de etapas lógicas que van desde la actividad que los genera hasta el impacto negativo que producen, independientemente de cada actividad o daño considerado. Esto permite calcular daños marginales, específicos para cada emplazamiento y tecnología, que posteriormente podrán ser incorporados en modelos de planificación y despacho mediante impuestos específicos, por ejemplo.

Este método se sustenta en tres principios: transparencia, coherencia, e integralidad del proceso. La transparencia implica que es necesaria una clara explicación de cómo se han obtenido los resultados, la incertidumbre asociada a ellos y la medida en que se han cuantificado o no todos los impactos del ciclo de vida. La coherencia conlleva la utilización de los mismos métodos, modelos e hipótesis para valorar los impactos, independientemente del ciclo de vida, de modo de poder efectuar una comparación justa entre diferentes ciclos y entre diferentes impactos dentro del mismo ciclo. La integralidad está dada porque el método debe considerar el ciclo de generación energética por entero, desde la extracción de la materia prima hasta la producción y deposición final de los residuos.

La valorización económica de los daños incluye, por un lado, diferenciar las externalidades propias de la actividad específica analizada (por caso, la producción de biomasa forestal para generar energía), de aquellos otros impactos que pudieran estar ya de alguna manera internalizados, y, por otro lado, la asignación de un valor económico a los diferentes daños cuantificados.

Lo anterior implica, por una parte, tener en cuenta que no todos los impactos ambientales pueden ser considerados externalidades, ya que algunos quizás se han internalizado, parcial o totalmente, por otras actividades; por otra parte, tomar en consideración que la asignación del valor económico a los daños se lleva a cabo midiendo, fundamentalmente, los cambios en el bienestar de la sociedad que se originan por una modificación en el ambiente, traducible esto en una variación en la disposición a pagar por un cambio favorable o a no aceptar un cambio desfavorable. Tal disposición a pagar se puede realizar por dos vías: si existe un mercado de bienes que se están valorando, se puede usar ese precio suponiendo que refleja 
Potencial de desarrollo de plantaciones dendroenergéticas en la Argentina

adecuadamente los costos; o, en los casos de los bienes que no tienen precio -como la vida humana-, el análisis se puede hacer mediante métodos de costos evitados.

Esta tarea de identificación y cuantificación es un trabajo pendiente pero ineludible para la generación a partir de ERNC, en general, y de dendroenergía, en particular; incluso, es una tarea para llevar adelante aun considerando solo la fase de las plantaciones dendroenergéticas.

Un primer paso en esta dirección podría ser establecer un set de indicadores que permita efectuar la evaluación y el seguimiento de la sostenibilidad -tanto ambiental como económica y social- de las plantaciones dendroenergéticas, que facilitaría la heurística del costeo requerido.

La configuración de un set así debe guardar un delicado equilibrio entre generalidad -de las plantaciones dendroenergéticas- y especificidad -de un emplazamiento forestoenergético en particular-. En el documento mencionado se enumeran los principales efectos ambientales que podrían aparejar las plantaciones dendroenergéticas, pero no se alcanza a conformar un set de indicadores para el seguimiento de aquellos efectos (INTA, 2016). Otros trabajos intentan hacerlo, pero no llegan a profundizar el análisis con la calidad ni el alcance con que lo hace el trabajo del INTA (Crosara Benelli, 2001).

A grandes rasgos, es factible enunciar un primer conjunto de indicadores que permitirían efectuar un seguimiento y evaluación de la sostenibilidad de las plantaciones forestales dendroenergéticas. Esto, de cara a guiar su proceso de costeo $y$, por ende, contribuir a la toma de decisiones, tanto desde el punto de vista del inversor privado, como del Estado, que aporta recursos para fomentar esas plantaciones a través de los mecanismos de incentivos en vigencia en cada momento.

Los indicadores son unidades de información que señalan qué está ocurriendo en el sistema bajo estudio. Operan como ventanas por las que se puede observar la dinámica de los sistemas analizados, señalando la dirección que siguen los procesos críticos que se dan en su interior, desde lo ambiental, lo económico y lo social. Así, los indicadores pueden definirse como herramientas para agregar y simplificar información de naturaleza compleja, de una manera clara y precisa, que permiten apoyar la toma de decisiones al proveer información sobre los procesos interiores de un sistema, con relación a su pasado y a los posibles impactos futuros. Un indicador de sostenibilidad es un valor o cualidad que pone de manifiesto el estado o condición de un proceso crítico dado en relación con la sostenibilidad del sistema.

La ventaja de apelar al uso de indicadores es que posibilita describir los aspectos más importantes de los procesos que hacen a la sostenibilidad de un sistema respecto de una decisión o un conjunto de decisiones. Por ende, siempre se deberá trabajar con un conjunto de indicadores, y no solo con uno, y ese conjunto estará definido en función del tipo de decisión y del nivel jerárquico en que se tome (sectorial, subsectorial, regional, local, etcétera).

Desde mediados de la década de 1990 se proponen sets de indicadores de sostenibilidad que intentan dar cuenta integralmente del devenir del sistema sobre el que hacen foco. Cada propuesta se compone de un conjunto de indicadores que se distribuyen entre las tres dimensiones: ambiental, económica y social, más allá de la escala del proceso sobre el cual se apliquen (un establecimiento productivo, una región geográfica, un país, un sector de actividad, una fase de un encadenamiento de actividades, por ejemplo). La integración de tales sets varía según el sistema, pero siempre respetando la tríada ambiente, economía y sociedad.

Al considerar las plantaciones dendroenergéticas, se avanza sobre una escala de carácter subsectorial (se trata de una fase dentro de la cadena de generación energética a partir de biomasa), por lo cual la selección de los indicadores incluidos en el set debe ser muy específica y adecuada al contexto territorial donde se aplique. En función de esta premisa y de la revisión bibliográfica de trabajos que se ocupan directa o indirectamente de las plantaciones forestales con destino energético, es posible esbozar un set de indicadores preliminares que guíen el trabajo de evaluar y/o monitorear la conveniencia 
y el desenvolvimiento de tales plantaciones desde el punto de vista de la inversión privada en sí y desde la perspectiva del Estado impulsor de las mismas.

Considerando las dimensiones mencionadas, los indicadores que se proponen son ${ }^{4}$ :

\section{- Dimensión ambiental:}

$\checkmark$ Indicador 1: Calidad de suelos

* Nivel de fertilidad.

* Presencia de procesos erosivos.

* Ejecución de medidas de conservación.

* Grado de estructura.

* Composición y diversidad biológica.

$\checkmark$ Indicador 2: Calidad de agua

* Grado de afectación a espejos y cursos de agua.

* Grado de afectación a napas.

$\checkmark$ Indicador 3: Nivel atmosférico

* Contribución a la fijación de dióxido de carbono.

$\checkmark$ Indicador 4: Biodiversidad

* Abundancia y riqueza de especies animales y vegetales.

* Presencia de especies animales y vegetales no deseables.

$\checkmark$ Indicador 5: Paisaje

* Cambios en el valor estético del paisaje circundante.

\section{- Dimensión económica:}

$\checkmark$ Indicador 1: Productividad

* Relación insumo-producto.

* Relación producto-unidad de superficie.

$\checkmark$ Indicador 2: Valor agregado bruto
* Salarios, rentas, intereses y beneficios pagados.

* Reservas para depreciación del capital.

* Impuestos.

* Subsidios recibidos.

\section{$\checkmark$ Indicador 3: Salario}

* Relación entre salarios forestales y salarios medios del sector rural.

\section{$\checkmark$ Indicador 4: Costos ambientales}

* Costos ambientales recurrentes (obtención de información medioambiental; diseño y ejecución del plan de gestión ambiental; adecuación tecnológica ambiental; gestión de residuos, emisiones y vertidos; gestión del producto; exigencias administrativas; auditoría medioambiental).

* Costos ambientales no recurrentes (diseño de sistemas de información y prevención; inversiones en instalaciones; erogaciones plurianuales de conservación y mantenimiento; interrupción en el proceso; accidentes; eventuales nuevas exigencias del entorno; mejora de la imagen medioambiental del establecimiento; sistema de control y medición).

\section{- Dimensión social:}

$\checkmark$ Indicador 1: Empleo

* Tasa de empleo de población local.

* Tasa de empleo por sexo.

$\checkmark$ Indicador 2: Capacitación

* Cantidad de capacitaciones brindadas a la mano de obra forestal.

* Cantidad de capacitaciones por sexo.

$\checkmark$ Indicador 3: Beneficios sociales

* Acceso a servicios de salud de trabajadores forestales respecto del resto de trabajadores rurales.

* Tasa de permanencia de hijos de trabajadores forestales en el sistema educativo respecto del resto de los hijos de trabajadores rurales.

\footnotetext{
${ }^{4}$ Varios de los indicadores señalados (particularmente algunos de la dimensión social) son de neto corte cualitativo, y deben ser trabajados de un modo particular para cuantificarlos y poder plasmarlos en el contexto de un set como el propuesto.
} 


\section{$\checkmark$ Indicador 4: Aceptación sociocultural \\ * Porcentaje de la población rural que valora positivamente la producción forestal.}

A un nivel de análisis macro, antecediendo a la promoción de la generación de energía por biomasa, en general, y en este caso en particular, a la promoción de plantaciones forestales dendroenergéticas, debe contemplarse la formulación de una política nacional clara, concreta y con asidero en la realidad, que encuadre, oriente y estimule el desarrollo energético sobre la base de ERNC, de la que se desprenda el impulso a la forestación energética en condiciones de sustentabilidad integral.

Para tal fin, las recomendaciones de los organismos internacionales (FAO, 2005, 2007 y 2008, entre otros) orientadas a la generación dendroenergética pueden resumirse en las siguientes propuestas:

- La dendroenergía debe enfocarse como un tema transectorial, integrando la política energética con la política forestal.

- Las decisiones de orientación y estímulo deben sustentarse en análisis pormenorizados sobre los impactos ambientales, económicos y sociales de los sistemas dendroenegéticos, en el contexto de las condiciones locales, regionales o nacionales específicas.

- Los diseños de estas políticas deben partir de un previo y fluido circuito de flujo informativo al que accedan inversores, propietarios de tierras, gestores públicos y consumidores.

- En aquel diseño deben considerarse ciertas variables claves como el empleo rural, la protección ambiental, la gestión del uso de la tierra, la actividad maderera industrial, con el fin de generar sinergias y administrar los conflictos de intereses en caso de que surjan.

- La orientación y promoción de las plantaciones forestales energéticas deberá estar coordinada con la dotación de infraestructura relacionada $y$, en particular, con los mecanismos operativos de generación distribuida vigentes en cada momento.
- La promoción de las forestaciones energéticas debe estar articulada con la política energética en general, a fin de evitar distorsiones de mercado que repercutan en distintos sectores de la economía.

- Se requiere diseñar e implementar en forma permanente un seguimiento sistemático de los impactos ambientales y sociales que generen las plantaciones dendroenergéticas.

- Es recomendable, por lo mencionado anteriormente, que las empresas que exploten esta línea de negocio sean independientes y especializadas en el mercado energético; aunque se trate de consorcios amplios, que estén centrados profesional y empresarialmente en el negocio de la energía.

\section{Potencial demanda de mano de obra}

Aquí se presenta la estimación del empleo directo demandado en la producción de plantaciones forestales con destino energético, determinado por los factores técnicos considerados en cada modelo, lo que incuye tanto el perfil técnico de producción como los rendimientos por hectárea (ha) que permiten obtener las especies seleccionadas en cada región.

Para determinar la demanda de empleo en plantaciones dendroenergéticas que abastezcan una planta de generación eléctrica de $1 \mathrm{MW}$, se realizan algunos supuestos. En primer lugar, se considera que las plantaciones cuentan con hectáreas de distintas edades, es decir, que están en diferentes estadios/fases y cada año se realiza una tala rasa. El número de jornales requeridos por hectárea difiere según la edad de la plantación, dependiendo de las tareas a realizar. Por lo tanto, la sumatoria de mano de obra diaria empleada en las diferentes edades permite determinar el número de jornales requerido para realizar un ciclo completo de producción.

En segundo lugar, se plantea el caso para una planta de $1 \mathrm{MW}$ con una demanda de $17568^{5}$ toneladas ( $t$ ) de rollos por año. En cuanto a los días

\footnotetext{
${ }^{5}$ Dato brindado por informante calificado.
} 
trabajados, se suponen 240 en el año. Además, se utilizan los rendimientos y jornales requeridos por hectárea según los modelos especificados para cada región.

En base a los datos mencionados, se determina el número de jornales necesarios por tonelada de producción y se deriva la mano de obra anual que requiere el nivel de producción de rollos de madera que consume una planta de $1 \mathrm{MW}^{6}$. En el Cuadro 1 se observan los principales indicadores y la mano de obra requerida, según región.

La región de Chaco-Formosa presenta una mayor demanda de mano de obra diaria por tonelada producida de madera, mientras que la zona Pampeana emplea la menor cantidad. Cabe resaltar que, dado el volumen de materia prima que se transporta a la industria, el efecto indirecto en el empleo del sector de transporte es relevante.

Con respecto a la industria, se puede considerar el de una planta de cogeneración de $4 \mathrm{MW}$ instala- da en Misiones (de la empresa Pindó), que emplea a siete personas, con tres turnos de dos operarios y un supervisor.

En relación con aspectos sociales ligados a factores culturales o tradiciones, no se observan restricciones o prejuicios que pudieran afectar el desenvolvimiento de la actividad en las regiones analizadas. Si bien no todas tienen el mismo grado de desarrollo de plantaciones energéticas, sí cuentan con una alta tradición en el sector forestal, con personal calificado y formación adecuada. Sí se necesita comunicar a la sociedad, con énfasis en las poblaciones locales, las ventajas de los usos alternativos de los recursos forestales y la sustentabilidad de los sistemas de producción. Los beneficios sociales de estas nuevas alternativas de negocios se dan no solo en la creación de empleos directos, sino también en los indirectos, que son difíciles de cuantificar, así como en la generación de nuevos mercados para nuevos productos.

\footnotetext{
${ }^{6}$ Bajo el supuesto de rendimientos constantes, el empleo directo estimado generado por plantas industriales de mayor capacidad productiva puede extrapolarse de manera lineal.
}

Cuadro 1. Mano de obra demandada en plantaciones forestales dendroenergéticas

\begin{tabular}{|c|c|c|c|c|c|c|}
\hline \multicolumn{7}{|c|}{ Planta de $1 \mathrm{MW}$} \\
\hline Regiones & $\begin{array}{l}\text { Duración } \\
\text { del ciclo de } \\
\text { producción } \\
\text { (años) }\end{array}$ & $\begin{array}{l}\text { N. }{ }^{\circ} \text { total de } \\
\text { jornales por } \\
\text { ciclo }\end{array}$ & $\begin{array}{l}\text { Rendimiento total } \\
\text { por ha por ciclo } \\
\text { (t) }\end{array}$ & $\begin{array}{l}\text { Jornal por } \\
\text { tonelada } \\
\text { producida }\end{array}$ & $\begin{array}{l}\text { Empleo } \\
\text { directo }\end{array}$ & $\begin{array}{l}\text { Superficie } \\
\text { (ha) }\end{array}$ \\
\hline Mesop. Tierras Coloradas & 15 & 86,45 & 332,00 & 0,26 & 19 & 794 \\
\hline Mesop. Planicies Arenosas & 15 & 45,79 & 253,00 & 0,18 & 13 & 1042 \\
\hline Mesop. Entre Ríos & 14 & 56,24 & 222,00 & 0,25 & 19 & 1108 \\
\hline Delta & 18 & 86,50 & 235,00 & 0,37 & 27 & 1346 \\
\hline Pampeana & 21 & 54,20 & 345,00 & 0,16 & 11 & 1069 \\
\hline NOA & 21 & 145,70 & 398,00 & 0,37 & 27 & 927 \\
\hline Chaco-Formosa & 24 & 125,25 & 258,00 & 0,49 & 36 & 1634 \\
\hline
\end{tabular}

Fuente: Elaborado por los autores. 
3.
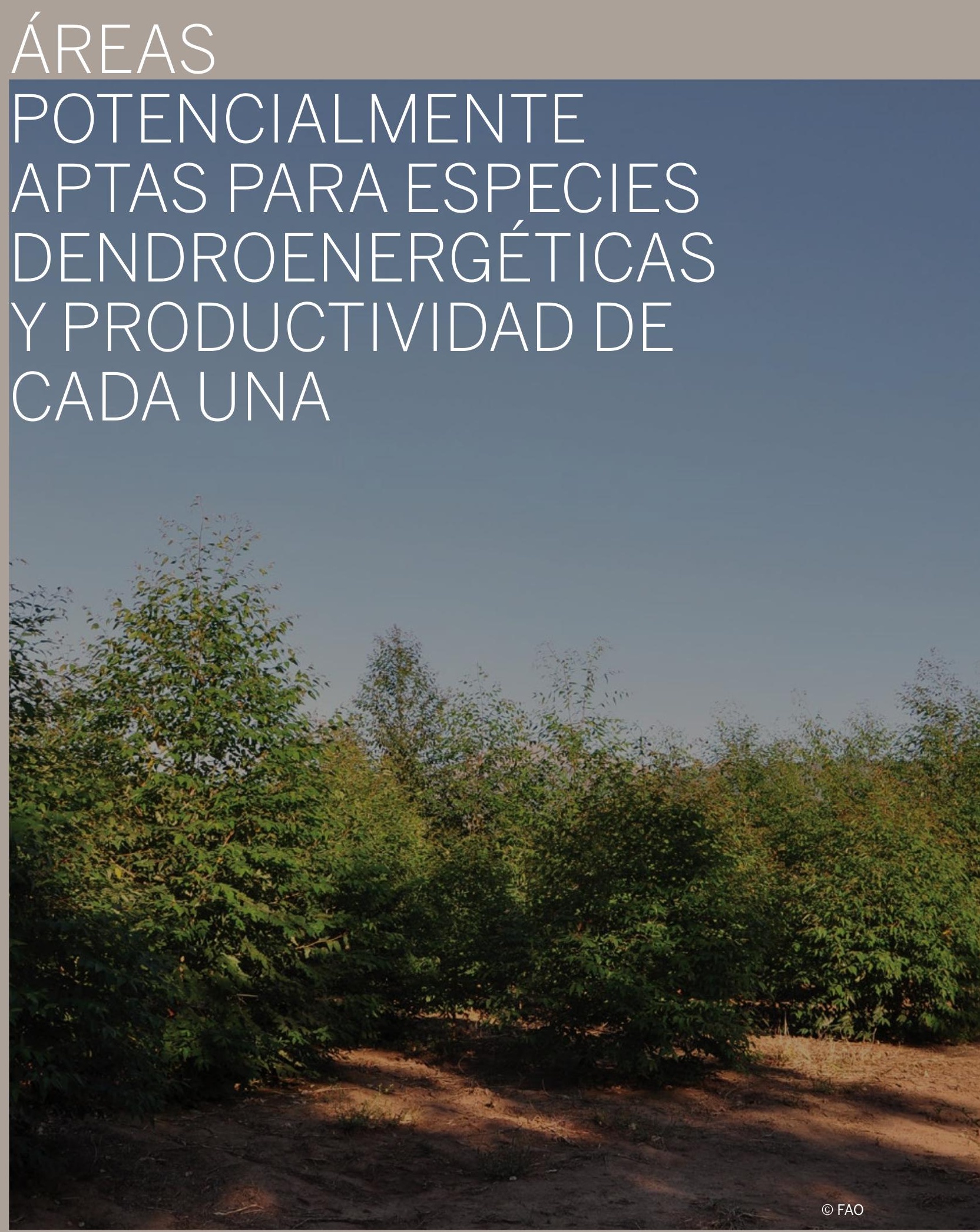


\section{Para realizar la cartografía de las áreas elegibles para establecer plantaciones dendroenergéticas se llevó a cabo un análisis integral, que incluyó lo productivo, lo ambiental y los servicios ecosistémicos.}

En el presente capítulo se presenta la cartografía, escala 1:500 000, de las áreas potencialmente aptas para el desarrollo de plantaciones dendroenergéticas en la Argentina, según los criterios y restricciones para la elegibilidad de las tierras y los requerimientos y tolerancias de las especies forestales seleccionadas.

Se trata de un mapa con la zonificación/delimitación de las regiones forestales consideradas como potenciales para el establecimiento de plantaciones dendroenergéticas en la Argentina, así como mapas de tales regiones con las áreas potenciales para las especies recomendadas, con una zonificación en rangos de aptitud definidos de acuerdo con la productividad esperada.

\section{Materiales y métodos \\ Mapa nacional}

La República Argentina es un país de amplia dimensión territorial, con una diversidad de ambientes naturales y productivos definidos como producto de la interacción del clima, el suelo y las realidades socioeconómicas. La actividad forestal se estableció históricamente en regiones contrastantes, con suelos de diferentes potenciales productivos, donde las especies cultivadas contribuyen a la generación de productos y subproductos, así como a la provisión de servicios.

Para la definición de las áreas elegibles para establecer plantaciones dendroenergéticas se planteó un análisis integral, que contemplara lo productivo, lo ambiental y los servicios ecosistémicos. Se estableció que aquellas regiones donde las precipitaciones son inferiores a los 800 milímetros $(\mathrm{mm})$ anuales y presentan balance hídrico negativo (regiones áridas, semiáridas y subhúmedas) no son elegibles para estos modelos productivos, debido al nivel esperable de consumo de agua por parte de las forestaciones densas y al posible desencadenamiento de procesos de degradación de los suelos por salinización secundaria. 
Potencial de desarrollo de plantaciones dendroenergéticas en la Argentina

Del mismo modo, la legislación actual establece la exclusión de cambio de uso del suelo de las áreas boscosas que bajo el procedimiento de ordenamiento territorial de bosques nativos (OTBN) fueron categorizadas como tipo I y II, así como también otras reservas de orden diverso destinadas a la preservación. Este criterio descarta como elegibles áreas del territorio con bosques nativos que deben ser preservados. También las tierras que a partir de una evaluación de capacidad de uso de suelo han sido clasificadas como Clase I, II, III y VIII en el sistema de USDA (Klingebiel y Montgomery, 1961) quedan excluidas como potencialmente aptas para la forestación.

\section{Mapas de las regiones forestales}

Se consideraron las cuatro regiones forestales del país, cada una con las siguientes especies o géneros:

- Mesopotamia: Pinus taeda, Eucalyptus (E.) grandis.

- NOA: E. grandis, E. camaldulensis.

- Pampeana: E. camaldulensis, E. viminalis, E. dunnii, Salix y Populus.

- Central: E. grandis, E. camaldulensis, E. tereticornis y E. viminalis.

La región Delta Pampeano no fue considerada en virtud de que no se contaba con cartografía que permitiera realizar el análisis por restricciones edáficas. La Patagonia fue excluida del análisis dado que de un primer informe se desprende la no viabilidad para este uso específico, básicamente debido al tiempo de las rotaciones.

\section{Criterios de diagnóstico para definir clases y}

subclases de aptitud por especie

La decisión del cultivo de una especie forestal y las expectativas de crecimiento en una determinada región deben surgir del análisis de los requerimientos y las tolerancias climáticas y edáficas de tal especie. En el Cuadro 2, se describen las clases de aptitud (Apta, Moderadamente apta y No apta) para las especies propuestas, de acuerdo con criterios diagnósticos, requerimientos y tolerancias indicados por los ingenieros Ana María Lupi y Roberto Fernández (comunicación personal).

\section{Producción de biomasa}

En el Cuadro 3 se muestran los rangos de productividad forestal para diferentes especies de potencial utilización como biomasa, y distintas regiones, de acuerdo con las clases de aptitud de las tierras.

\section{Información de base utilizada y Sistema de Información Geográfica}

Teniendo en cuenta los criterios de selección descritos y para poder realizar la cartografía referida, se utilizó la siguiente información de base, en formato digital:

- Mapa de precipitaciones anuales medias en formato digital ráster (Bianchi y Cravero, 2010).

- Mapa de balance hídrico en formato digital ráster (Bianchi y Cravero, 2010).

- Mapas en formato digital vectorial del OTBN de las provincias (MAyDS).

- Mapas de Áreas Naturales Protegidas (ANP, nacionales y provinciales) en formato digital vectorial (MAyDS).

- Mapa de suelos en formato digital vectorial, escala 1:500 000 (Atlas de Suelos de la República Argentina, 1990), como base de información de la capacidad de uso del suelo (sólo se incluyó el suelo principal de la unidad cartográfica).

Como primer paso, se realizó una adecuación de las capas de información debido a sus distintos orígenes y la heterogeneidad en la calidad de la información (escalas de trabajo, referencias geográficas, duplicación de información, entre otras diferencias). Para esto fue necesario: i) unificar sistemas de coordenadas (georreferenciar); ii) digitalizar capas ráster a polígonos (mapas de interpolación) y generar metadatos y tablas de atributos; iii) corregir errores topológicos en capas de OTBN y ANP (duplicación de polígonos, superposición y otros); iv) unificar tablas de atributos. 
Cuadro 2. Clases de aptitud de las especies forestales propuestas, por región

Pinus taeda - Región Mesopotamia

\begin{tabular}{l|l|l|l}
\hline Variable/Suelo & Apto & Moderadamente apto & No apto \\
\hline Profundidad efectiva & $>100 \mathrm{~cm}$ & $50-100 \mathrm{~cm}$ & $<50 \mathrm{~cm}$ \\
\hline Drenaje & $\begin{array}{l}\text { Bien drenado a } \\
\text { moderadamente bien } \\
\text { drenado. }\end{array}$ & $\begin{array}{l}\text { Imperfectamente drenado. } \\
\text { Algo excesivamente } \\
\text { drenado. }\end{array}$ & $\begin{array}{l}\text { Pobre a muy pobremente } \\
\text { drenado. } \\
\text { Excesivamente drenado. }\end{array}$ \\
\hline Alcalinidad & No alcalino. & No alcalino. & Alcalino*.
\end{tabular}

Eucalyptus grandis - Región Mesopotamia, NOA y Central

\begin{tabular}{|c|c|c|c|}
\hline Variable/Suelo & Apto & Moderadamente apto & No apto \\
\hline Profundidad efectiva & $>100 \mathrm{~cm}$ & $50-100 \mathrm{~cm}$ & $<50 \mathrm{~cm}$ \\
\hline Drenaje & Bien drenado. & $\begin{array}{l}\text { Moderadamente bien } \\
\text { drenado. } \\
\text { Algo excesivamente } \\
\text { drenado. }\end{array}$ & $\begin{array}{l}\text { Pobre o muy pobremente } \\
\text { drenado. Imperfectamente } \\
\text { drenado. } \\
\text { Excesivamente drenado. }\end{array}$ \\
\hline Alcalinidad & No alcalino. & No alcalino. & Alcalino*. \\
\hline
\end{tabular}

* Cualquier grado de alcalinidad.

\section{Eucalyptus dunnii - Región Pampeana}

\begin{tabular}{l|l|l|l} 
Variable/Suelo & Apto & Moderadamente apto & No apto \\
\hline Profundidad efectiva & $>100 \mathrm{~cm}$ & $50-100 \mathrm{~cm}$ & $<50 \mathrm{~cm}$ \\
\hline Drenaje & $\begin{array}{l}\text { Bien drenado. } \\
\text { Moderadamente bien } \\
\text { drenado. }\end{array}$ & $\begin{array}{l}\text { Algo excesivamente } \\
\text { drenado. Imperfectamente } \\
\text { drenado. }\end{array}$ & $\begin{array}{l}\text { Pobre o muy pobremente } \\
\text { drenado. } \\
\text { Excesivamente drenado. }\end{array}$ \\
\hline Alcalinidad & No alcalino. & Débilmente alcalino. & $\begin{array}{l}\text { Moderadamente alcalino. } \\
\text { Fuertemente alcalino. }\end{array}$ \\
\hline
\end{tabular}

Eucalyptus camaldulensis - Región NOA, Pampeana y Central

\begin{tabular}{|c|c|c|c|}
\hline Variable/Suelo & Apto & Moderadamente apto & No apto \\
\hline Profundidad efectiva & $>100 \mathrm{~cm}$ & $50-100 \mathrm{~cm}$ & $<50 \mathrm{~cm}$ \\
\hline Drenaje & $\begin{array}{l}\text { Bien drenado a } \\
\text { moderadamente bien } \\
\text { drenado. }\end{array}$ & $\begin{array}{l}\text { Imperfecta a pobremente } \\
\text { drenado. } \\
\text { Algo excesivamente } \\
\text { drenado. }\end{array}$ & $\begin{array}{l}\text { Muy pobremente drenado. } \\
\text { Excesivamente drenado. }\end{array}$ \\
\hline Alcalinidad & No alcalino. & $\begin{array}{l}\text { Débil a moderadamente } \\
\text { alcalino. }\end{array}$ & $\begin{array}{l}\text { Fuerte a muy fuertemente } \\
\text { alcalino. }\end{array}$ \\
\hline
\end{tabular}


Potencial de desarrollo de plantaciones dendroenergéticas en la Argentina

Eucalyptus viminalis - Región Pampeana y central

\begin{tabular}{|c|c|c|c|}
\hline Variable/Suelo & Apto & Moderadamente apto & No apto \\
\hline Profundidad efectiva & $>100 \mathrm{~cm}$ & $50-100 \mathrm{~cm}$ & $<50 \mathrm{~cm}$ \\
\hline Drenaje & Bien drenado. & $\begin{array}{l}\text { Moderadamente bien drenado a } \\
\text { imperfectamente drenado } \\
\text { Algo excesivamente drenado. } \\
\text { Excesivamente drenado. }\end{array}$ & $\begin{array}{l}\text { Pobre a muy pobremente } \\
\text { drenado. }\end{array}$ \\
\hline Alcalinidad & No alcalino. & Débilmente alcalino. & $\begin{array}{l}\text { Moderada a fuertemente } \\
\text { alcalino. } \\
\text { Muy fuertemente alcalino. }\end{array}$ \\
\hline
\end{tabular}

Eucalyptus tereticornis - Región Central

\begin{tabular}{|c|c|c|c|}
\hline Variable/Suelo & Apto & Moderadamente apto & No apto \\
\hline Profundidad efectiva & $>100 \mathrm{~cm}$ & $50-100 \mathrm{~cm}$ & $<50 \mathrm{~cm}$ \\
\hline Drenaje & Bien drenado. & $\begin{array}{l}\text { Moderadamente bien drenado a } \\
\text { imperfectamente drenado. } \\
\text { Algo excesivamente drenado. }\end{array}$ & $\begin{array}{l}\text { Pobre a muy pobremente } \\
\text { drenado. } \\
\text { Excesivamente drenado. }\end{array}$ \\
\hline Alcalinidad & No alcalino. & Débil a moderadamente alcalino. & $\begin{array}{l}\text { Fuerte a muy fuertemente } \\
\text { alcalino. }\end{array}$ \\
\hline
\end{tabular}

Populus sp. - Región Pampeana (FAO, 2014)

\begin{tabular}{l|l|l|l}
\hline Variable/Suelo & Apto & Moderadamente apto & No apto \\
\hline Profundidad efectiva & $>100 \mathrm{~cm}$ & $60-100 \mathrm{~cm}$ & $<60 \mathrm{~cm}$ \\
\hline Drenaje & Bien drenado. & $\begin{array}{l}\text { Imperfectamente drenado a } \\
\text { moderadamente bien drenado. }\end{array}$ & $\begin{array}{l}\text { Pobre a muy pobremente } \\
\text { drenado. }\end{array}$ \\
\hline Alcalinidad & No alcalino. & No alcalino. & Alcalino. \\
\hline
\end{tabular}

Salix sp. - Región Pampeana

\begin{tabular}{l|l|l|l}
\hline Variable/Suelo & Apto & Moderadamente apto & No apto \\
\hline Profundidad efectiva & $>80 \mathrm{~cm}$ & $50-80 \mathrm{~cm}$ & $<50 \mathrm{~cm}$ \\
\hline Drenaje & $\begin{array}{l}\text { Bien a } \\
\text { moderadamente } \\
\text { bien drenado. }\end{array}$ & Imperfectamente drenado. & $\begin{array}{l}\text { Pobre y muy pobremente } \\
\text { drenado. }\end{array}$ \\
\hline Alcalinidad & No alcalino. & Débil o ligeramente alcalino. & $\begin{array}{l}\text { Moderadamente a muy } \\
\text { alcalino. }\end{array}$ \\
\hline
\end{tabular}

Fuente: Elaborado por los autores. 
Cuadro 3. Crecimiento en volumen para diferentes especies y regiones según la aptitud de las tierras

\begin{tabular}{|c|c|c|c|}
\hline \multirow{2}{*}{ Región } & \multirow{2}{*}{ Especie } & \multicolumn{2}{|c|}{ Biomasa (m³/ha.año) } \\
\hline & & Apto & Moderadamente apto \\
\hline \multirow{2}{*}{ Mesopotamia } & Pinus taeda & $25-35$ & $20-25$ \\
\hline & Eucalyptus grandis & $35-45$ & $30-35$ \\
\hline \multirow{4}{*}{ Central } & Eucalyptus grandis & $20-30$ & $15-20$ \\
\hline & Eucalyptus camaldulensis & $25-30$ & $20-25$ \\
\hline & Eucalyptus tereticornis & $20-25$ & $15-20$ \\
\hline & Eucalyptus viminalis & $25-35$ & $20-25$ \\
\hline \multirow{2}{*}{ NOA } & Eucalyptus grandis & $35-40$ & $30-35$ \\
\hline & Eucalyptus camaldulensis & $25-30$ & $20-25$ \\
\hline \multirow{5}{*}{ Pampeana } & Eucalyptus dunnii & $25-30$ & $15-25$ \\
\hline & Eucalyptus camaldulensis & $20-25$ & $15-20$ \\
\hline & Eucalyptus viminalis & $25-30$ & $20-25$ \\
\hline & Populus sp. & $25-30$ & $20-25$ \\
\hline & Salix sp. & $18-20$ & $15-18$ \\
\hline
\end{tabular}

Fuente: Elaborado por los autores. 
Potencial de desarrollo de plantaciones dendroenergéticas en la Argentina

Una vez estandarizada toda la información, se generó un SIG (Sistema de Información Geográfica) y se fueron aplicando los criterios de selección para delimitar las áreas potencialmente aptas para plantaciones dendroenergéticas. Para todo esto se utilizó el software ArcGis 9.2 con las extensiones correspondientes.

En el Gráfico 3 se muestra un diagrama que resume los pasos para obtener el mapa a nivel nacional de las áreas potencialmente aptas para plantaciones dendroenergéticas. Básicamente el procedimiento fue, en primer lugar, eliminar las áreas que no cumplían los requisitos ambientales (precipitaciones menores a $800 \mathrm{~mm}$ anuales, áreas con balance hídrico negativo o neutro y tierras con capacidad de uso I, II, III y VIII). Posteriormente, a las áreas que cumplían con los requisitos ambientales se les sustrajeron las áreas con restricciones legales (clases I y II de la Ley de Ordenamiento Territorial de Bosques Nativos y las diferentes categorías de Áreas Naturales Protegidas).

\section{Mapas de aptitud para plantaciones}

dendroenergéticas en la Argentina

A partir del trabajo cartográfico realizado, se logró generar un mapa a nivel nacional con la zonificación/delimitación de las potenciales regiones forestales para establecer plantaciones dendroenergéticas. Teniendo en cuenta las cuatro regiones propuestas (Central, NOA, Mesopotamia y Pampeana), las áreas con potencial dendroenergético abarcan cerca de 15 millones de hectáreas (Cuadro 4, Cuadro 5 y Mapa 1).

Además, se generaron mapas de las regiones forestales consideradas, con las especies y su productividad (cuadros 6 a 9 y mapas 2 a 14).

Gráfico 3. Pasos para la obtención del mapa de áreas potencialmente aptas para plantaciones dendroenergéticas
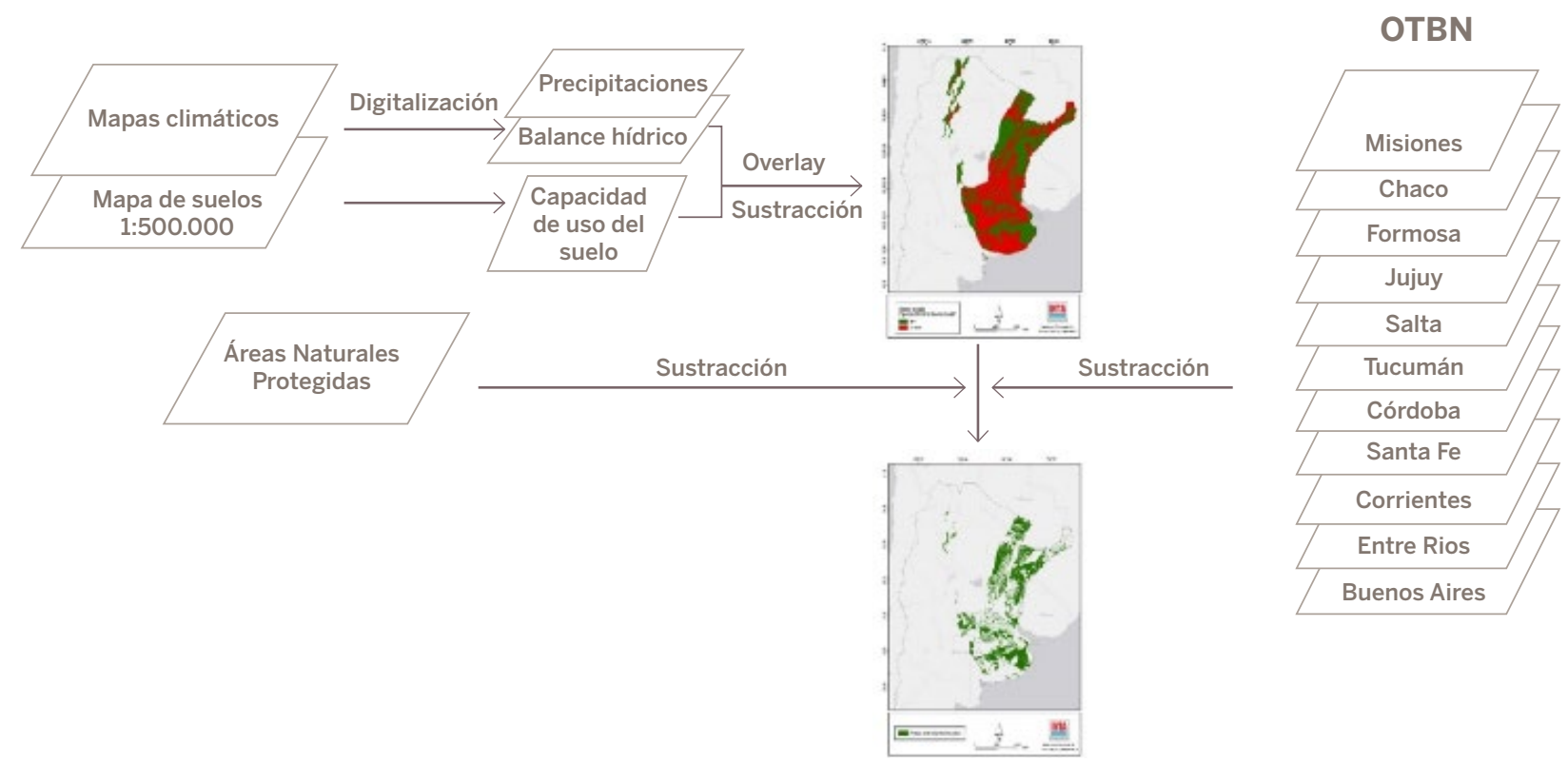

Fuente: Elaborado por los autores. 
Cuadro 4. Superficie potencialmente apta para plantaciones dendroenergéticas en la Argentina, por regiones

\begin{tabular}{l|c} 
Región & Superficie (ha) \\
\hline Central & 2544057 \\
\hline Mesopotamia & 5375463 \\
\hline NOA & 325104 \\
\hline Pampeana & 7008254 \\
\hline Total & 15252878 \\
\hline
\end{tabular}

Fuente: Elaborado por los autores.

Cuadro 5. Superficie potencial para plantaciones dendroenergéticas en la Argentina, según aptitud de las especies en cada región

\begin{tabular}{l|c|c}
\multirow{2}{*}{ Región } & \multicolumn{2}{c}{ Superficie (ha) } \\
\hline Central & Apta & Moderadamente apta \\
\hline Mesopotamia & 106157 & 2437900 \\
\hline NOA & 631019 & 4744444 \\
\hline Pampeana & - & 325104 \\
\hline Total & 1383322 & 6398524 \\
\hline
\end{tabular}

Fuente: Elaborado por los autores. 
Potencial de desarrollo de plantaciones dendroenergéticas

en la Argentina

Mapa 1. Áreas potencialmente aptas para plantaciones dendroenergéticas en la Argentina, según criterios propuestos por el INTA en 2016

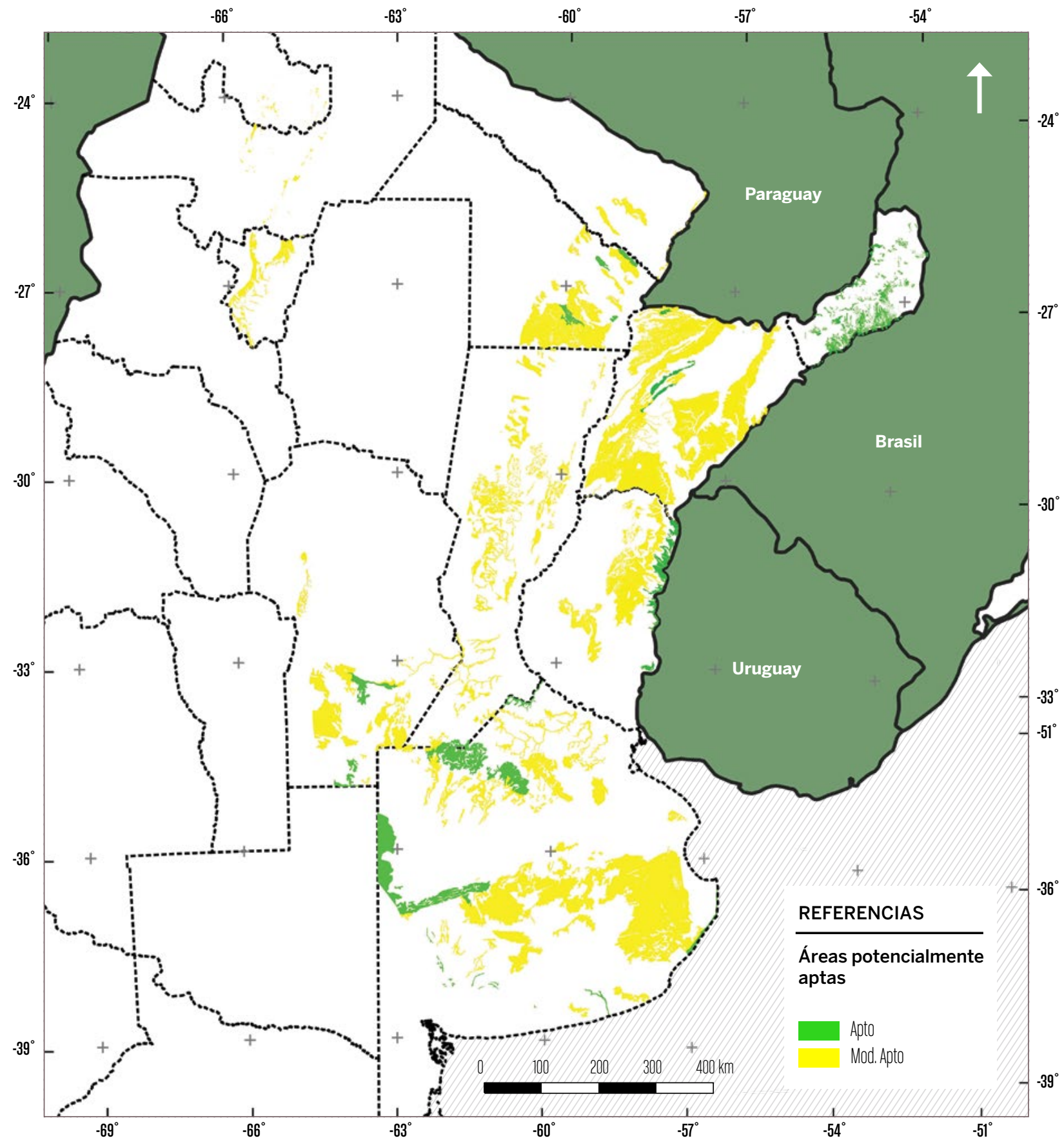

Fuente: Elaborado por los autores. 


\section{Región Mesopotamia}

Cuadro 6. Superficie potencialmente apta para Eucalyptus grandis y Pinus taeda en la Región Mesopotamia

\begin{tabular}{l|c|c|c}
\hline Especie & \multicolumn{3}{|c}{ Superficie (ha) } \\
\hline Eucalyptus grandis & Apta & Moderadamente apta & No apta \\
\hline Pinus taeda & 348146 & 59099 & 517939 \\
\hline
\end{tabular}

Fuente: Elaborado por los autores.

\section{Región Central}

Cuadro 7. Superficie potencialmente apta para Eucalyptus grandis, E. camaldulensis, E. tereticornis y E. viminalis en la Región Central

\begin{tabular}{l|c|c|c}
\hline Especie & \multicolumn{3}{|c}{ Superficie (ha) } \\
\hline E. grandis & Apta & Moderadamente apta & No apta \\
\hline E. camaldulensis & 22 & 339014 & 6304566 \\
\hline E. tereticornis & 106157 & 2333383 & 4204063 \\
\hline E. viminalis & 104631 & 1526823 & 5012148 \\
\hline
\end{tabular}

Fuente: Elaborado por los autores. 
Potencial de desarrollo de plantaciones dendroenergéticas en la Argentina

Mapa 2. Áreas potencialmente aptas para Eucalyptus grandis en la Región Mesopotamia

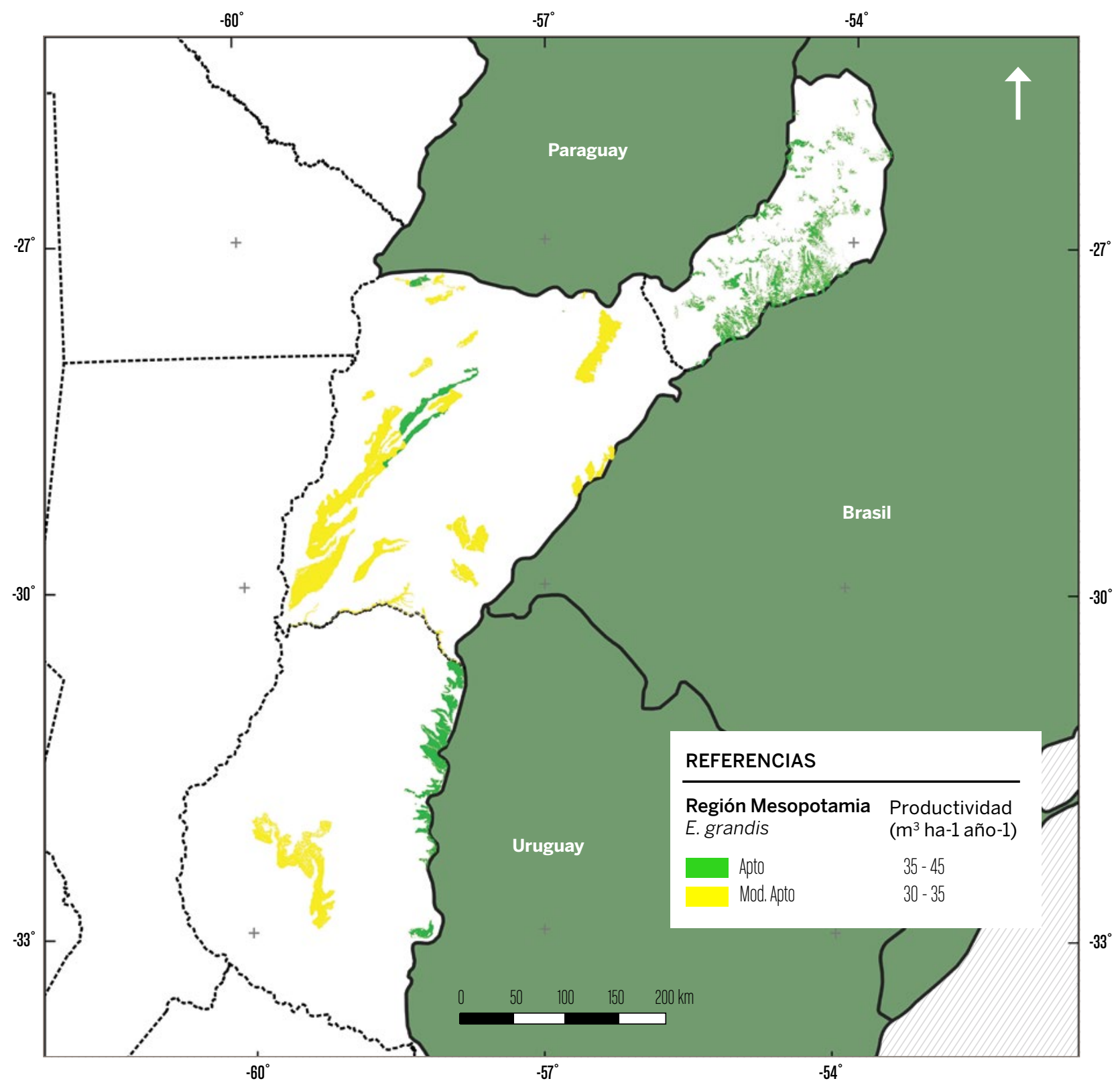

Fuente: Elaborado por los autores. 
Áreas potencialmente aptas para especies

dendroenergéticas y productividad de cada una

Mapa 3. Áreas potencialmente aptas para Pinus taeda en la Región Mesopotamia

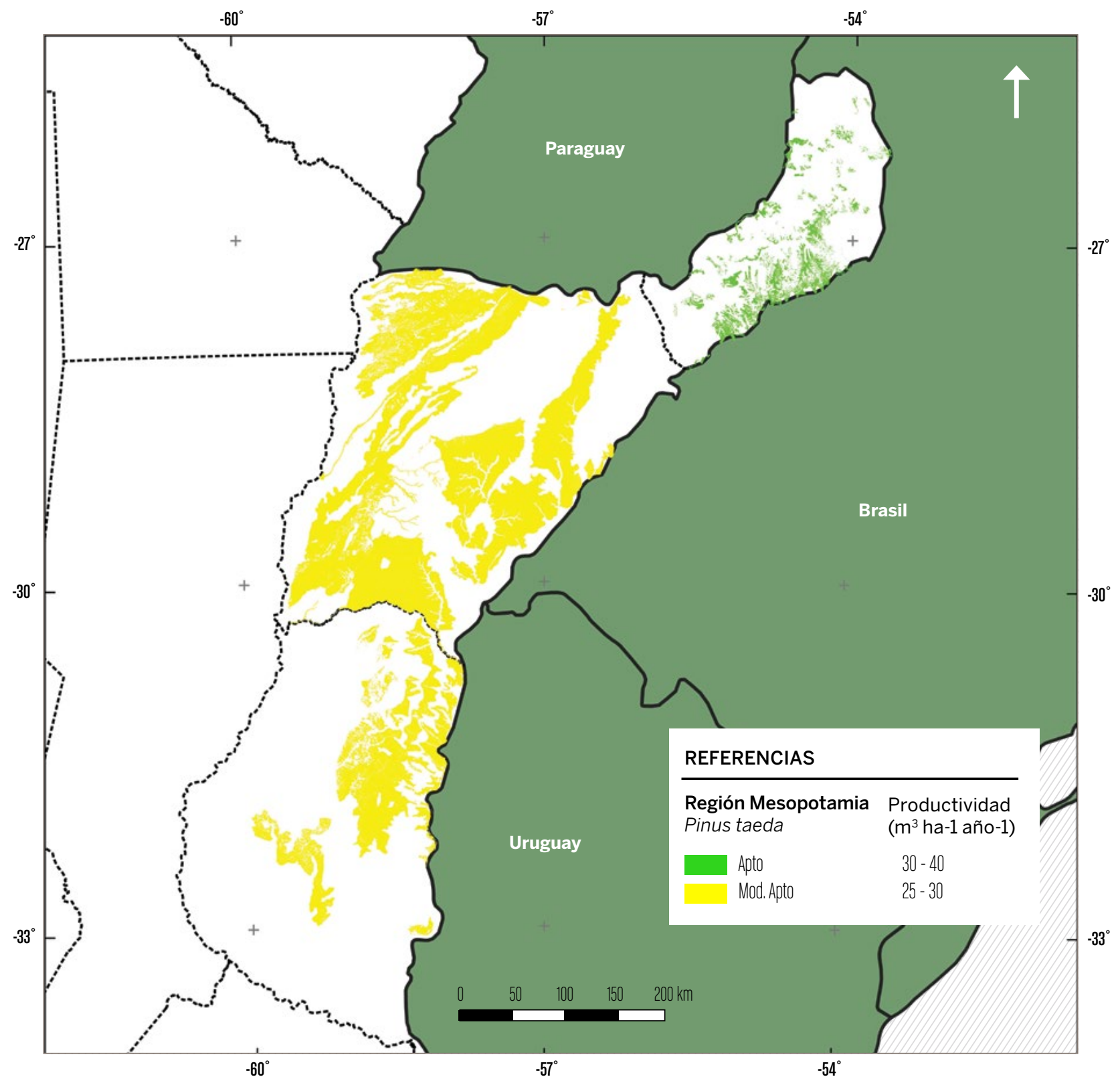

Fuente: Elaborado por los autores. 
Potencial de desarrollo de plantaciones dendroenergéticas

en la Argentina

Mapa 4. Áreas potencialmente aptas para Eucalyptus grandis en la Región Central

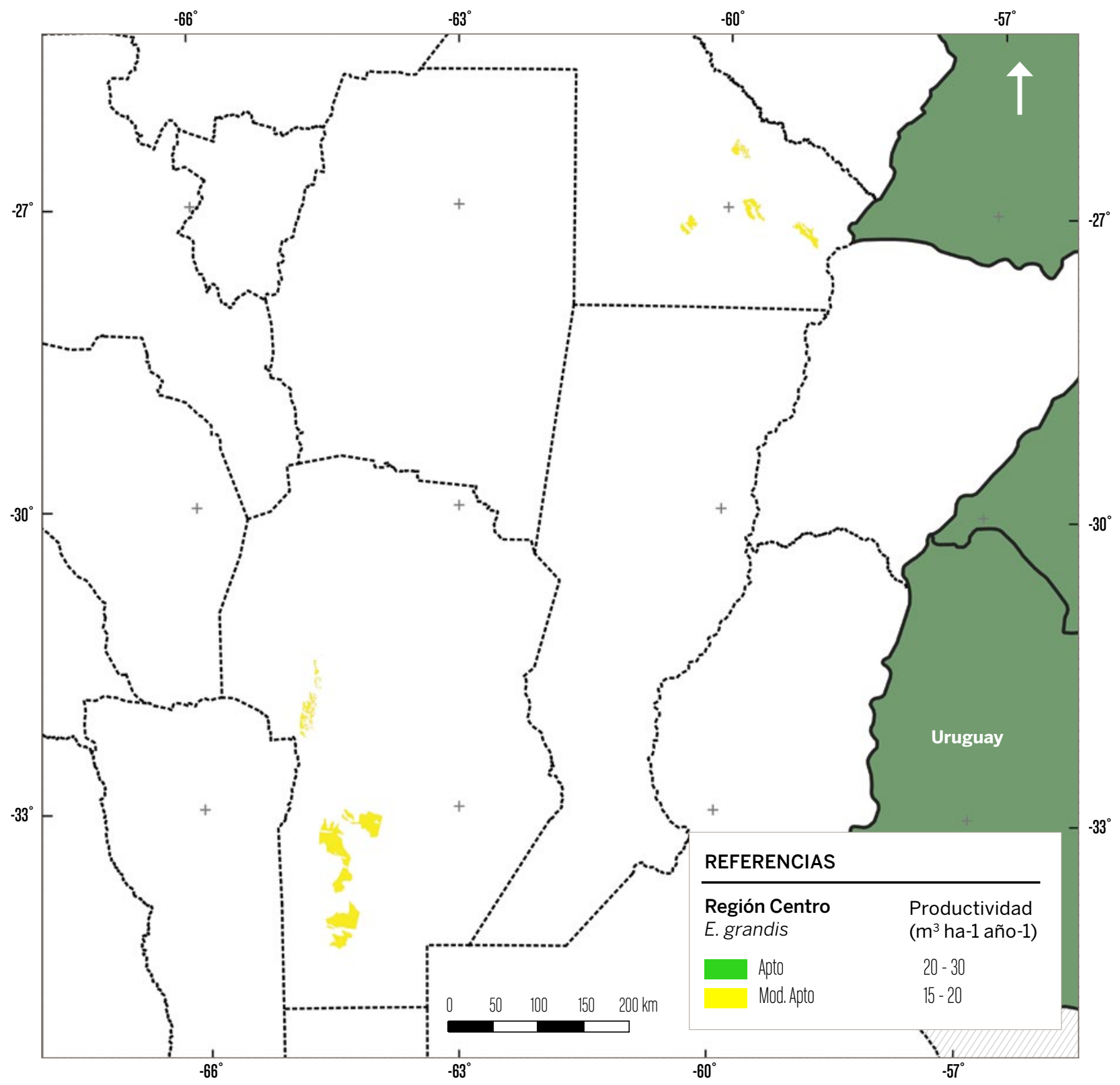

Fuente: Elaborado por los autores 
Áreas potencialmente aptas para especies

Mapa 5. Áreas potencialmente aptas para Eucalyptus camaldulensis en la Región Central

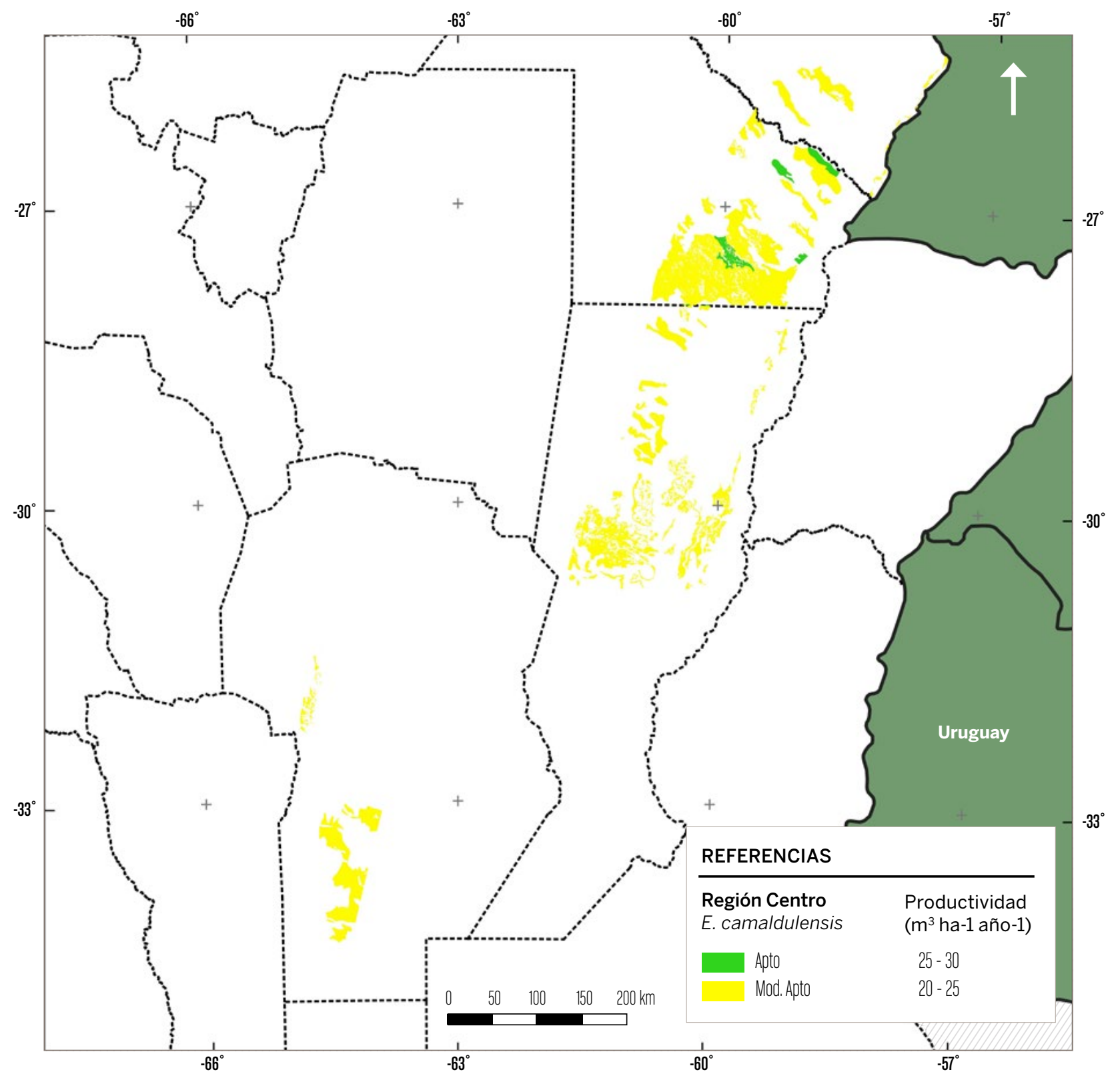

Fuente: Elaborado por los autores. 
Potencial de desarrollo de plantaciones dendroenergéticas

en la Argentina

Mapa 6. Áreas potencialmente aptas para Eucalyptus tereticornis en la Región Central

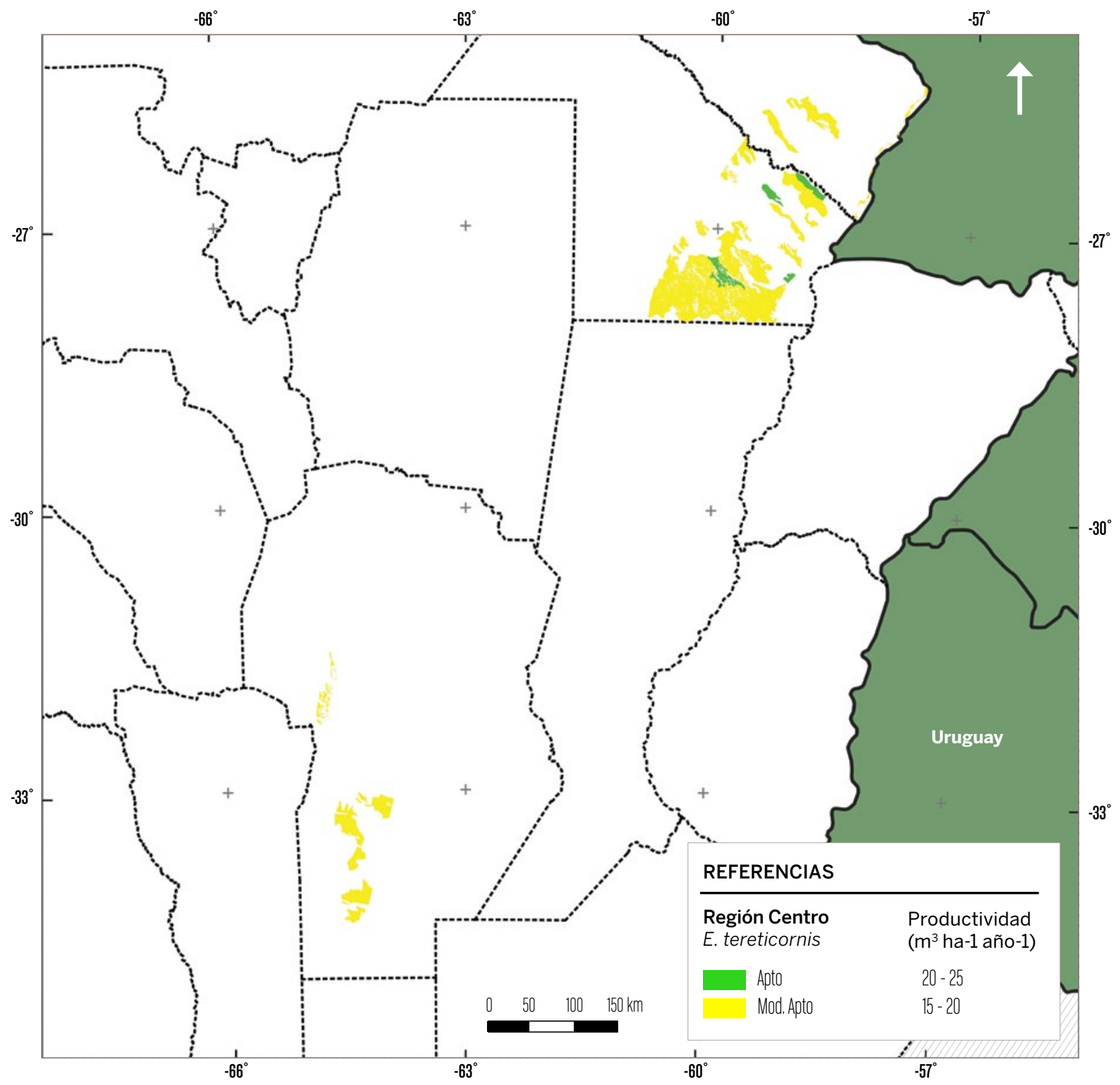

Fuente: Elaborado por los autores 
Áreas potencialmente aptas para especies

Mapa 7. Áreas potencialmente aptas para Eucalyptus viminalis en la Región Central

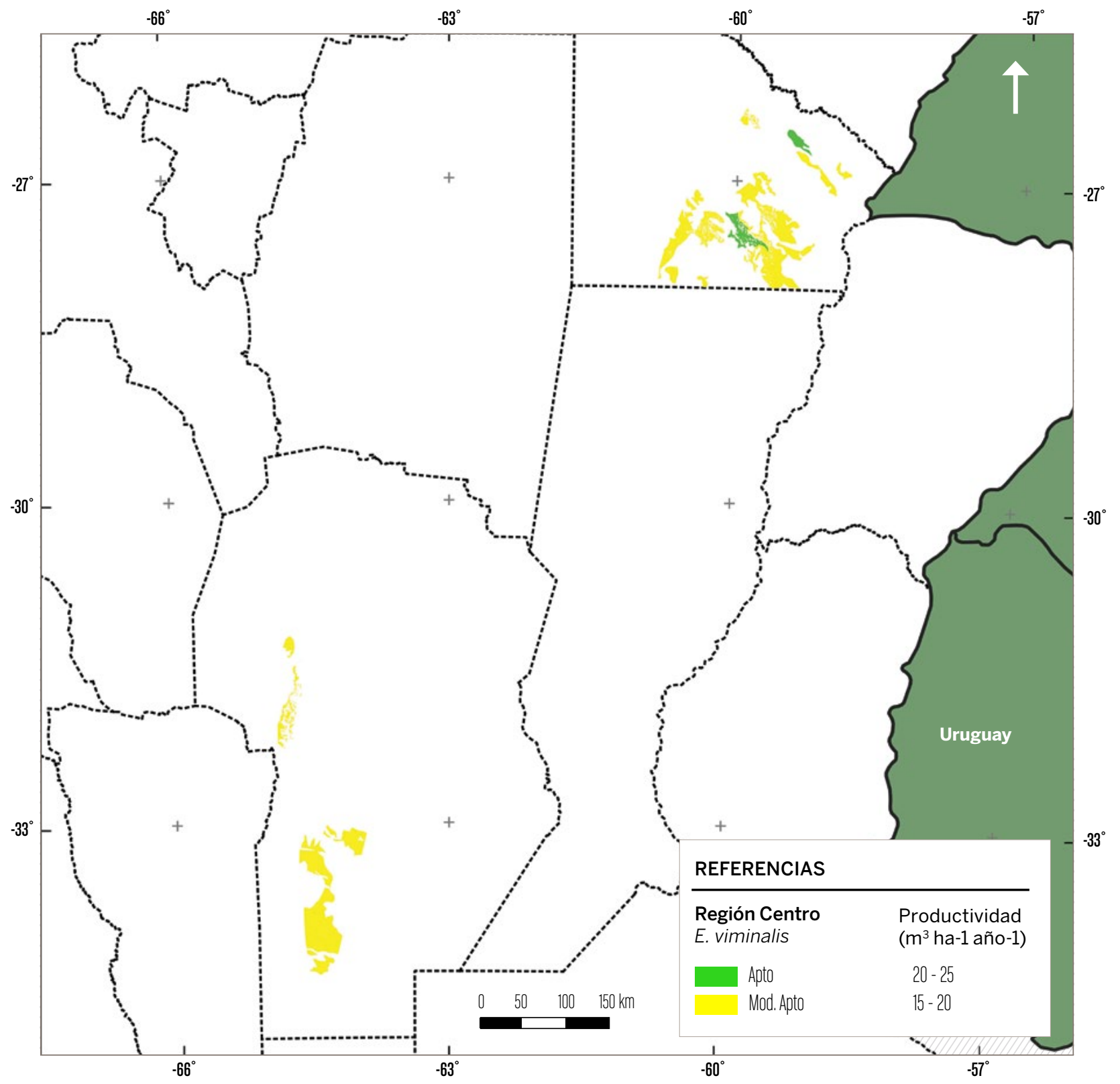

Fuente: Elaborado por los autores. 
Potencial de desarrollo de plantaciones dendroenergéticas

en la Argentina

\section{Región NOA}

Cuadro 8. Superficie potencialmente apta para las especies Eucalyptus grandis y E. camaldulensis en la Región NOA

\begin{tabular}{l|c|c|c}
\hline Especie & \multicolumn{3}{|c}{ Superficie (ha) } \\
& Apta & Moderadamente apta & No apta \\
\hline E. grandis & - & 294850 & 162661 \\
\hline E. camaldulensis & - & 325104 & 132779 \\
\hline
\end{tabular}

Fuente: Elaborado por los autores.

\section{Región Pampeana}

Cuadro 9. Superficie potencialmente apta para Eucalyptus dunnii, E. camaldulensis, E. viminalis, Populus spp. y Salix spp. en la Región Pampeana

\begin{tabular}{l|c|c|c}
\hline Especie & \multicolumn{3}{|c}{ Superficie (ha) } \\
\hline E. dunnii & Apta & Moderadamente apta & No apta \\
\hline E. camaldulensis & 623526 & 4884174 & 5484251 \\
\hline E. viminalis & 569417 & 6083256 & 4339277 \\
\hline Populus sp. & 569417 & 5253551 & 5168982 \\
\hline Salix sp. & 1288902 & 729746 & 8973303 \\
\hline
\end{tabular}

Fuente: Elaborado por los autores. 
Áreas potencialmente aptas para especies

dendroenergéticas y productividad de cada una

Mapa 8. Áreas potencialmente aptas para Eucalyptus grandis en la Región NOA

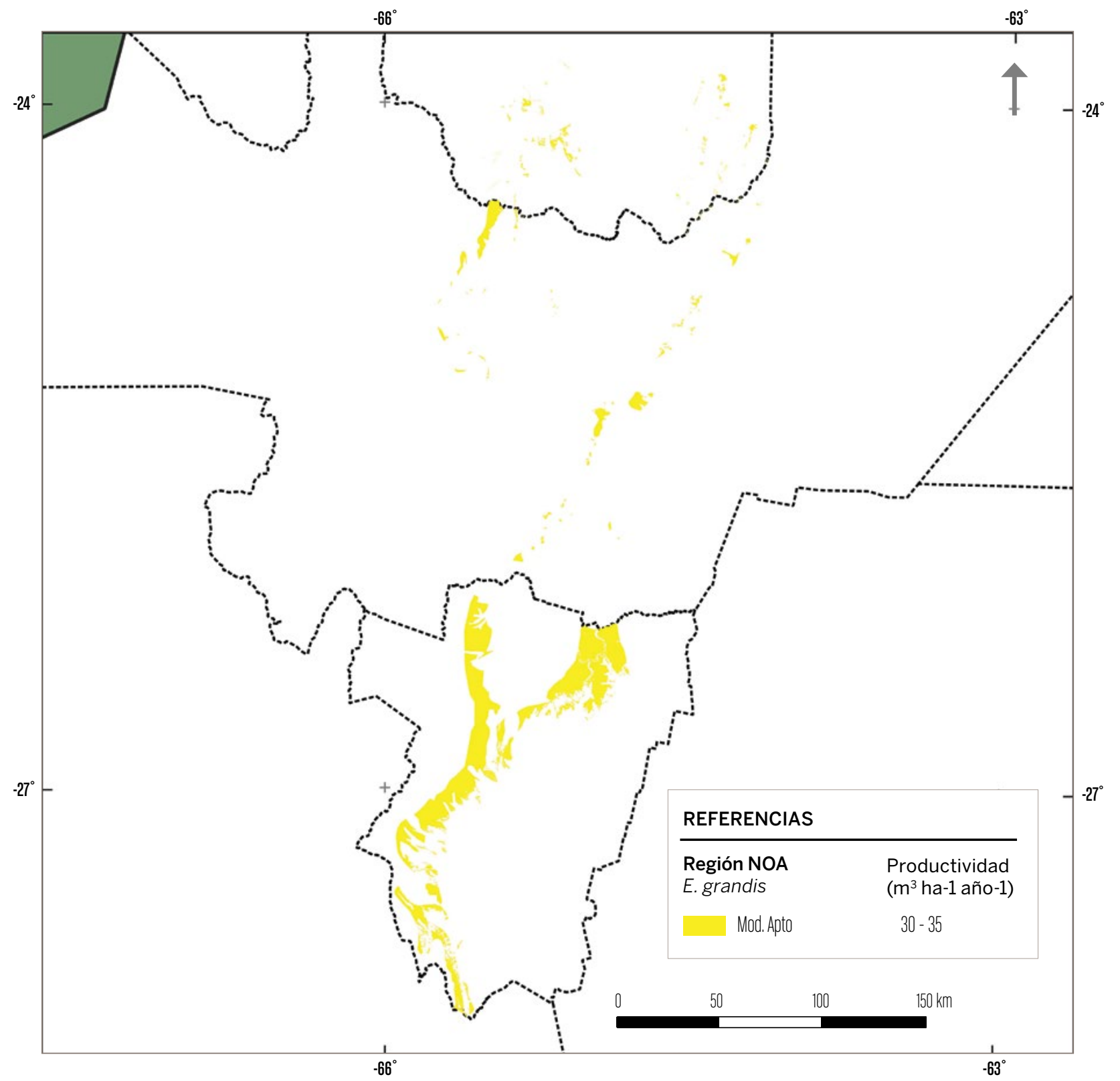

Fuente: Elaborado por los autores. 
Potencial de desarrollo de plantaciones dendroenergéticas en la Argentina

Mapa 9. Áreas potencialmente aptas para Eucalyptus camaldulensis en la Región NOA

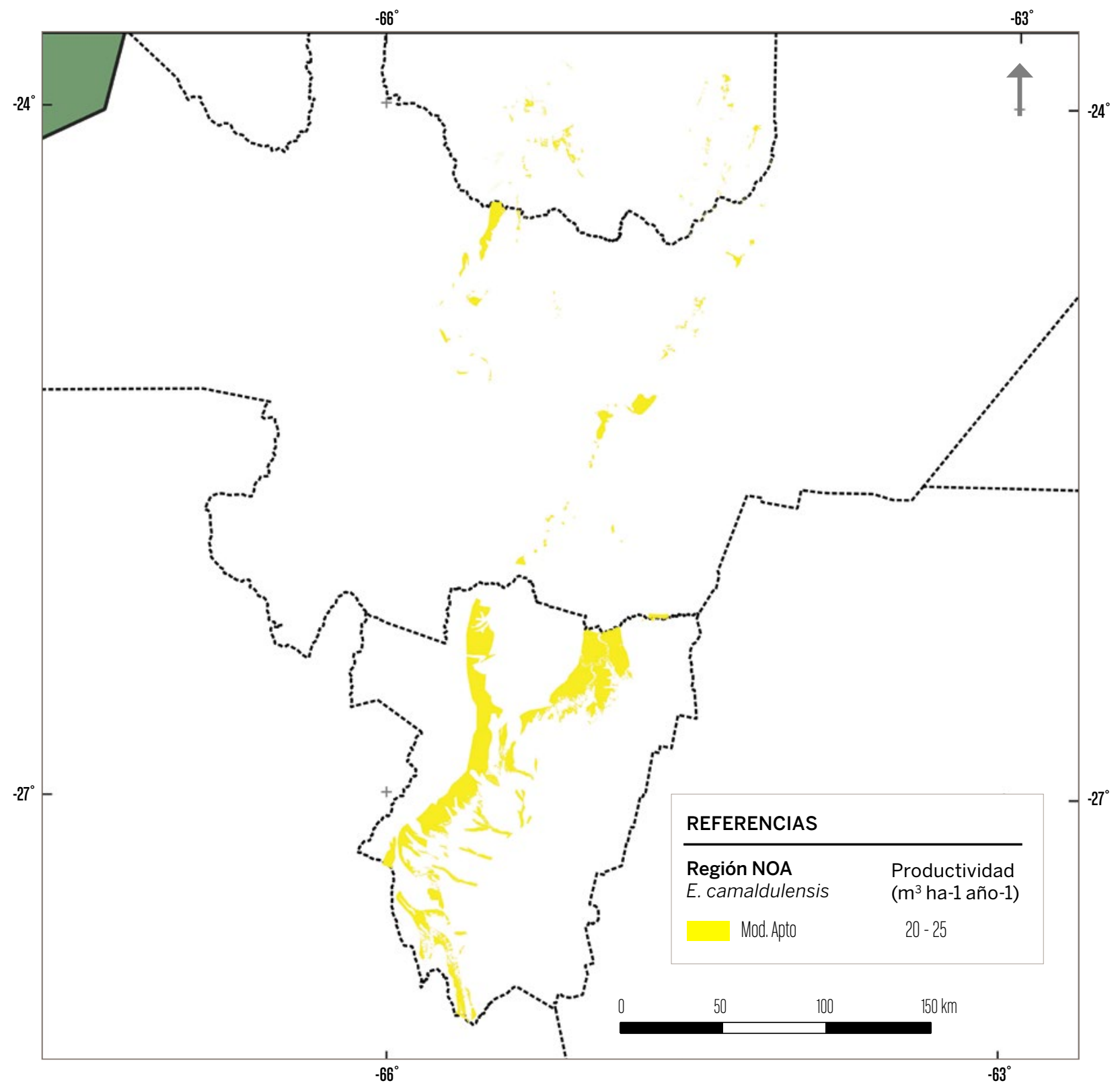

Fuente: Elaborado por los autores. 
Áreas potencialmente aptas para especies

dendroenergéticas y productividad de cada una

Mapa 10. Áreas potencialmente aptas para Eucalyptus dunnii en la Región Pampeana

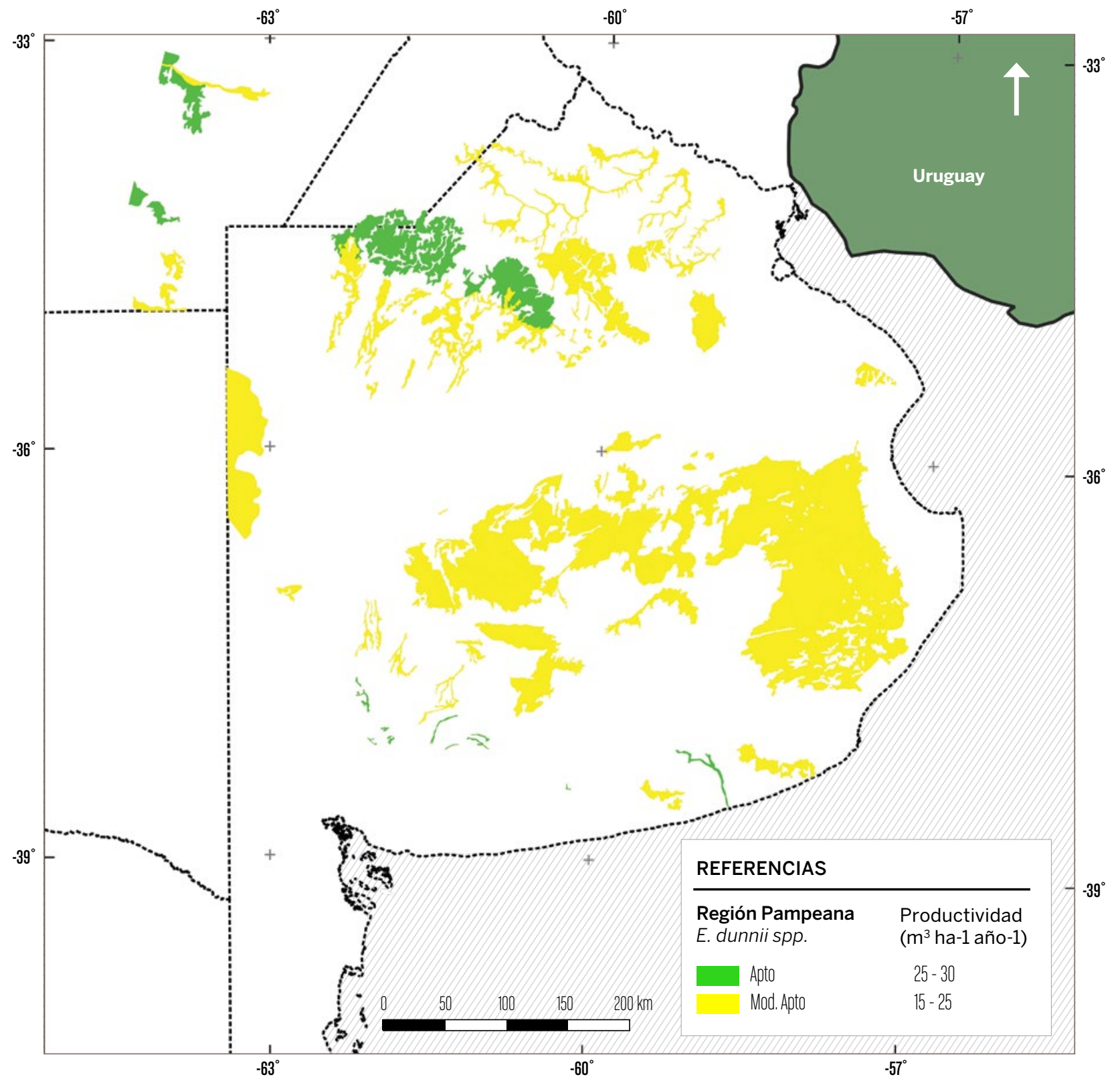

Fuente: Elaborado por los autores. 
Potencial de desarrollo de plantaciones dendroenergéticas en la Argentina

Mapa 11. Áreas potencialmente aptas para Eucalyptus camaldulensis en la Región Pampeana

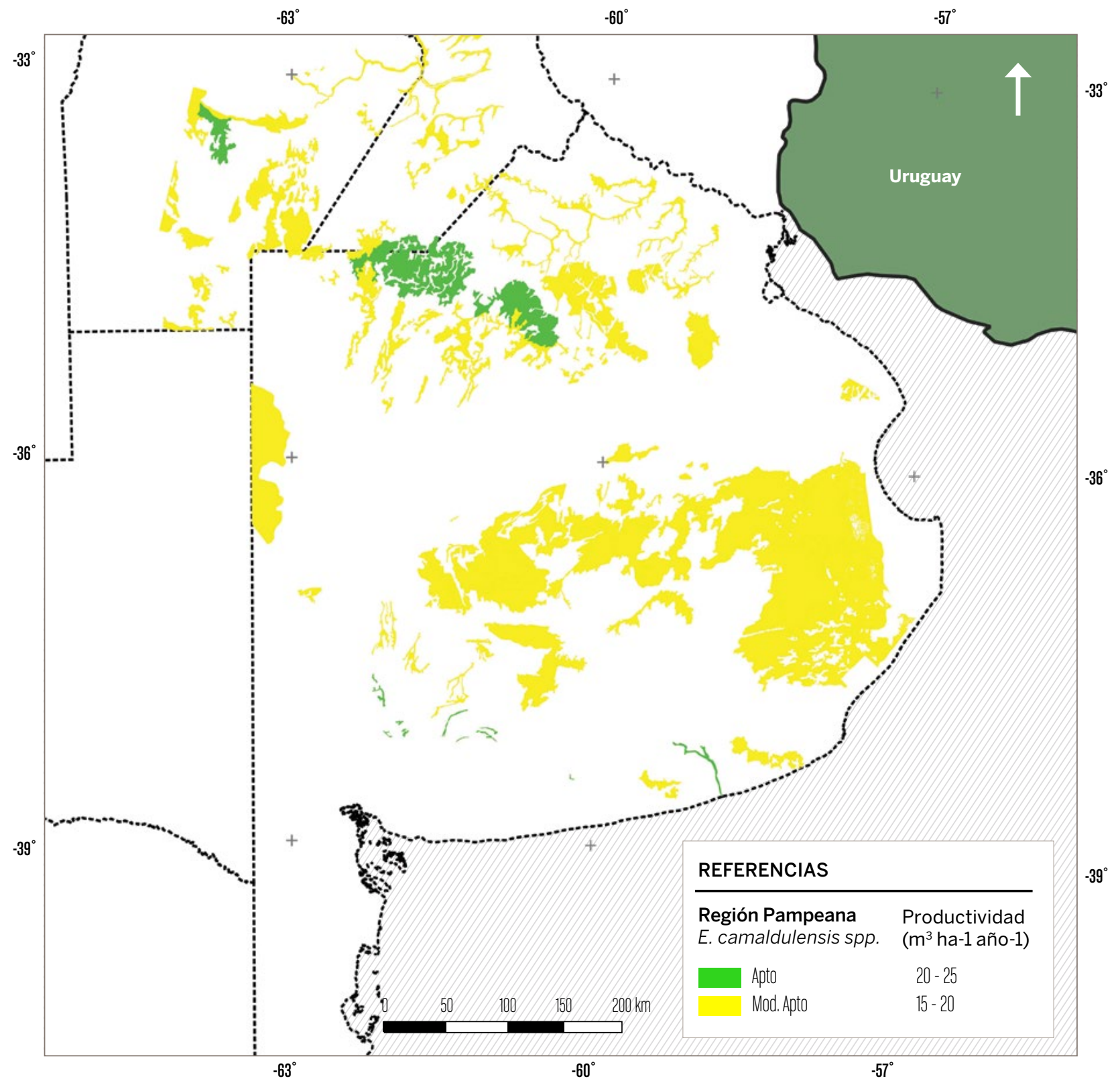

Fuente: Elaborado por los autores. 
Áreas potencialmente aptas para especies

dendroenergéticas y productividad de cada una

Mapa 12. Áreas potencialmente aptas para Eucalyptus viminalis en la Región Pampeana

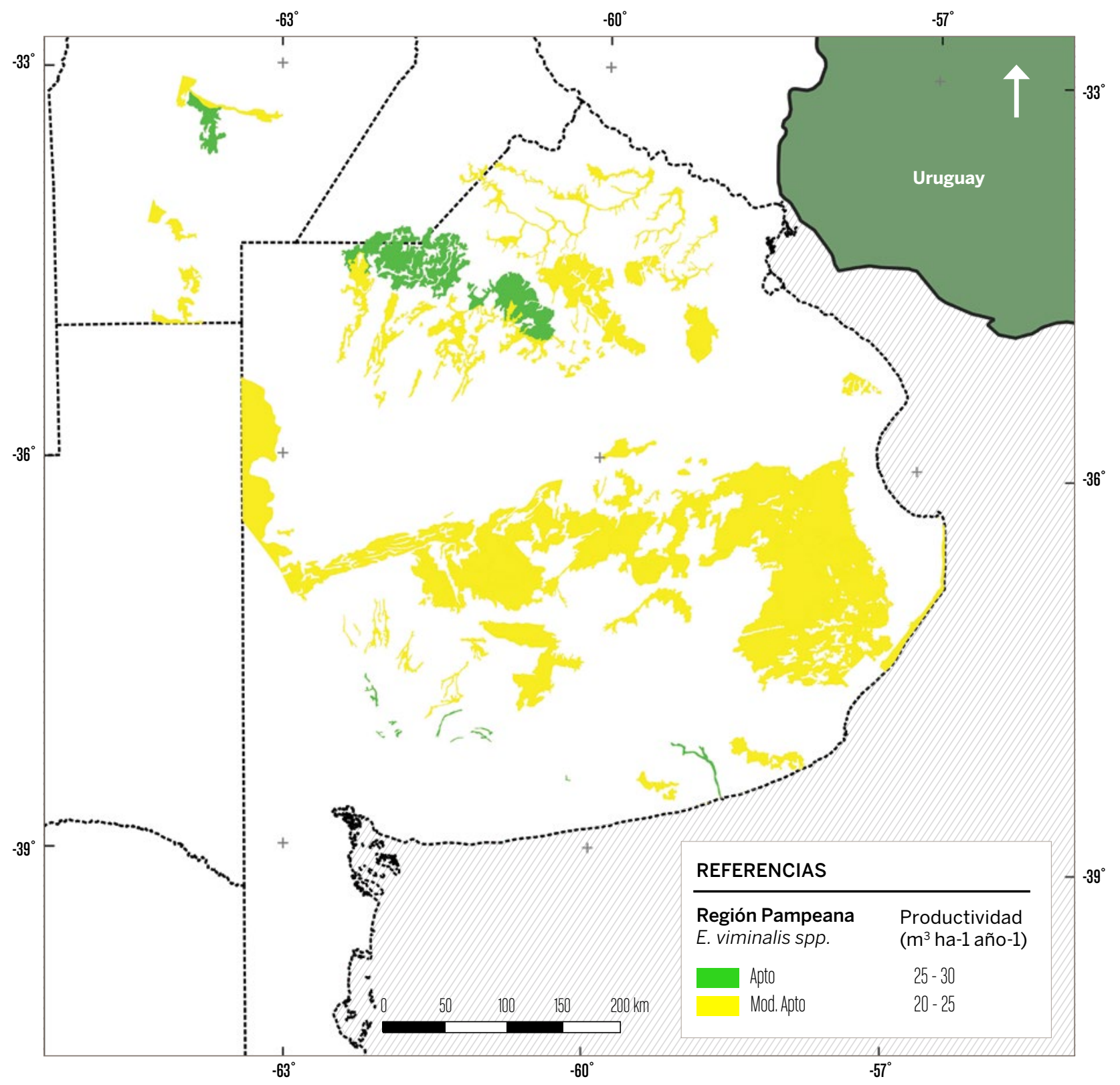

Fuente: Elaborado por los autores. 
Potencial de desarrollo de plantaciones dendroenergéticas en la Argentina

Mapa 13. Áreas potencialmente aptas para Populus spp. en la Región Pampeana

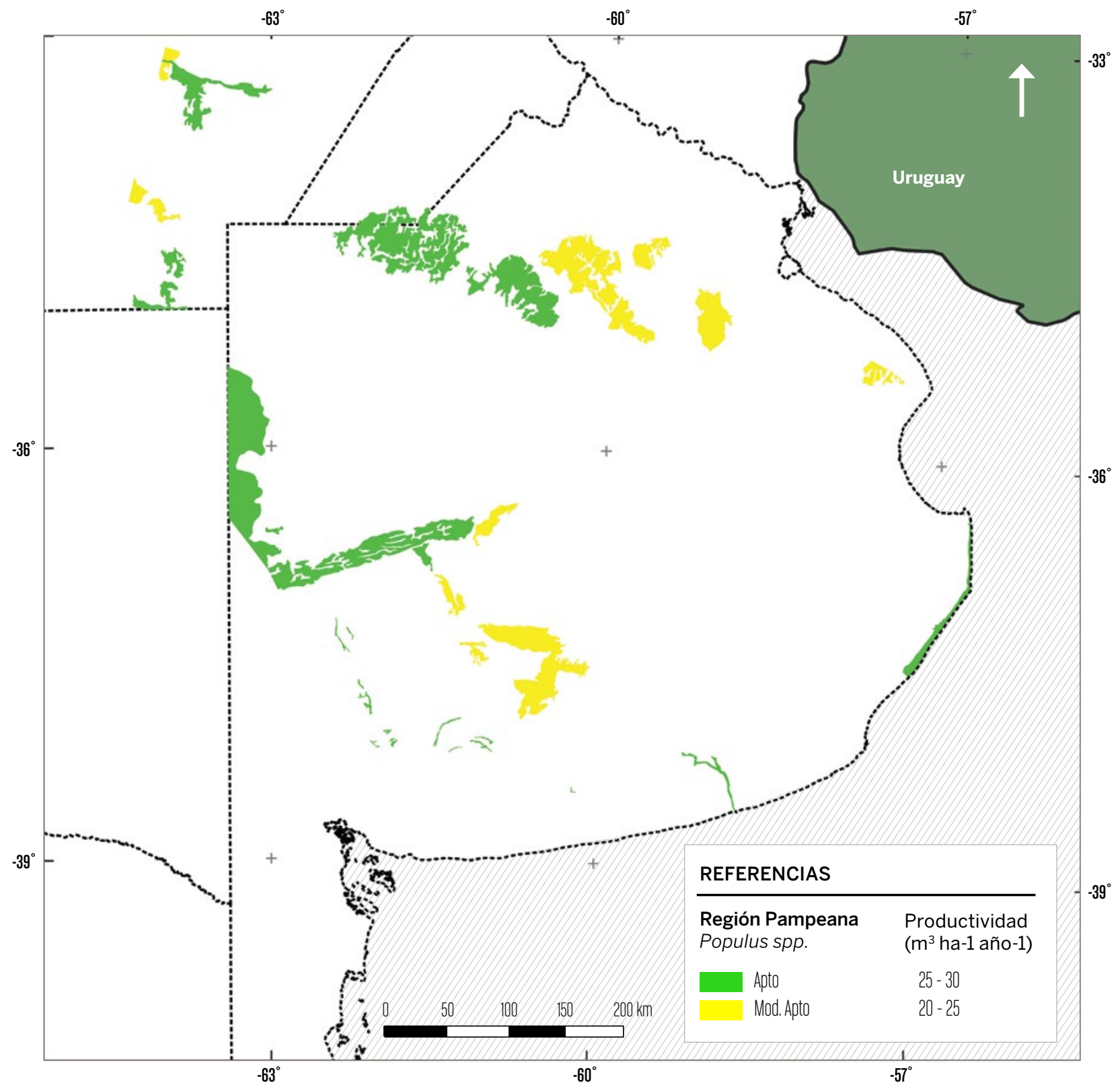

Fuente: Elaborado por los autores. 
Áreas potencialmente aptas para especies

dendroenergéticas y productividad de cada una

Mapa 14. Áreas potencialmente aptas para Salix spp. en la Región Pampeana

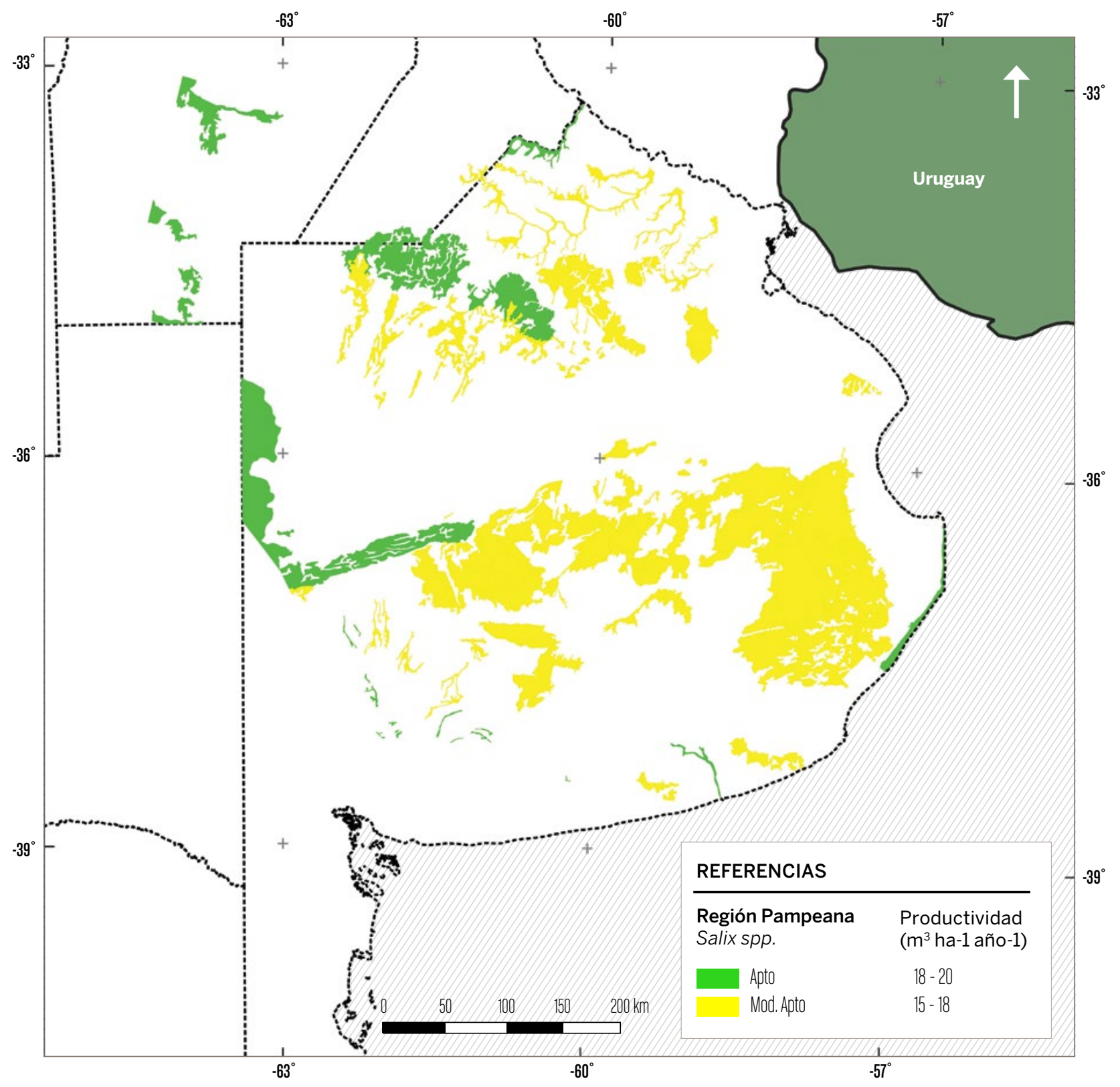

Fuente: Elaborado por los autores. 


\section{MODELOS TÉCNICO- ECONÓMICOS DE \\ PLANTACIONES \\ DENDROENERGÉTICAS}

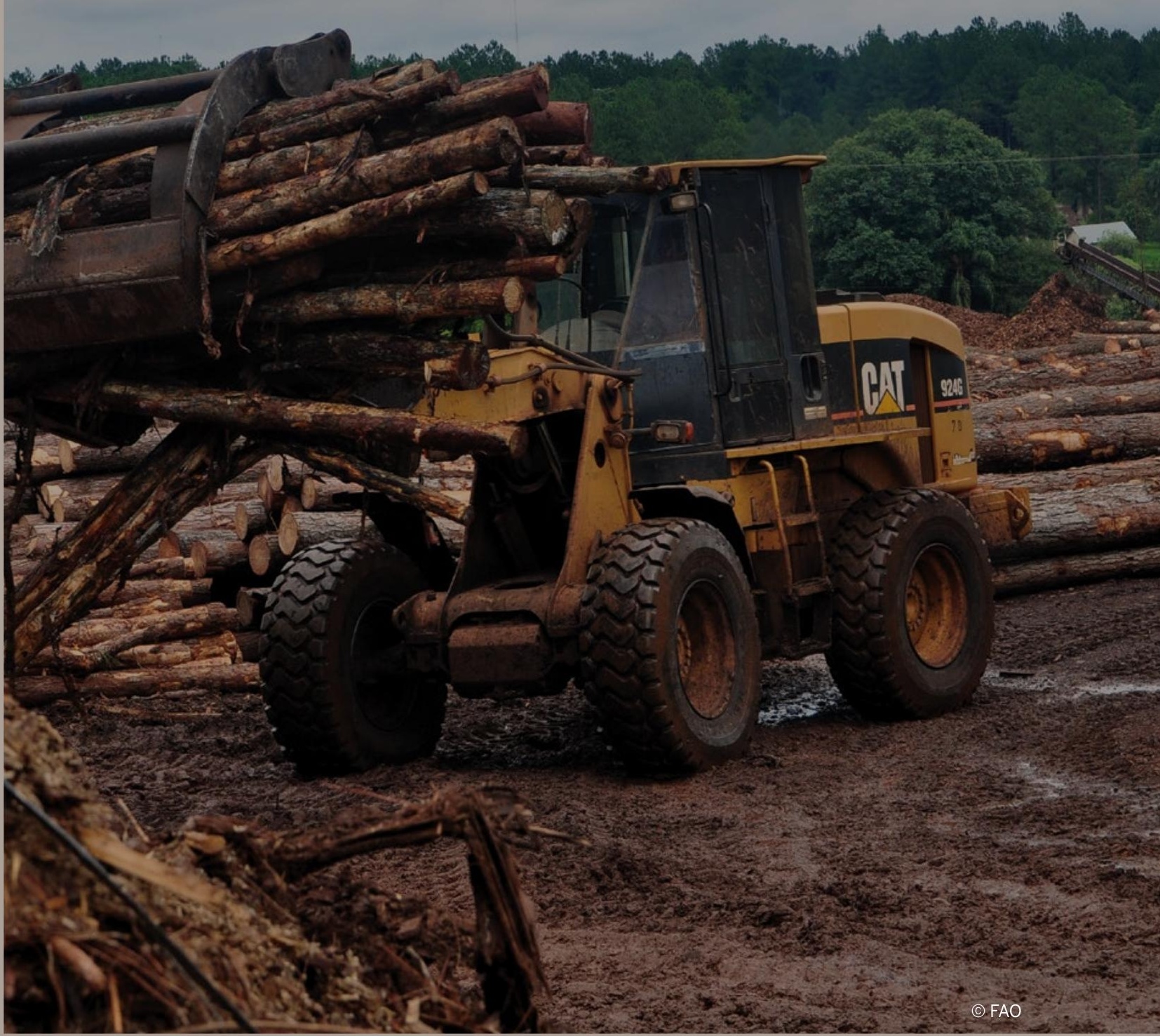


La viabilidad técnico-económica del desarrollo de plantaciones para dendroenergía se estableció a partir de modelos representativos de las condiciones típicas de cada una de las siete áreas estudiadas.

A partir de la información derivada de la regionalización y el mapeo presentados en el Capítulo 3, y sobre la base de una especie por región, se analizaron los modelos técnico-económicos de la viabilidad del desarrollo de plantaciones forestales con destino dendroenergético.

Con ese fin, se elaboró la matriz insumo-producto para un modelo productivo potencialmente aplicable en las regiones enumeradas a continuación, considerando solo las áreas donde la precipitación media anual supera los $800 \mathrm{~mm}$ y que no presentan déficit hídrico anual?:

- NOA

- Mesopotamia (Misiones y NE Corrientes, suelos rojos)

- Mesopotamia (Corrientes, lomas arenosas)

\footnotetext{
7 Observar los criterios de delimitaciones de zonas en el Capítulo 3.
}

- Mesopotamia (Entre Ríos)

- Pampeana (Buenos Aires-Santa Fe-Córdoba)

- Chaco-Formosa

- Delta

Los equipos de trabajo regionales eligieron los modelos técnicos (variedad, densidad, manejo y otros) según criterios acordados ${ }^{8}$ con los referentes locales de cada región, investigadores del Programa Nacional Forestal, teniendo en cuenta resultados de los experimentos en campos demostrativos. En las reuniones de equipos regionales se determinó:

- Seleccionar especies con capacidad de rebrote para ser manejadas bajo régimen tallar.

${ }^{8}$ No se prevén modificaciones en las condiciones de sitio a través de inversiones y otras intervenciones que cambien las condiciones del suelo. 
Potencial de desarrollo de plantaciones dendroenergéticas en la Argentina

- Contar con suficiente información para definir los aspectos básicos de cada modelo y para elaborar el costo de producción.

- Estimar los costos de producción y la biomasa esperada considerando sitios de mediano a bajo potencial productivo (baja a nula competencia con la agricultura).

- Prever la cosecha de fuste entero.

Más allá de la heterogeneidad propia de cada región, para cada una se seleccionó un modelo que representara condiciones típicas posibles para desarrollar la actividad. Así se determinaron características que definen cada modelo técnico-productivo, como la condición previa del campo, las técnicas silviculturales para implementar, la/s especie/s para cultivar, la rotación óptima, los rendimientos esperados, entre otras. En la selección de cada caso operaron decisiones tanto técnico-productivas como propias de los condicionantes económico-sociales.

Los modelos económico-financieros se elaboraron a partir de la cuantificación de los insumos utilizados y los productos obtenidos en cada etapa del proceso productivo forestal, con base anual. Los resultados se derivaron de hallar analíticamente el precio de referencia del producto bioenergético que compense los costos, y luego de estimar las sensibilidades de los valores obtenidos ante cambios en distintas variables clave de los modelos, de forma de poder prever dinámicamente diferentes escenarios posibles.

Estos resultados se complementaron con la estructura de los modelos en relación con la demanda de mano de obra, de los distintos insumos y de utilización de maquinaria, contemplando sus respectivos impactos en términos energéticos.

Para realizar el análisis económico-financiero se estimó el valor actual del flujo de fondos en pesos corrientes de 2017 por hectárea por año, en función de los insumos y productos detallados en el modelo productivo de cada región.

Para el diseño de flujo de fondos se determinó una estructura general de costos, identificando, por un lado, los costos que permanecen constantes en todas las regiones, y por otro, aquellos que varían según la región. Respecto de los ingresos, se consideraron los distintos ciclos de corte según el modelo regional y sus respectivos rendimientos. A partir de los flujos de ingresos y egresos, descontados a una tasa de referencia del 15\% anual, se calcularon distintos indicadores de viabilidad para los proyectos. En los flujos de fondos no se internalizó el costo de la tierra, que debe ser considerado por separado en la evaluación de los proyectos respectivos.

En lo que respecta a la estructura de costos, los valores relativos a amortizaciones de bienes de capital, impuestos y al costo por hora del tractor se asumieron como similares en todas las regiones. En cambio, los valores correspondientes a jornales, precio del gasoil, insumos empleados en las distintas etapas productivas, gastos administrativos y el material de plantación se consideraron según los precios promedio en cada región.

Dentro de los costos constantes para todas las regiones, las amortizaciones se estimaron para un bien de uso con un valor aproximado de 800000 ARS, con una vida útil estimada de 20 años y una capacidad de trabajo mínima de 80 hectáreas, con lo que se generó una amortización de referencia de 1500 ARS/ha/año. En cuanto a los impuestos y otros gastos fijos (como tasas viales y otros), se determinó un monto fijo aproximado de 500 ARS/ ha/año, mientras que el costo horario del tractor se estableció en 100 ARS (sin incluir su amortización y consumo de combustible).

En cuanto al conjunto de costos variables según región, se determinó que el componente de mano de obra se sitúa en un rango de 848 a 1060 ARS por jornal medio, asumiendo su valor mínimo en la región de Chaco-Formosa y NOA. La cotización de los insumos se consideró en dólares, pero los valores fueron convertidos a pesos corrientes, de modo tal que la variación de los costos correspondientes a insumos está sujeta a la modificación de la cotización del tipo de cambio pesos-dólares ${ }^{9}$.

Los gastos administrativos, si bien varían por región, se calcularon sobre la base de un porcentaje

${ }^{9}$ La cotización del dólar empleada fue de 17 ARS/USD. 
fijo (5\%) de los costos estimados para cada modelo regional, y se prorratearon como un monto anual fijo por hectárea. En cuanto al precio del gasoil, fue tomado como un promedio representativo de cada zona, variando en un rango de 17,81 a 21,81 ARS.

En función del flujo de fondos, se estimó el precio de referencia en campo de la madera ${ }^{10}$ destinada a dendroenergía que se requiere para que el proyecto sea económicamente rentable a la tasa de descuento exigida. No obstante, es importante resaltar que ese precio no incluye el costo del flete desde la finca del productor hasta la industria, ni el chipeado u otras transformaciones.

Por último, se realizaron análisis de sensibilidad para cada modelo productivo regional, con el fin de evaluar cambios en el precio mínimo ${ }^{11}$ requerido para que el proyecto sea económicamente viable ante cambios de diferentes variables clave. Para ello, se calcularon variaciones porcentuales en el precio teórico (precio de referencia) ante modificaciones de diferentes componentes de la estructura de costos: las elasticidades jornal, material de plantación, insumos (tipo de cambio) y gasoil, y la sensibilidad con respecto a la tasa de descuento.

Los principales resultados de los modelos económico-financieros para cada región se presentan a continuación.

Modelos económicos-financieros regionales A continuación se presentan las especificaciones técnicas de los modelos para las áreas seleccionadas.

\section{Mesopotamia Tierras Coloradas:}

Misiones y Noreste de Corrientes

Especie: Eucalyptus grandis.

Calidad de sitio: media a baja, suelos rojos, arcillosos, profundos, bien drenados, con niveles

\footnotetext{
${ }^{10}$ El precio de la madera está considerado en pesos por tonelada de materia seca. Para transformar este precio en una referencia comparable de mercado se debe relacionar y compensar según la humedad típica de la madera comercializable en cada caso.

${ }^{11}$ Este precio es el que compensa mínimamente los costos y la tasa de interés requerida al proyecto.
}

moderados de degradación por erosión, compactación y/o pérdida de materia orgánica.

Limitante principal: susceptibilidad a la erosión. Cultivo antecedente: plantación forestal.

Estado del lote: residuos recientes de tala rasa.

Preparación del terreno: herbicida total previo al despeje y laboreo de banda de plantación. Todas las operaciones mecanizadas a nivel o bien cortando la pendiente principal. Despeje en banda de plantación, con un ancho de 1,0-1,2 metros. Después del laboreo, herbicida preemergente en la banda de plantación. Mantener el mayor porcentaje de suelo cubierto con residuos de la cosecha. Control de hormigas previo a plantación.

Material de plantación: plantines de semilla. Época de plantación: inicio de primavera.

Densidad inicial: 2000 plantas por hectárea.

Plantación: manual.

Fertilización: no.

Control de malezas: químico y manual durante los dos primeros años.

Control de hormigas: durante los 24 meses siguientes a la plantación.

Régimen: tallar; tres rotaciones de 5 años cada una.

Sistema de cosecha: fuste entero. Volteo con motosierra y extracción de fuste entero al borde de camino.

De acuerdo con las especificaciones del modelo considerado para esta región, el ciclo de producción es de 15 años, y comprende tres turnos de corta de cinco años cada uno, con rendimientos estimados de 122, 110 y 100 toneladas por hectárea ( $t / h a)$ de biomasa seca en estufa cada uno, en ese orden.

Es oportuno aclarar que la humedad considerada para estimar los costos de producción de biomasa -seca en estufa- es menor que la humedad que puede estimarse como esperable luego de unos pocos días posteriores al volteo de los árboles. Por ejemplo, las $122 \mathrm{t} / \mathrm{ha}$ de la primera cosecha se estiman equivalentes a $256 \mathrm{t} / \mathrm{ha}$ de rollizos con la humedad al momento del volteo, y a $182 \mathrm{t} / \mathrm{ha}$ luego de cuatro a cinco días desde la cosecha, período medio probable hasta la pesada en la báscula para el proceso de comercialización. 
El jornal medio considerado fue de 1060 ARS, y el precio del litro del gasoil, de 18 ARS. El costo por plantín en promedio se determinó en 3,5 ARS. Se incurre en gastos de insumos principalmente durante la preparación del terreno (53,5 USD/ha/ año), y a un año de los turnos de corta (con un importe algo menor al antes mencionado). Los costos de administración por hectárea se estimaron en 630 ARS anuales.

En función de estos costos y del rendimiento en cada cosecha, el valor mínimo de la madera destinada a dendroenergía debería ser de 938 ARS por tonelada seca. Además, de acuerdo con los resultados del análisis de sensibilidad, se observa que el precio del producto es muy susceptible a cambios en la tasa de interés que es posible exigir al proyecto y a cambios en el jornal medio. Ante un cambio del $1 \%$ de la tasa de descuento, el precio mínimo requerido varía en $3,02 \%$, mientras que la elasticidad del jornal es de 0,49.

\section{Mesopotamia Planicies Arenosas:}

\section{Centro-Sudoeste de Corrientes}

Este modelo se presenta para las arenas hidromórficas (arenas amarillas), suelos que están ubicados entre lagunas y esteros, y se caracterizan por tener baja fertilidad natural, bajo contenido de materia orgánica y ser susceptibles a la erosión hídrica y eólica.

Se trata de arenas de color pardo-amarillento, agrupadas en el orden Entisoles (series Chavarría y Pampín), que conforman un manto de 0,6 a 1,5 m de profundidad depositado sobre un suelo más antiguo de textura franco-arcillosa. El cambio textural abrupto dificulta el movimiento del agua, lo que da origen a una falsa napa que fluctúa hasta cerca de la superficie.

Especie: Eucalyptus grandis.

Calidad de sitio: media (32-36 m) a baja (28-32 m). Ciclo de cultivo: segundo forestal.

Estado del lote al inicio del proyecto: residuos de tala rasa.

Control de hormigas: preplantación; cebo químico $\left(20 \mathrm{gr} / \mathrm{m}^{2}\right)$ hasta los 8 meses.

Preparación del terreno: despeje mecanizado en banda de plantación (1,0-1,5 m); dos pasadas de rastra + camellón; herbicida preemergente sobre la banda de plantación.

Plantación: manual, plantines de semilla.

Época: primavera.

Densidad: 2500 plantas/ha.

Fertilización: 100 gr/planta de fosfato diamónico.

Control de malezas: químico (3,5 I/ha) hasta los

6-8 meses de edad (se estiman dos controles químicos posplantación).

Ciclo forestal: 5 años.

Sistema de cosecha: fuste entero.

Régimen: tallar con manejo de rebrotes (dos varas). Ciclos: 3.

El ciclo productivo representativo de las Planicies Arenosas del centro sudoeste de Corrientes es de 15 años, con tres turnos de corta cada cinco años y cuyos rendimientos se estiman en 95,84 y $74 \mathrm{t} /$ ha de materia seca en cada turno.

El jornal medio de la zona fue de 1060 ARS; el precio del litro del gasoil, de 20,81 ARS, y el valor del plantín en promedio, de 3,63 ARS. La adquisición de insumos se realiza esencialmente durante la preparación del terreno, por un importe de 604 USD/ha, y, un año después de los turnos de corta, los insumos representan un costo de 50 USD/ha. Los costos de administración se estimaron en 513 ARS/ha anuales.

En función de estos costos y del rendimiento en cada cosecha, el valor mínimo de la madera destinada a dendroenergía debería ser 1074 ARS por tonelada seca.

En el análisis de sensibilidad, se observa que el precio del producto es muy susceptible a cambios en la tasa de descuento y en el jornal medio. Ante un cambio del $1 \%$ de la tasa de descuento, el precio mínimo requerido varía en 3,57\%, mientras que la elasticidad del jornal es de 0,26.

\section{Mesopotamia: Entre Ríos}

Especie: Eucalyptus grandis.

Calidad de sitio: suelos llamados localmente "mestizos", arcillosos de menor índice de sitio (IS 29), en general de clase III o IV, con problemas de excesos hídricos y con riesgo de compactación superficial y subsuperficial.

Cultivo antecedente: usos en ganadería y otras actividades productivas agrícolas (sin forestación 
previa), dado que la reforestación en la región se destina fundamentalmente a plantaciones de eucaliptus destinadas a producción de madera sólida.

Preparación del terreno: subsolado y laboreo en la línea de plantación.

Plantación: manual; plantines de semilla.

Época: inicio de primavera.

Densidad inicial: 2500 plantas/ha.

Fertilización: no.

Control de malezas: químico; intensivo durante el ciclo de crecimiento.

Control de hormigas: durante los 24 meses siguientes a la plantación.

Turno: 7 años.

Sistema de cosecha: fuste entero.

Régimen: tallar; conducción del rebrote en dos rotaciones; luego, replantación.

Sobre la base de la proyección del flujo de fondos para un ciclo productivo de 14 años (el menor de todas las regiones), con dos turnos de corta cada siete años, y cuyos rendimientos se estiman en 120 t/ha de materia seca en el primer aprovechamiento, y 102 t/ha en el turno final, se estimó el precio mínimo que debería obtener este producto en el mercado.

Para ello se consideraron los siguientes valores promedio de los componentes del costo, que varían por zona. El jornal medio en Entre Ríos fue de 1060 ARS; el precio del litro del gasoil, 17,82 ARS, y el costo del plantín, 3,63 ARS. Además, la preparación del terreno demanda insumos por un importe de 205,5 USD/ha, y en el primer y octavo año de la plantación, los insumos fueron de 18 USD/ha. Los costos anuales de administración se calcularon en 431 ARS/ha.

En función de estos costos y del rendimiento en cada cosecha, el valor mínimo de la madera destinada a dendroenergía debería ser 1047 ARS por tonelada seca. Este precio es muy sensible a cambios en la tasa de descuento y a variaciones del jornal medio. Ante un cambio de $1 \%$ de la tasa de descuento, el precio mínimo estimado varía en $4,39 \%$, mientras que ante una variación de $1 \%$ del jornal medio, el valor mínimo se incrementa en 0,39 puntos porcentuales.
NOA

Especie: Eucalyptus camaldulensis - HSP EEA INTA Famaillá.

Calidad de sitio: media a baja. Suelos muy diversos de pedemonte y transición a las yungas en las provincias de Jujuy, Salta y Tucumán.

Antecedentes: campos procedentes de cultivos agrícolas.

Densidad: $3 \mathrm{~m} \times 2 \mathrm{~m}-1666$ plantas/ha.

Plantación: manual; plantines de semillas.

Fertilización: no.

Turno de corta: 7 años.

Cosecha: motosierra.

Manejo de rebrote: 3 rotaciones.

Se realizó el análisis económico-financiero sobre la base de la proyección de flujo de ingresos a 21 años, período que comprende tres ciclos de corta con turnos que suceden cada siete años, los cuales presentan un rendimiento de $145 \mathrm{t} / \mathrm{ha}$ en el primer corte, $133 \mathrm{t} /$ ha en el segundo corte y $120 \mathrm{t} /$ ha en el corte final.

Respecto de los costos, que varían según la región, se consideraron los siguientes valores: 800 ARS el jornal medio, 18 ARS el litro de gasoil y 5 ARS cada plantín. La adquisición de insumos se realiza principalmente durante la preparación del terreno, por un importe de 118 USD/ha, y posteriormente este monto se reduce a 54,7 USD/ha/ año. Los costos de administración por hectárea se estimaron en 569 ARS anuales.

Del flujo estimado, se obtiene que el precio de la tonelada de madera con destino dendroenergético en campo deber ser como mínimo de 1193 ARS para que el proyecto sea rentable. En el análisis de sensibilidad se ve que un cambio en un punto porcentual en la tasa de descuento produce una variación de 4,39\% en el precio mínimo requerido para la viabilidad del proyecto. Además, se observa que otras variables como el precio del gasoil, insumos en dólares y material de plantación tienen un impacto muy pequeño en comparación con el jornal medio. Ante un cambio de $1 \%$ del jornal, el precio mínimo necesario varía en 0,47 puntos porcentuales. 


\begin{abstract}
Región Pampeana
Alternativa 1

Especie: Eucalyptus dunnii.

Preparación del terreno: puede variar desde una totalmente química (sin laboreo) hasta combinaciones de preparación química y mecánica. En el caso de suelos de texturas francas a franco-arcillosas, que provienen de uso agrícola y/o ganadero, la preparación tradicional consiste en una pasada de rastra cruzada y una de cincel en la línea de plantación, y posterior control químico con herbicidas preemergentes, que puede realizarse en forma total o en la banda de plantación.
\end{abstract}

Plantación: manual, a partir de plantines de semilla. Densidad: 1920 plantas/ha.

Uso previo: se considera una situación de partida de un suelo ocupado por pastizal, barbecho y marcación.

Fertilización: no.

Control de plagas y malezas: considerando la plantación de primavera, se realizarán, entre el momento de la plantación y hasta 18 meses después, al menos cuatro controles de la entrelínea y al menos tres controles en la línea de plantación, dependiendo de las condiciones particulares del sitio.

Producción: se asume que se puede lograr un incremento medio anual (IMA) de $26,3 \mathrm{~m}^{3} / \mathrm{ha}$, y se considera que a partir de allí el incremento periódico medio es de $36,5 \mathrm{~m}^{3} / \mathrm{ha}$.

Se estimó el flujo de ingresos para un ciclo productivo de 21 años, que consiste en tres aprovechamientos con rendimientos de 128 t/ha en el séptimo año de la plantación, 115 t/ha en el décimo cuarto año y $102 \mathrm{t} / \mathrm{ha}$ al finalizar el ciclo productivo.

En cuanto a los costos, que varían según la región, se tomaron los siguientes valores: 1060 ARS el jornal medio, 18 ARS el litro de gasoil y 5 ARS el plantín.

El valor de los insumos empleados durante la preparación del terreno se determinó en 95,7 USD/ha, y aproximadamente 8 USD/ha/año durante el primer año y en los años posteriores a los turnos de corta. Los costos de administración por hectárea se estimaron en 340 ARS anuales.

A partir del flujo estimado, se obtuvo un precio mínimo de la tonelada de madera seca en campo de 772 ARS para que el proyecto sea viable económicamente. En lo que respecta a los análisis de sensibilidad, se observa que, ante un cambio de $1 \%$ en la tasa de descuento, se produce una variación de 4,21\% en el precio mínimo requerido para la viabilidad del proyecto, y una sensibilidad de 0,31 a variaciones del jornal.

\section{Alternativa 2}

Especie: Eucalyptus viminalis.

Preparación del terreno: herbicida total antes del despeje y laboreo total con cincel. Después del laboreo, herbicida posemergente en la banda de plantación y desmalezada mecánica entre líneas. Control de hormigas previo a la plantación.

Plantación: manual; plantines de semilla al inicio de la primavera, con densidad inicial de 1500 plantas/ha.

Fertilización: 80 g por planta, con fosfato diamónico.

Control de malezas: químico y manual, durante los dos primeros años.

Control de hormigas: durante los 24 meses siguientes a la plantación.

Régimen: tallar, tres ciclos de 7 años cada uno.

Sistema de cosecha: volteo con motosierra, extracción de fuste entero al borde de camino apto para camiones.

Producción de biomasa: sitio de calidad buena: primer ciclo, 92,6 t/ha de biomasa de rollos (base seca); segundo ciclo, 90 t/ha, y tercer ciclo de 82 t/ha.

Considerando los costos para la región, más arriba señalados, el precio mínimo esperable es de 984 ARS/t seca, con una elasticidad al jornal de 0,31 .

\section{Chaco-Formosa}

Especie: Eucalyptus camaldulensis.

Calidad de sitio: media a baja; suelos de pastizales de media loma o loma baja, con poco tiempo de anegamiento y/o suelos de chacras abandonadas que presentan cierto nivel de degradación. Clases de capacidad de uso III, IV y VI, con horizonte arcilloso o álbico cerca de superficie.

Limitante principal: susceptibilidad a la salinización en superficie. 
Modelos técnico-económicos de plantaciones

\begin{tabular}{|c|c|c|c|c|c|c|c|c|c|}
\hline 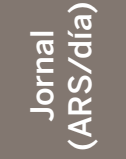 & \begin{tabular}{l}
0 \\
$\circ$ \\
$\stackrel{0}{0}$ \\
$\bigcirc$ \\
\hdashline
\end{tabular} & $\begin{array}{l}0 \\
0 \\
0 \\
0 \\
0 \\
-1\end{array}$ & $\begin{array}{l}0 \\
\stackrel{0}{0} \\
\stackrel{0}{0}\end{array}$ & $\begin{array}{l}0 \\
0 \\
0 \\
0 \\
-1\end{array}$ & $\begin{array}{l}0 \\
\stackrel{0}{0} \\
\stackrel{0}{0}\end{array}$ & $\begin{array}{l}\circ \\
\infty \\
+ \\
\infty\end{array}$ & $\begin{array}{l}0 \\
\stackrel{0}{0} \\
0 \\
0\end{array}$ & $\begin{array}{l}\circ \\
\infty \\
\infty \\
\infty\end{array}$ & \\
\hline 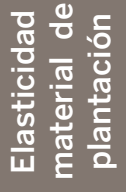 & $\begin{array}{l}\infty \\
\stackrel{\infty}{0}\end{array}$ & $\begin{array}{l}\infty \\
\stackrel{\infty}{0} \\
0\end{array}$ & $\begin{array}{l}\stackrel{2}{2} \\
\stackrel{0}{0}\end{array}$ & $\begin{array}{l}\mathscr{0} \\
\stackrel{1}{0}\end{array}$ & 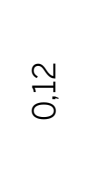 & $\begin{array}{l}\text { 음 } \\
\text { - }\end{array}$ & $\stackrel{m}{\stackrel{m}{0}}$ & $\stackrel{\text { L }}{\mathrm{O}^{\circ}}$ & \\
\hline 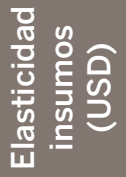 & $\begin{array}{l}m \\
O \\
O \\
0\end{array}$ & Õ & $\begin{array}{l}\text { Oे } \\
\text { O. }\end{array}$ & $\begin{array}{l}\mathscr{0} \\
0 \\
0\end{array}$ & $\begin{array}{l}\Delta \\
0\end{array}$ & $\stackrel{L}{\circ}$ & O̊ & $\stackrel{\circ}{0}$ & \\
\hline 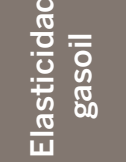 & $\underset{O}{\stackrel{\Delta}{0}}$ & $\frac{\sigma}{0}$ & $\begin{array}{l}\vec{A} \\
\overrightarrow{0}\end{array}$ & $\begin{array}{l}\stackrel{7}{0} \\
0\end{array}$ & $\begin{array}{l}\underset{0}{N} \\
\tilde{O}\end{array}$ & $\stackrel{m}{\dddot{m}}$ & 足 & $\begin{array}{l}\infty \\
\stackrel{0}{0}\end{array}$ & \\
\hline $\begin{array}{l}\frac{\sqrt{0}}{0} \overline{0} \\
\frac{0}{5} \\
\frac{0}{5} \\
\frac{\pi}{w}\end{array}$ & $\vec{m}$ & 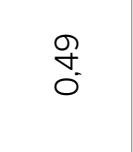 & $\begin{array}{c}\vec{m} \\
0 \\
0\end{array}$ & $\begin{array}{c}\text { m} \\
\text { a } \\
0^{\prime}\end{array}$ & $\begin{array}{l}\stackrel{0}{v} \\
\stackrel{0}{0}\end{array}$ & f & 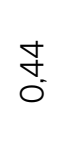 & م. & \\
\hline 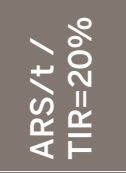 & $\begin{array}{l}m \\
m_{n}^{m} \\
m\end{array}$ & $\begin{array}{l}\stackrel{+}{~} \\
\infty \\
0 \\
-1\end{array}$ & 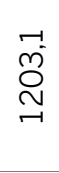 & $\underset{\stackrel{\sim}{N}}{\stackrel{\sim}{\sim}}$ & 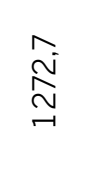 & $\begin{array}{l}\stackrel{N}{\overparen{\sigma}} \\
\stackrel{-}{-}\end{array}$ & $\begin{array}{l} \\
\infty \\
\infty \\
\infty \\
\infty \\
-1\end{array}$ & 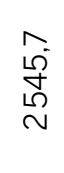 & 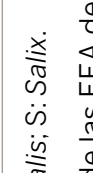 \\
\hline 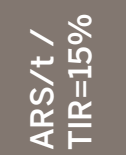 & $\frac{0}{i}$ & $\begin{array}{l}\vec{\infty} \\
m \\
m\end{array}$ & $\begin{array}{l}\text { a } \\
\text { } \\
\infty \\
\text { o }\end{array}$ & $\underset{\sim}{\stackrel{+}{J}}$ & 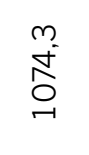 & $\begin{array}{l}\stackrel{+}{m} \\
\underset{\exists}{\mid}\end{array}$ & $\begin{array}{l}\hat{0} \\
\text { ○े } \\
\stackrel{\leftrightarrow}{n}\end{array}$ & 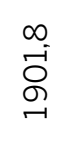 & 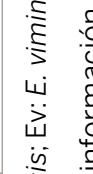 \\
\hline 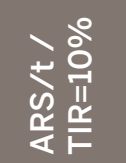 & $\begin{array}{l}m \\
\text { స్ } \\
\sigma\end{array}$ & $\begin{array}{l}\circ \\
\stackrel{\rho}{\rho} \\
\infty\end{array}$ & $\begin{array}{l}\hat{m} \\
\stackrel{\infty}{\infty}\end{array}$ & $\begin{array}{l}\widehat{D} \\
\infty \\
\infty \\
\infty\end{array}$ & नें & $\begin{array}{l}\hat{\infty} \\
\hat{\sigma}\end{array}$ & $\begin{array}{l}\stackrel{\sigma}{-} \\
\underset{\sim}{\sim} \\
\sim\end{array}$ & 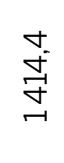 & $\frac{\frac{\sigma}{\partial}}{\frac{\sigma}{\sigma}}$ \\
\hline 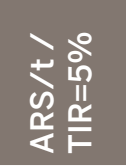 & $\begin{array}{l}\stackrel{n}{0} \\
\stackrel{N}{N}\end{array}$ & $\begin{array}{l}\stackrel{\llcorner}{L} \\
\stackrel{\rho}{N}\end{array}$ & $\begin{array}{l}\infty \\
\sim_{0}^{-} \\
0 \\
0\end{array}$ & 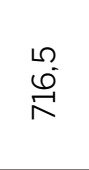 & $\stackrel{\hat{D}}{\stackrel{\infty}{\wedge}}$ & $\begin{array}{l}\stackrel{0}{\oplus} \\
\stackrel{\infty}{\infty}\end{array}$ & 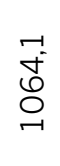 & 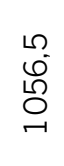 & 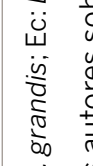 \\
\hline 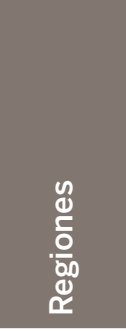 & 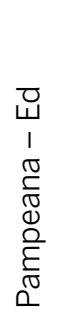 & 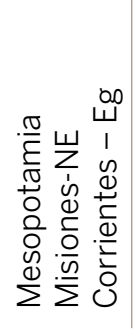 & 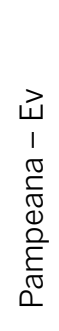 & 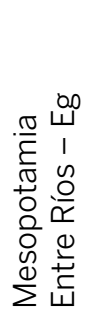 & 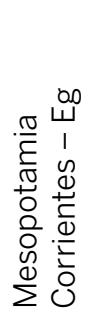 & $\begin{array}{l}u \\
\dot{u} \\
1 \\
\frac{1}{z} \\
\text { Z }\end{array}$ & $\begin{array}{l}\infty \\
1 \\
0 \\
\frac{\pi}{0} \\
0\end{array}$ & 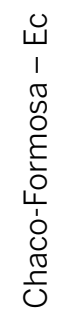 & 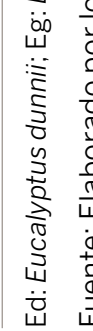 \\
\hline
\end{tabular}


Potencial de desarrollo de plantaciones dendroenergéticas en la Argentina

Actividad antecedente: agricultura (algodón principalmente) o ganadería (pasturas naturales o cultivadas).

Preparación del terreno: mediante pasada de rastra de discos, dos pasadas cruzadas. Herbicida total después del laboreo. Todas las operaciones mecanizadas.

Fertilización: no.

Control de hormigas: previo a plantación.

Plantación: plantines de semilla implantados manualmente a inicio de primavera, con densidad de 1111 plantas/ha.

Control de malezas: químico; intensivo durante el ciclo de crecimiento; solo en la línea de plantación.

Control de hormigas: durante los 24 meses siguientes a la plantación.

Turnos: 8 años.

Sistema de cosecha: fuste entero.

Régimen: tallar; conducción de dos rebrotes, luego replantación.

El análisis económico-financiero se realizó a partir de un ciclo productivo de 24 años con tres ciclos de corta cada ocho años, con un rendimiento de 86 t/ha de biomasa seca. En cuanto a los costos, que varían según la región, en Chaco-Formosa se asumen los siguientes valores: 848 ARS el jornal medio, 20 ARS el litro de gasoil, y 7 ARS cada plantín.

El costo en relación con los insumos es el más bajo de las regiones consideradas: no supera los 24 USD/ha/año en los momentos de mayor gasto, mientras que los costos de administración por ha se estimaron en 396 ARS anuales.

Del flujo estimado se desprende que, para que el proyecto sea viable, se requiere un precio mínimo de venta del producto en el campo de 1902 ARS/t seca. Se observa que este precio es muy sensible a la tasa de descuento: para una variación de esta de $1 \%$, el precio cambiará $6,89 \%$. En cuanto a las otras variables, se observa que el precio es más sensible a variaciones en el valor del jornal que respecto a los demás componentes del costo (ante cambios de $1 \%$, el precio mínimo requerido varía en 0,5\%).

\section{Delta del Paraná}

Especie: Salix spp. Considerando las características de los sitios que podrían incorporarse a esta actividad forestal, se planteará el modelo para sauces, y como posibles genotipos, Salix nigra "Ibicuy INTA CIEF"; Salix alba "Yaguareté INTA CIEF"; Salix matsudana "Géminis INTA CIEF"; Salix matsudana x Salix alba "Los Arroyos INTA CIEF"; y Salix matsudana x Salix nigra clon "Lezama INTA-CIEF".

Calidad de sitio: media a baja; suelos del orden Entisoles, con alto contenido de materia orgánica y nutrientes en los primeros $15 \mathrm{~cm}$, y una marcada reducción en profundidad. Estos suelos hidromórficos tienen escasa estructura (masiva) y pueden presentar una capa de arcillas limitante en condiciones de sequía dentro del metro de profundidad. Las características del sitio están reguladas en gran medida por la sistematización del predio y el manejo del agua (adecuando el ingreso/egreso en función de las características del rodal, la influencia del río y las condiciones climáticas).

Cultivo antecedente: plantación forestal con salicáceas.

Estado del lote: pajonal o residuos de tala rasa de álamos o sauces.

Preparación del terreno: aplastado de pajonal con rolo y control químico (herbicida) en la línea de plantación. Se mantienen los residuos en sitio y se realiza control de hormigas previo a plantación.

Plantación: manual, con utilización del hoyado con barreta; material clonal, utilizando estacas de $1 \mathrm{~m}$ procedentes de guías de un año de estaqueros establecidos con fines de propagación, implantados en agosto-septiembre.

Densidad inicial: 1905 plantas/ha. El distanciamiento de 3,5 m x 1,5 m tiende a facilitar las labores mecánicas de preparación y mantenimiento general (principalmente limpieza) del lote de plantación.

Fertilización: no.

Control de malezas: rolo entre filas y machete en la línea solo durante la instalación (primer año).

Control de plagas: protección plástica para roedores durante la instalación y control de hormigas durante todo el ciclo, aunque se hará con mayor intensidad durante los 12 meses siguientes a la plantación.

Reducción del número de brotes: se hará una reducción de la cantidad de brotes en los primeros años para concentrar el crecimiento en un número menor y facilitar la cosecha.

Turno: 6 años. 
Sistema de cosecha: apeo con motosierra. Fuste entero.

Régimen: tallar; conducción del rebrote durante 2 ciclos más. Luego de 18 años, transcurridos los 3 ciclos se hará la replantación del lote. La duración del turno total se plantea en función de la capacidad de rebrote a lo largo del tiempo y, por otra parte, de la posibilidad de renovar el material genético en función del programa de mejora.

Rendimiento esperado: el modelo plantea una densidad levemente mayor a la utilizada actualmente en plantaciones para papel y triturado, dado que no sería recomendable realizar un uso más intensivo del suelo y de agroquímicos en esta región de humedales.

El ciclo productivo para la región Delta del Paraná se proyecta en 18 años, con tres turnos de corta cada seis años hasta el corte final, cuyos rendimientos se estiman en 81 t/ha de biomasa seca para los dos primeros, y en $73 \mathrm{t} /$ ha en el turno final. En relación con los costos considerados, el jornal medio relevado fue de 1060 ARS, el precio del litro del gasoil de 17,81 ARS y el material de plantación de 5,50 ARS. Los gastos en insumos oscilan entre 0,7 y 4,7 USD/ha/año, a excepción del primer año de la plantación, cuando asciende a 107 USD/ha/ año debido a los cuidados necesarios hasta lograr la instalación inicial. Los costos de administración por hectárea se determinaron en 542 ARS.

Sobre la base de estos costos y del rendimiento en cada cosecha, el valor mínimo de la tonelada de madera destinada a dendroenergía debería ser de 1501 ARS. Este precio estimado es sensible a cambios en la tasa de descuento y del jornal medio. Si la tasa de descuento varía 1\%, el precio mínimo requerido varía en $3,92 \%$ y la elasticidad del jornal es de 0,44 .

El Cuadro 10 resume el análisis de modelos expuesto.

\section{Resultados analíticos de los modelos productivos}

En relación con el precio mínimo que debería pagarse por tonelada de materia seca de madera en cada región, estimado en función de los costos productivos de cada modelo de plantaciones dendroenergéticas, se observa que el más bajo se encuentra en la Región Pampeana Alternativa 1 (E. dunnii), con 762/t de materia seca, seguido por el de Mesopotamia Tierras Coloradas, donde la tonelada de materia seca cuesta 938 ARS. En las demás regiones, el precio mínimo se estima por encima de los 1000 ARS/t seca, hasta los 1902 ARS/t en la región de Chaco-Formosa.

Estas diferencias de precios se atribuyen a distintos factores: duraciones de cada proyecto, técnicas productivas con sus particulares demandas de insumos, y rendimientos en el aprovechamiento de la plantación según la región (Gráfico 4).

La proporción en que inciden los diferentes componentes del costo en el precio mínimo estimado depende tanto del modelo productivo como de los precios vigentes de cada zona. Pero, en general, los modelos planteados son intensivos en mano de obra, por lo que el jornal medio es una de las variables que incide más fuertemente en la estructura de costos.

Asimismo, en los costos de aprovechamiento, el combustible tiene una participación elevada, por lo que se trata de un ítem sensible al precio del gasoil. El mayor precio de este combustible se observa en la provincia de Corrientes, región Mesopotamia Planicies Arenosas (20,81 ARS/I), donde también aparecen los costos iniciales más altos en insumos y jornal medio

Los mayores costos totales se registran en la región Chaco-Formosa, lo que se explica no tanto por su estructura, sino, en parte, por los bajos rendimientos en el aprovechamiento respecto de otras regiones.

Los modelos de plantaciones forestales con destino energético se caracterizan por generar flujos negativos hasta alcanzar el primer turno de corta. El flujo de fondos neto negativo más importante se da en el primer año de los proyectos, básicamente debido a los costos de implantación, que asumen valores desde $16546 \mathrm{ARS} / \mathrm{ha}$ (en la Región Pampeana Alternativa 2 - E. viminalis) hasta 36029 ARS (en Corrientes, Mesopotamia Planicies Arenosas). No obstante, el aprovechamiento representa el costo operativo más elevado, con la diferencia que, en los turnos de corta, el flujo neto de fondos no se vuelve negativo debido a los ingresos derivados de la venta de madera. 
Potencial de desarrollo de plantaciones dendroenergéticas en la Argentina

Otro factor importante para tener en cuenta en el flujo de fondos es el horizonte temporal de los proyectos. Los modelos aquí planteados abarcan horizontes desde 14 años (Mesopotamia-Entre Ríos) hasta 24 años (Chaco-Formosa), con proyectos intermedios que duran 15 años en la Mesopotamia (Planicies Arenosas y Tierras Coloradas), 18 años en la región del Delta y 21 años en la Región Pampeana y NOA.

Por último, las diferencias entre modelos también son notorias en los análisis de sensibilidad. En el caso de la tasa de descuento (Gráfico 4), se observa que la región donde el precio del producto es más sensible a esta variable es Chaco-Formosa, en tanto que frente a un cambio de un punto porcentual en la tasa de descuento, el precio varía en 6,29 puntos porcentuales; para las demás regiones esta sensibilidad ronda entre 3 y 4,5 puntos porcentuales.

A partir del análisis de sensibilidad del precio ante cambios en el valor de variables clave en la estructura de costos, como el jornal medio, el valor del gasoil, los insumos y los plantines, se concluye que la mayor sensibilidad se da en torno del jornal (Gráfico 5).

Por regiones, se puede observar que hay zonas más sensibles al precio del jornal, como Chaco-Formosa, NOA y Mesopotamia Tierras Coloradas, con elasticidades de 0,50, 0,47 y 0,49 puntos porcentuales, respectivamente, por punto porcentual en que varía el jornal. En el otro extremo, la Región Pampeana presenta la menor sensibilidad a variaciones del jornal medio, con $0,31 \%$ por $1 \%$ de variación del precio de la mano de obra por hora.

Gráfico 4. Precios mínimos en cada región según tasa de descuento

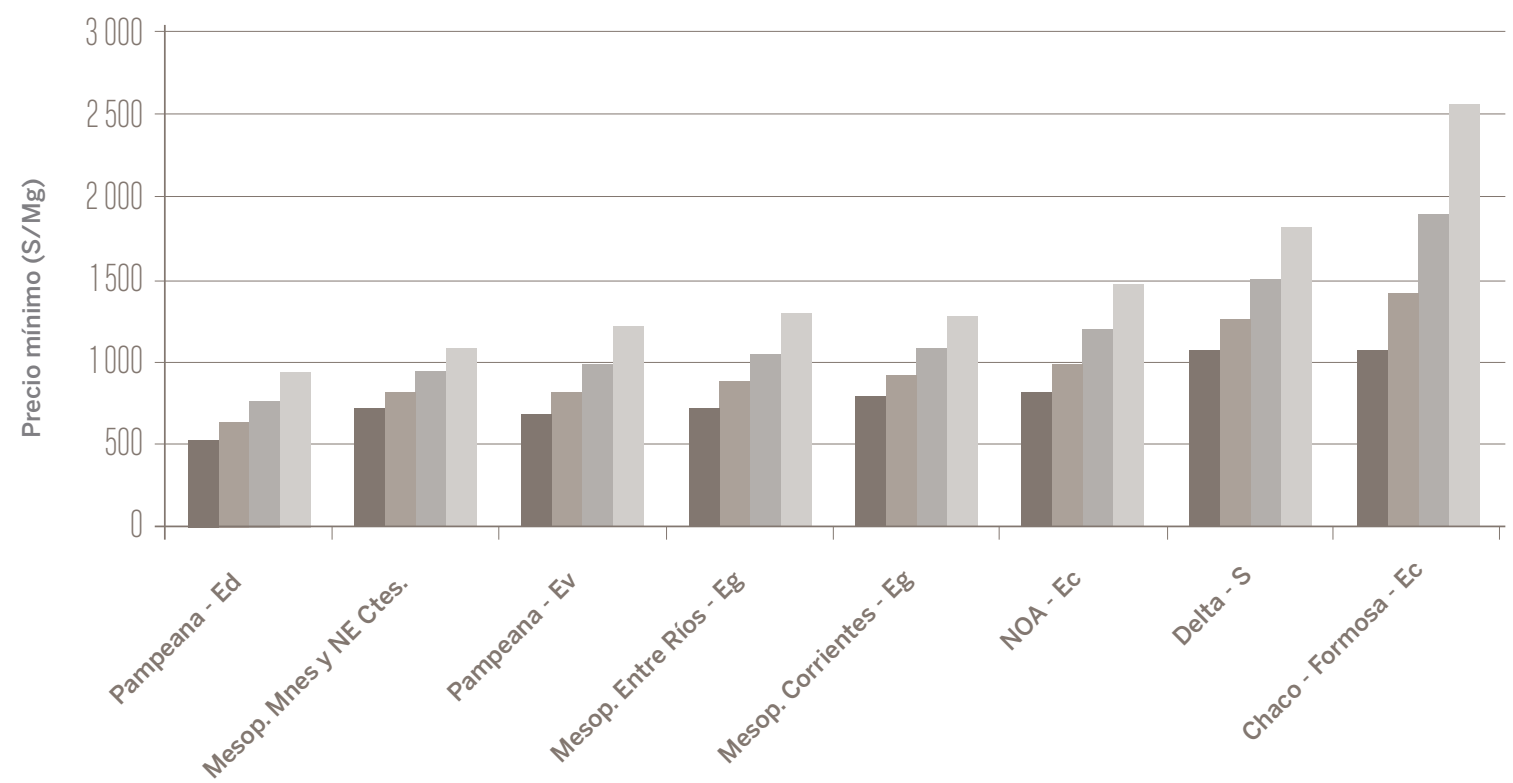

Ed: Eucalyptus dunnii; Eg: E. grandis; Ec: E. camaldulensis; Ev: E. viminalis; S: Salix.

Fuente: Elaborado por los autores sobre la base de información de las EEA del INTA de cada región. 
Modelos técnico-económicos de plantaciones

Gráfico 5. Sensibilidad del precio ante cambios en el valor de variables clave en la estructura de costos

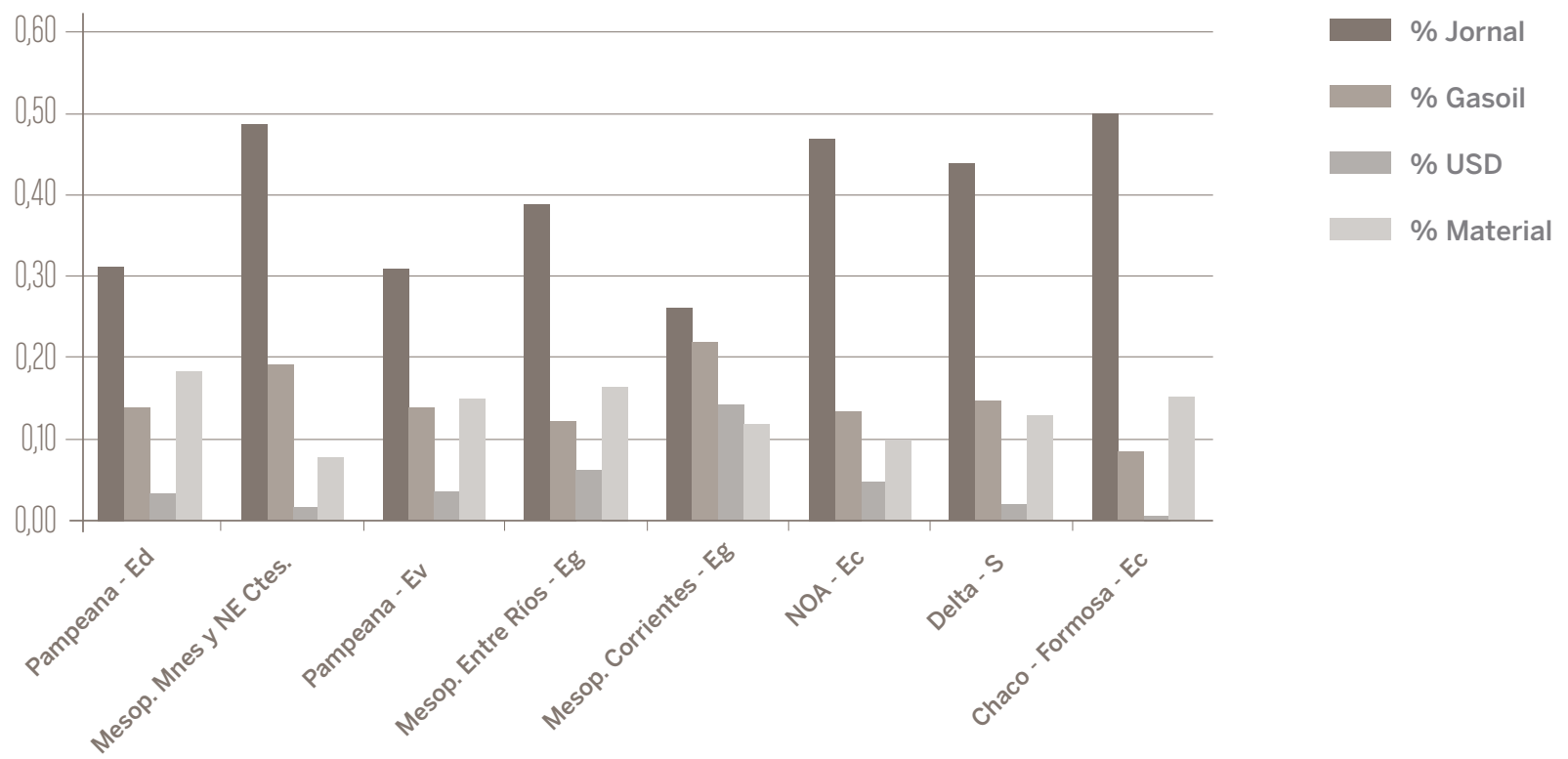

Ed: Eucalyptus dunnii; Eg: E. grandis; Ec: E. camaldulensis; Ev: E. viminalis; S: Salix.

Fuente: Elaborado por los autores sobre la base de información de las EEA del INTA de cada región. 


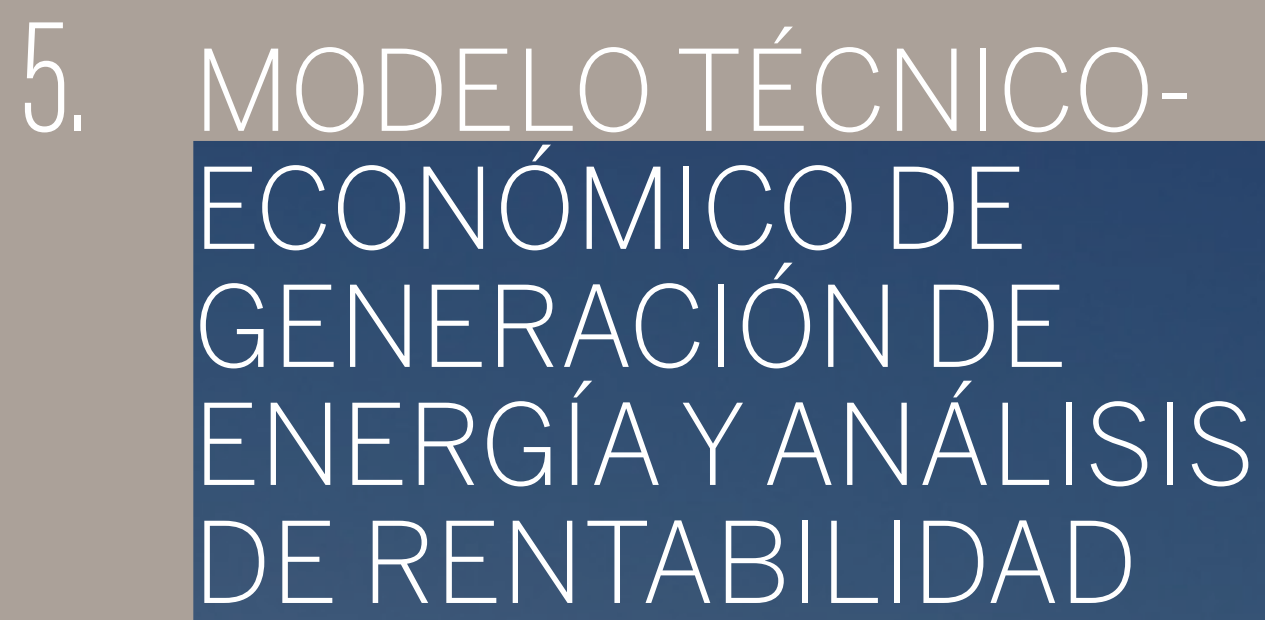


Para evaluar de manera exhaustiva

la viabilidad de una estrategia de

desarrollo dendroenergético, se ha

elaborado un modelo de generación

de energía a partir de plantaciones

forestales, con sus aspectos

técnicos y económicos.

Con el fin de delinear un panorama integral de la viabilidad de una estrategia de desarrollo de plantaciones forestales destinadas a la producción de energía, además de efectuar un análisis económico-financiero de los posibles modelos que podrían asentarse en distintas regiones del país, se ha procedido a modelizar un ejemplo de generación energética a partir del producto de tales plantaciones.

Para ello, se construyó un modelo hipotético de generación en base a forestación destinada a dendroenergía, que se localizó en la provincia de Misiones. En las páginas siguientes se presentan las características de este modelo, desde el tipo de explotación forestal en sí, hasta el balance energético final derivado de la transformación de la biomasa en energía.

\section{Modelo de generación dendroenergética} Este estudio presenta información sobre costos operativos, consumo energético y balance de energía del procesamiento de biomasa forestal, desde la carga en campo hasta su transformación en usinas de 0,5 MW, 1,0 MW y $2 \mathrm{MW}$ de potencia, con análisis de la demanda anual de biomasa para abastecer dichas usinas y la descripción técnica de vehículos, equipos e instalaciones y mano de obra requeridos.

El estudio se compone de las siguientes partes:

- Descripción de operaciones y datos utilizados para los cálculos de producción y costos relacionados a ellas.

- Cuadros ilustrativos de los datos utilizados.

Escenario y operaciones

1. Región NO de Misiones

2. El abastecimiento provendrá de pequeñas superficies de tala rasa.

3. La biomasa verde - fustes trozados- oreada, o secada al aire, se dispondrá en pilas aledañas a un camino transitable por camión.

4. El transporte en camión será en caminos de tierra (off road) en alta proporción (alrededor de $80 \%)$. 
Potencial de desarrollo de plantaciones dendroenergéticas en la Argentina

5. La producción estimada de biomasa en rollos de eucaliptus es de $182 \mathrm{t} / \mathrm{ha}$ (período de 5 años de crecimiento, con 36,4 t/ha año), o sea, el primer ciclo de la rotación.

6. La carga sobre camión se hará con un equipo cargador con grampa maderera.

7. Entre la posibilidad de chipeado de la biomasa en campo o en usina, se opta por esta última, debido a la superficie reducida destinada a tala rasa de las parcelas en estudio y a fin de optimizar la operación.

El chipeado en campo requeriría la operación de varias chipeadoras portátiles trabajando en distintas parcelas, todas de baja producción, con accionamiento mediante tomas de fuerza de tractores, con trabajo intermitente y una importante proporción de tiempo inactivo. También requeriría contar con dos tractores en cada parcela: uno para accionar la chipeadora y otro para cargar el camión.

Los fustes de árboles para chipear pueden alcanzar $30 \mathrm{~cm}$ de diámetro, es decir que requerirían potencias de chipeado muy elevadas, de 200 a $300 \mathrm{HP}$, imposibles de justificar económicamente en un régimen de trabajo intermitente y de baja producción como el mencionado.
Hacer el chipeado en usina optimiza el trabajo de la chipeadora, que podrá ser accionada con motor eléctrico, tener mayor capacidad tanto en diámetro de rollos como en volumen para procesar, y funcionar de modo más continuado. Una única chipeadora de mayor tamaño y accionamiento eléctrico es más eficiente que varias chipeadoras portátiles pequeñas accionadas por motor de explosión, operando en forma intermitente, y que además estarían muy limitadas en el diámetro de rollos que podrían procesar.

Cabe destacar la conveniencia de chipear rollos cuyo diámetro sea menor a $25-30 \mathrm{~cm}$ en punta gruesa. Los rollos que superan los $25 \mathrm{~cm}$ en punta gruesa son aptos para aserrado, que resultaría más rentable.

La operación en campo, previa al transporte de los rollos a la usina, consistirá en el trozado de fustes utilizando motosierras portátiles, y la carga en camión mediante un tractor con grampa maderera. Las motosierras utilizadas normalmente son de las marcas Husqvarna o Stihl, con motor de 4-HP de dos tiempos, 3-5 kg de peso, nafta con $5 \%$ de aceite como combustible, espadas de $0,45 \mathrm{~m}$ (con un consumo de una espada por mes, con un piñón y 3 a 4 cadenas por espada), medio litro por día de lubricante

Cuadro 11. Costos de los elementos para el trabajo en el campo

\begin{tabular}{l|c}
\hline Motosierra Stihl 361 (2 años de vida útil) (ARS) & 13550 \\
\hline Espada 45-50 cm (1 por mes) (ARS) & 1085 \\
\hline Cadena (3 entre cambios de espada) (ARS) & 49 \\
\hline Piñón (1 con cada cambio de espada) (ARS) & 190 \\
\hline Aceite 2T Stihl (litro) (ARS) & 150 \\
\hline Aceite para cadena Stihl (ARS) & 50 \\
\hline Afilado de cadena (1 por cadena) (ARS) & 150 \\
\hline Nafta (litro) (consumo de 2-3 tanques de 4 I/día. Total estimado: 12 l/día) (ARS) & 300 \\
\hline Seguro mensual operario (ARS) & $812 /$ día - 19448/mes \\
\hline Jornal motosierrista (6 h/día) (ARS) & 10 \\
\hline Producción media (trozado de fustes por hora) (m³) & $734 /$ día - 17616/mes \\
\hline Jornal de peón (ARS) & \\
\hline
\end{tabular}

Fuente: Zaderenko, Constantino, sobre la base de datos de informantes calificados de la región. 
de espada (Eco Lube de soja), 6 horas de trabajo diarias y una producción media de $10 \mathrm{~m}^{3}$ por hora.

En el Cuadro 11 se presentan los precios de los materiales necesarios para el trabajo en campo.

Una vez desramados, los fustes serán trozados a 2,4 m de largo, transportados y apilados al borde de los caminos internos de la plantación. Las trozas se cargarán sobre el camión y, eventualmente, sobre acoplado mediante el tractor equipado con grampa maderera, formando dos bultos (atados).

En el campo se utilizará un tractor de 70-100 HP con grampa maderera de 0,6 t y alcance de 6-8 m (abraza 4 toras por vez). Eventualmente se podrá utilizar un acoplado de $4 \mathrm{t}$ para el acarreo y apilado de trozas, para su posterior carga sobre camión, con el mismo tractor con grampa maderera (Cuadro 12).

Cuadro 12. Costos de las tareas de extracción de la biomasa del campo

\begin{tabular}{l|r}
\hline Concepto & Valor (ARS) \\
\hline Tractor de 70-100 HP & 1000000 \\
\hline Grampa maderera hidráulica de 2t & 1500000 \\
\hline Acoplado playón de 2 ejes, de 4t & 500000 \\
\hline $\begin{array}{l}\text { Amortización de los equipos } \\
\text { (25\% al año) }\end{array}$ & \\
\hline $\begin{array}{l}\text { Juego de cubiertas para tractor } \\
\text { (uno por año) }\end{array}$ & 50000 \\
\hline $\begin{array}{l}\text { Service de tractor (aceite motor, } \\
\text { filtros de aire, combustible y aceite), } \\
\text { por mes }\end{array}$ & 4000 \\
\hline $\begin{array}{l}\text { Cubiertas para acoplado } \\
\text { (3500 ARS cada una, un juego } \\
\text { de } 4 \text { por año) }\end{array}$ & 14000 \\
\hline $\begin{array}{l}\text { Aceite hidráulico (90 ARS el litro, } \\
\text { reposición 20 l/año) (por año) }\end{array}$ & 1800 \\
\hline $\begin{array}{l}\text { Seguro tractor (mensual) } \\
\text { Productividad (12 t por número de } \\
\text { cargas de camión por año) }\end{array}$ & 2700000 \\
\hline $\begin{array}{l}\text { Precio típico global del equipo } \\
\text { explotación forestal (150 000 USD) }\end{array}$ \\
\hline Funte: Zaderenko, Constantino, sobre
\end{tabular}

Fuente: Zaderenko, Constantino, sobre la base de datos de informantes calificados de la región.

\section{Abastecimiento a usina}

El transporte de rollos desde el campo de explotación forestal para chipear en usina se hará con camiones. Los camiones de caja playa son más aptos para transitar cerca de un $80 \%$ por caminos de tierra, como se plantea en este caso. El transporte de rollos desde el lugar de explotación hasta la usina simplifica dicha operación, frente al transporte de chips en grandes camiones jaula, que requeriría camiones de caja cerrada, de gran volumen $\left(60 \mathrm{~m}^{3}\right)$, con mayor exigencia de pavimento de caminos. La densidad estérea de chips es de aproximadamente $0,3 \mathrm{t} / \mathrm{m}^{3}$, mientras que las trozas tienen una densidad estérea de aproximadamente $0,8 \mathrm{t} / \mathrm{m}^{3}$.

Se propone utilizar camiones tipo Ford Cargo 14 000, con capacidad de carga de entre 10 y 14 t, con plataforma de carga playa de $2,4 \mathrm{~m}$ de ancho por $6 \mathrm{~m}$ de largo, equipados con parantes laterales para seguridad de transporte. Las trozas de rollos de mayor diámetro tendrán 20 a $35 \mathrm{~cm}$ en punta gruesa, mientras que los largos serán de 2,4 m, para permitir la carga de dos bultos colocados a lo largo, o en forma transversal, sobre la plataforma de carga del camión. Para obtener el costo de transporte por camión se consideran los costos fijos, como la inversión en camiones y equipos para carga y descarga de rollos, y el sueldo de choferes, y los variables, que dependen de los insumos, proporcionales a las distancias recorridas (Cuadro 13).

- Costos fijos: camión, tractor con grampa maderera, eventualmente un acoplado, y cargadora hidráulica con pala y grampa maderera.

- Costos variables: combustible, cambios de aceite y filtros, desgaste de neumáticos, reemplazos de baterías, reemplazos de cintas y pastillas de frenos, y mantenimiento periódico menor (services).

Además de los conceptos anteriores, las variables que inciden en los costos son:

1. Número de viajes diarios (mínimo 6 viajes/ camión).

2. Tiempo de viaje: para 6 viajes/día se asignan 2 horas por viaje de ida y vuelta, incluyendo tiempos de carga y descarga.

3. Duración de carga y descarga: media hora por cada operación. 
Potencial de desarrollo de plantaciones dendroenergéticas

en la Argentina

Cuadro 13. Costos fijos y variables del transporte por camión

\begin{tabular}{|c|c|}
\hline Concepto & Valor (ARS) \\
\hline $\begin{array}{l}\text { Camión tipo F-14000 playo, balancín neumático, } 2 \text { ejes traseros, 10-14t, motor } \\
\text { Cummins } 162 \text { HP }\end{array}$ & 1400000 \\
\hline $\begin{array}{l}\text { Amortización del camión ( } 25 \% \text { primer año y } 5 \% \text { siguientes, se estima } \\
\text { amortización en } 5 \text { años, } 500000 \mathrm{~km} \text { ). Año } 1\end{array}$ & 350000 \\
\hline Neumático de camión (duración 50000 km). Son 10 neumáticos en cada cambio & 8800 \\
\hline Reparación de frenos del camión, cada 50000 km & 15000 \\
\hline $\begin{array}{l}\text { Service de camión, cada } 20000 \text { km, aceite de motor, capacidad del cárter (más } \\
\text { filtro) } 20 \text { I }\end{array}$ & 10000 \\
\hline $\begin{array}{l}\text { Gasoil por año (Consumo de combustible } 250 \mathrm{~g} / \mathrm{HP} / \mathrm{hora}, 40 \mathrm{I} / \mathrm{h} \text {, a } 70 \mathrm{~km} / \mathrm{h}, 1,75 \\
\mathrm{~km} / \mathrm{I}, 0,57 \mathrm{l} / \mathrm{km} \text {. Recorrido medio } 420 \mathrm{~km} / \mathrm{día}=10080 \mathrm{~km} / \mathrm{mes}=121000 \mathrm{~km} / \\
\text { año = } 68970 \mathrm{I} .1 \mathrm{I}=23 \mathrm{ARS} \text { ) }\end{array}$ & 1586310 \\
\hline Litro de aceite de motor & 120 \\
\hline $\begin{array}{l}\text { Litro de aceite de caja de velocidades y diferencial, capacidad } 15 \text { I (Hipoidal 80- } \\
\text { 90) }\end{array}$ & 80 \\
\hline Filtro de aire & 1500 \\
\hline Filtro de aceite & 240 \\
\hline Filtro de combustible & 715 \\
\hline Litro de líquido de frenos & 120 \\
\hline Litro de aceite de dirección hidráulica & 90 \\
\hline Sueldo chofer, mensual & 16000 \\
\hline Seguro chofer, mensual & 300 \\
\hline Seguro camión, anual & 8800 \\
\hline Precio de terceros en la región de Misiones, t/km & 4,25 \\
\hline $\begin{array}{l}\text { Costo total de transporte en } \mathrm{t} / \mathrm{km} \text { (viaje de regreso, sin carga, incluido en el } \\
\text { precio) }\end{array}$ & 9,35 \\
\hline
\end{tabular}

Fuente: Zaderenko, Constantino, sobre la base de datos de informantes calificados de la región. 
4. Velocidad de transporte: $60 \mathrm{~km} / \mathrm{h}$ de ida $y$ $80 \mathrm{~km} / \mathrm{h}$ de vuelta, promedio $70 \mathrm{~km} / \mathrm{h}$.

5. Con un tiempo neto de viaje de camión de 1 hora, a velocidad promedio de $70 \mathrm{~km} / \mathrm{h}$, el radio de abastecimiento queda limitado a un radio de $35 \mathrm{~km}$.

6. Horarios disponibles para carga y transporte de rollos, limitados por disponibilidad luz natural, de 6:00 a 18:00 h (12 h diarias).

La instalación de chipeado en usina consistirá en una playa de descarga y acopio de rollos, una chipera con sistema de alimentación y un galpón depósito de combustible (material chipeado). El acondicionamiento de biomasa combustible se considera hasta su depósito en el galpón de acopio de combustible. Una cargadora hidráulica con pala y grampa maderera (doble función) realizará la descarga de camiones colocando los rollos sobre una mesa de alimentación transversal inclinada ascendente, que dosificará los rollos que serán transportados longitudinalmente, en forma continua de uno en uno, a la boca de la chipera. Los costos se presentan en el Cuadro 14.
El excedente de rollos (los que no se puedan colocar directamente sobre la mesa de alimentación) se apilará en la playa aledaña, y conformará un stock para horarios y períodos de no recepción de camiones. Precio del sistema de alimentación a chipera: con mesa de 5 cadenas transportadoras transversales ascendentes (unitizador de rollos) y transportador a cadena o cinta longitudinal (100 000 USD): 1800000 ARS. La potencia de motores del sistema de alimentación es de $10 \mathrm{~kW}$. La cargadora tendrá como segunda función mover las pilas de chips dentro del depósito de combustible para colocarlas sobre el sistema de piso reciprocante de alimentación a caldera, y también para airear las pilas a fin de reducir su contenido de humedad.

\section{Chiperas a tambor}

El sistema de descarga de rollos a la mesa de alimentación a chipera y la chipera se incorporan a la usina como parte de su equipamiento. Los operadores de descarga de rollos y alimentación a chipera se consideran personal de planta mensualizado, a diferencia de los equipos y personal de carga y transporte de rollos de campo a usina, que

Cuadro 14. Costos de instalación del chipeado

\begin{tabular}{l|r}
\hline Concepto & Valor (ARS) \\
\hline Cargadora hidráulica con pala 100 HP & 2000000 \\
\hline Grampa maderera de 0,6 t & 1500000 \\
\hline Depreciación de equipos (25\% primer año y siguientes). Año 1 & 875000 \\
\hline Productividad 25 t/h & 140000 \\
\hline Services y mantenimiento (4\% por año) & 83950 \\
\hline Consumo de gasoil por año (22 I/h, 1I=23 ARS) & - \\
\hline Horas de disponibilidad diaria 24, 10 h/día de trabajo neto & 3200 \\
\hline Aceite hidráulico, capacidad del circuito, 40 I (capacidad del cárter del motor 19 I, \\
\hline \begin{tabular}{l} 
cambio aceite hidráulico por año) \\
\hline Jornal mensual del operador de cargadora (812 ARS/día, 24 días/mes)
\end{tabular} \\
\hline Seguro de operador & 19448 \\
\hline
\end{tabular}

Fuente: Zaderenko, Constantino, sobre la base de datos de informantes calificados de la región. 
Potencial de desarrollo de plantaciones dendroenergéticas en la Argentina

se consideran contratistas jornalizados. Los costos se presentan en el Cuadro 15.

La chipera será del tipo a tambor (picadora a tambor), de mayor eficiencia para la producción de astillas que las de disco, dado que para producir combustible triturado (hog fuel) no se requiere conservar las fibras de la madera como en el caso de chips para pulpado, cuyas dimensiones es preciso poder regular.

Se considera que resultará más eficiente el empleo de una chipera de $200 \mathrm{HP}$ (150 kW) con capacidad para rollos de $35 \mathrm{~cm}$ en punta gruesa. Esta chipera trabajará en un turno, y producirá el combustible necesario para los tres turnos de usina.

Al evitar la partidora se reducen el costo de personal y los gastos de mantenimiento. El chipeado de rollos de eucaliptus se debe realizar en estado verde, para conservación del filo de las cuchillas de la chipera.

\section{Usinas de biomasa}

Los suministros críticos que se deben considerar para la localización de una usina de biomasa son:
- Agua de proceso y agua de enfriamiento.

- Biomasa combustible.

En ambos casos se debe garantizar la calidad y continuidad de los suministros. El precio del combustible y su transporte hasta la usina son los factores de mayor peso en los costos de operación.

Las instalaciones de generación de energía eléctrica con biomasa tienen a su vez consumos de energía eléctrica internos, que normalmente alcanzan cerca del $10 \%$ de la capacidad de generación de la usina.

Las instalaciones principales de una usina de biomasa forestal son:

- Sistema de preparación y acopio de combustible triturado, hog fuel.

- Sistema de abastecimiento y tratamiento de agua.

- Caldera híbrida (acuo-humotubular) o solo acuotubular.

- Máquina de vapor: motor a vapor o turbina de vapor.

- Alternador eléctrico.

Cuadro 15. Costos del chipeado

\begin{tabular}{l|c} 
Concepto & Valor (ARS) \\
$\begin{array}{l}\text { Chipera para rollos menores a } 15 \mathrm{~cm} \text { de diámetro, } 60 \mathrm{HP}, \text { partido de rollos gruesos } \\
\text { con partidora hidráulica }\end{array}$ & 700000 \\
\hline $\begin{array}{l}\text { Chipera para rollos de hasta } 20 \mathrm{~cm} \text { de diámetro, } 100 \mathrm{HP} \text {, partido de rollos gruesos } \\
\text { con partidora hidráulica }\end{array}$ & 1080000 \\
\hline $\begin{array}{l}\text { Chipera para rollos hasta } 30-35 \mathrm{~cm} \text { de diámetro, } 200 \mathrm{HP}(150 \mathrm{~kW}) \text {. Mando de rollos } \\
\text { de entrada, } 3 \mathrm{HP}\end{array}$ & 2000000 \\
\hline \begin{tabular}{l} 
Capacidad de producción chipera de $200 \mathrm{HP}, 83 \mathrm{~m}^{3}$ estéreos/h, $25 \mathrm{t} / \mathrm{h}$ \\
\hline $\begin{array}{l}\text { Partidora hidráulica para diámetro de } 30-35 \mathrm{~cm}, 25 \mathrm{HP} \\
\text { (en este caso se descarta su empleo) }\end{array}$
\end{tabular} & 800000 \\
\hline $\begin{array}{l}\text { Depreciación anual del equipo de chipeado (20\% por año para la chipera de 60 HP } \\
\text { con partidor, o solo chipera de } 200 \mathrm{HP})\end{array}$ & 400000 \\
\hline Afilado anual de cuchillas de chipera (2 juegos por semana, 500 ARS cada juego) & 52000 \\
\hline Consumo anual de lubricantes (10 kg/mes, 130 ARS/kg) & 15600 \\
\hline
\end{tabular}

Fuente: Zaderenko, Constantino, sobre la base de datos de informantes calificados de la región. 
Las usinas de biomasa forestal requieren un sistema de preparación, depósito y transporte interno de biomasa triturada hasta la tolva de alimentación al hogar de caldera.

Las calderas de biomasa forestal normalmente utilizadas son de tipo acuotubular o híbridas. Para las potencias planteadas en este trabajo, la caldera podrá ser de $21 \mathrm{~kg} / \mathrm{cm}^{2}$ (300 psi) de presión (a mayor presión mayor eficiencia), con capacidad para $7 \mathrm{t} / \mathrm{h}, 15 \mathrm{t} / \mathrm{h}$ y $30 \mathrm{t} / \mathrm{h}$ de vapor, en correspondencia con las potencias eléctricas de generación, y con sobrecalentamiento a $340-440{ }^{\circ} \mathrm{C}$, según exigencia de las turbinas. Estas calderas tienen rendimientos térmicos de entre 50 y $85 \%$, según su grado de recuperación de calor. En calderas que cuentan con precalentador de aire, economizador y reinyección de hollín, se logran rendimientos térmicos de alrededor de $80 \%$, y además se reduce la emisión de partículas no quemadas.

Los turbogeneradores serán del tipo "a condensación" y estarán compuestos por una turbina de vapor, reductor de velocidad y generador eléctrico en $13,2 \mathrm{kV}$.

Para generación eléctrica con potencias de hasta $1 \mathrm{MW}$ presentan ventajas los motores a vapor; a partir de $1 \mathrm{MW}$ resulta más conveniente el empleo de turbinas de vapor.

Para el agua de reposición de caldera se contará con abastecimiento de pozo profundo. El agua de alimentación de caldera deberá ser tratada por un sistema de ósmosis inversa, seguido de pulido por electrodesionización (EDI), considerando los requerimientos de pureza de agua exigidos para el vapor de turbina.

Para el enfriamiento de turbina se podrá utilizar agua de superficie, río o arroyo cercano a la planta, o también agua de pozo. Dado el elevado caudal de agua de refrigeración requerido por las turbinas que trabajan a condensación total, se necesitarán torres de enfriamiento para reducir el consumo de agua fresca.

Los gases de combustión pasarán por separadores de hollín ciclónicos con retorno al hogar antes de la salida por chimenea, para aumentar el rendimiento térmico de la caldera y reducir la polución.
Para usinas de biomasa de 0,5 a 2,0 MW con turbinas a vapor, se estima un costo indicativo total de instalación de 2500 USD/kW generado; para las de mayor potencia, a partir de $2 \mathrm{MW}$, el costo se reduce a 2000 USD, y continúa disminuyendo hasta 1000 USD/kW generado para potencias superiores a $15 \mathrm{MW}$.

Como ejemplo, dos instalaciones de la región, con capacidad de aproximadamente 3,5 MW cada una, requirieron inversiones del orden de 8500000 USD (2 429 USD/kW); el 65\% fue destinado a la caldera (5525000 USD), el 30\% al turbogenerador (2 550000 USD) y el 5\% (425 000 USD) al silo de combustible y tratamiento de agua.

El precio de fomento por MWh generado con biomasa asignado por la Secretaría de Gobierno de Energía, es de 110 USD (que con beneficios adicionales vigentes en 2017 alcanza 130 USD/MWh), mientras que el precio para generación convencional es de aproximadamente 65 USD/MWh (2,34 ARS/kWh y 1,17 ARS/kWh, respectivamente).

Una instalación para generación eléctrica de $400 \mathrm{~kW}$ con motor a vapor se cotiza en 525000 USD, es decir, 1400 USD/kW, aproximadamente.

El precio actual de la biomasa triturada (hog fuel) en la región es de 252 ARS/t (14 USD/t, con un precio del dólar de 18 ARS), lo que se puede tomar como referencia. El precio de referencia actual sobre la Ruta Nacional 14 para chips combustibles de especies nativas es de 480 ARS/t, y para chips combustibles de especies implantadas, de $400 \mathrm{ARS} / \mathrm{t}$.

El seguro de instalaciones industriales por mes es de $0,2 \%$ del valor de la instalación, lo que equivale a 1700 USD (o 30600 ARS).

El jornal mensual del operador de caldera/turbina es de 17000 ARS más un 22\% (contemplando cargas sociales, vacaciones y despido, que se debe multiplicar por 15 meses por año).

En cuanto a los costos de mantenimiento, debe considerarse como normal un valor de $4 \%$ del precio de las instalaciones, por año.

El consumo específico de vapor de una turbina es función de la potencia, de la presión de vapor y del grado de sobrecalentamiento del vapor. Para 
turbinas que trabajan a condensación, el consumo específico típico es:

- generación de 0,5 MW $6,5 \mathrm{~kg} / \mathrm{kWh}$

- generación de 1,0 MW $5,8 \mathrm{~kg} / \mathrm{kWh}$

- generación de 2,0 MW $5,5 \mathrm{~kg} / \mathrm{kWh}$

Para motores a vapor, el consumo específico típico es de 12 a $20 \mathrm{~kg} / \mathrm{kWh}$

Cuando existe la posibilidad de aprovechar el calor de condensación de la turbina, (cogeneración de energía eléctrica y térmica), el rendimiento del sistema de generación se incrementa notablemente. En caso contrario, del $100 \%$ de la energía contenida en el combustible, un $20 \%$ se disipa al medio ambiente como pérdidas de la caldera y un $3 \%$ como otras pérdidas; un $12 \%$ se transforma en energía eléctrica y un $65 \%$ se disipa en la condensación del vapor de escape de turbina.

En cambio, en cogeneración la energía eléctrica generada se mantiene en el $12 \%$, mientras que el calor del vapor de escape es aprovechado como energía térmica. Esto ocurre en los casos en que la turbina trabaja a contrapresión (sin condensación) y el total del calor contenido en el vapor de escape de turbina es aprovechado en procesos de calefacción, cocción y otros.

Normalmente, la cogeneración es parcial y se basa en extracciones de vapor a diferentes presiones, que se realizan en la turbina para procesos industriales o de calefacción, y el vapor restante es condensado.

El costo de obtención de vapor para procesos de secado en Misiones se encuentra en el orden de $9 \mathrm{USD} / \mathrm{t}$.

Para las instalaciones de usinas termoeléctricas se considera una amortización de 10 años y un período de repago de 5.

Para la carga de camiones en campo se requiere un motosierrista con ayudante, para el trozado de los rollos, y un operador de tractor con grampa, para la carga en los camiones. Seis días por semana en un turno de 8 horas por día.

Para el transporte se necesita un chofer de camión, 5 días por semana en un turno de 12 horas diarias. Para la descarga y el chipeado de rollos en usina se requiere un operador de la cargadora con grampa y pala, con un ayudante, y un operador de chipera con su respectivo ayudante, seis días por semana, en un turno diario.

\section{Estimación de la superficie necesaria para forestación dendroenergética}

El cálculo de la superficie de forestación necesaria para abastecer los casos de generación de energía planteados se basa en el siguiente razonamiento:

- el consumo específico de vapor de turbina para generación eléctrica multiplicado por la generación es igual al caudal de vapor necesario con su correspondiente entalpía;

- la entalpía total necesaria dividida por el rendimiento térmico de caldera da el calor que debe aportar el combustible:

- el calor útil del combustible es función de su contenido de humedad, de lo que resulta su poder calorífico útil;

- el calor que debe aportar el combustible dividido por su poder calorífico útil da el consumo de combustible de biomasa triturada en toneladas por hora, con el contenido de humedad que tiene;

- las toneladas de combustible por hora consumidas por la caldera corresponden a las toneladas de rollos que se deben suministrar a la usina.

Los rollos en estado verde tienen un contenido de humedad en base seca (CHbs) de alrededor de $80 \%$, e ingresan a la caldera con un $50 \%$; por lo tanto, para tener $1 \mathrm{t}$ de biomasa con $50 \%$ de $\mathrm{CHbs}$ se deben ingresar $1,2 \mathrm{t}$ de rollos en estado verde.

Si la plantación dendroenergética tiene un crecimiento medio de $182 \mathrm{t} /$ ha en un ciclo de 5 años, esto corresponde a 36,4 t/ha/año en estado verde.

El consumo de combustible de la caldera por día (t/día), previamente corregido por contenido de humedad en estado verde, se multiplica por los 365 días del año, de lo cual resulta el requerimiento anual de biomasa para combustión que se debe extraer de la plantación (en estado verde). 
Para obtener la superficie total necesaria para abastecer a la usina en forma sostenible, se debe multiplicar el requerimiento de tala rasa anual por 5 (años de crecimiento), y dividirlo por las 182 (toneladas de crecimiento por hectárea).

\section{Resultados}

El Cuadro 16 muestra que los costos de preparación y transporte de biomasa combustible se reducen con el aumento de potencia de la usina, estimados para una distancia de $10 \mathrm{~km}$.

El Cuadro 17 plantea que los consumos energéticos para preparación de biomasa se mantienen constantes con el aumento de potencia de usina.
Esto se debe a los consumos específicos no afectados por mayor producción.

El Cuadro 18 muestra que los requerimientos de biomasa combustible crecen proporcionalmente con el aumento de potencia de usina.

De la energía generada por la usina se descuenta el consumo de la energía utilizada en el acondicionamiento de biomasa combustible (desde el trozado de rollos en el campo hasta su consumo en usina).

El Cuadro 19 expone que el consumo de biomasa decrece levemente con el aumento de potencia de usina, y el aporte de combustibles y lubricantes se mantiene prácticamente constante.

Cuadro 16. Costos operativos de usinas de 0,5, 1,0 y 2,0 MW

\begin{tabular}{|c|c|c|c|}
\hline Acopio, transporte y triturado de biomasa forestal & \multicolumn{3}{|c|}{ Capacidad de usina } \\
\hline Tarea/Proceso & $0,5 \mathrm{MW}$ & $1,0 \mathrm{MW}$ & 2,0 MW \\
\hline Trozado de rollos en campo (ARS/t) & 16,76 & 16,76 & 16,76 \\
\hline Carga sobre camión (ARS/t) & 30,49 & 30,49 & 30,49 \\
\hline Suma parcial & 47,25 & 47,25 & 47,25 \\
\hline Transporte de campo a usina (ARS/t/km) & 9,35 & 9,35 & 9,35 \\
\hline Transporte a 10 km de distancia (ARS/t) & 93,5 & 93,5 & 93,5 \\
\hline $\begin{array}{l}\text { Total instalaciones de usina -con chipeado- } \\
\text { (ARS/kWh) }\end{array}$ & 0,84 & 0,77 & 0,63 \\
\hline $\begin{array}{l}\text { Total instalaciones de usina-usina (factor }=3,72 \mathrm{~kg} \\
\text { combustible verde/kWh) (ARS/t) }\end{array}$ & 3,12 & 2,86 & 2,34 \\
\hline Total gastos operativos con chipeado en usina (ARS/kWh) & 0,64 & 0,57 & 0,54 \\
\hline $\begin{array}{l}\text { Total gastos operativos con chipeado en usina } \\
\text { (factor }=3,72 \mathrm{~kg} \text { combustible verde/kWh) }\end{array}$ & 2,38 & 2,12 & 2,00 \\
\hline Mano de obra (ARS/kWh) & 2,05 & 1,28 & 0,90 \\
\hline $\begin{array}{l}\text { Mano de obra en usina (factor }=3,72 \mathrm{~kg} \text { combustible verde/ } \\
\mathrm{kWh} \text { ) (ARS/t) }\end{array}$ & 7,60 & 4,46 & 3,35 \\
\hline Total & 153,85 & 150,19 & 148,44 \\
\hline
\end{tabular}

Fuente: Zaderenko, Constantino, sobre la base de datos de informantes calificados de la región. 
Potencial de desarrollo de plantaciones dendroenergéticas en la Argentina

En la cogeneración, el costo del kWh puede llegar a compensarse totalmente con la venta de vapor.

\section{Rentabilidad de la producción de biomasa en función del costo de transformación en usinas}

Para ejemplificar la variación en el costo de transformación energética en función de distintos precios hipotéticos de adquisición de biomasa, se elaboraron los Cuadros 20 a 23, que resumen el costo de la energía para seis alternativas de usinas, correspondientes a potencias $0,5,1,0$ y 2,0 MW, con y sin opción de cogeneración (energía eléctrica y vapor).

Se parte de un precio base mínimo de 100 ARS/t de biomasa (con contenido de humedad, $\mathrm{CHbs}$, de $80 \%$, rollos en estado verde), y se evalúan las alternativas de 300, 400 y 500 ARS/t, para observar la repercusión de estas variaciones sobre el costo de la energía obtenida en cada caso.

El análisis de esos tres cuadros muestra que los costos disminuyen con el aumento de potencia de usina. Los costos de los kWh generados se reducen, y en consecuencia queda mayor margen

Cuadro 17. Consumos energéticos para acondicionamiento de biomasa combustible en usinas de $0,5,1,0$ y 2,0 MW

\begin{tabular}{l|c|c|c}
\hline Combustibles, lubricantes y energía eléctrica & \multicolumn{3}{|c}{ Capacidad de usina } \\
\hline Tarea/Proceso & $0,5 \mathrm{MW}$ & $1,0 \mathrm{MW}$ & $2,0 \mathrm{MW}$ \\
\hline Trozado de rollos en campo (kg/t) & 0,21 & 0,21 & 0,21 \\
\hline Carga sobre camión (kg/t) & 0,88 & 0,88 & 0,88 \\
\hline Transporte de campo a usina (kg/t) & 9,70 & 9,70 & 9,70 \\
\hline $\begin{array}{l}\text { Descarga y procesos en playa de abastecimiento de usina y en } \\
\text { depósito de combustible (kg/t) }\end{array}$ & 0,88 & 0,88 & 0,88 \\
\hline Total (kg/t) & 3,81 & 3,81 & 3,81 \\
\hline Operación usina (chipeado) (kWh/t) & 3,90 & 3,80 & 3,80 \\
\hline
\end{tabular}

Fuente: Zaderenko, Constantino, sobre la base de datos de informantes calificados de la región.

Cuadro 18. Biomasa necesaria para abastecer usinas de 0,5, 1,0 y 2,0 MW, en toneladas y superficie plantada

\begin{tabular}{l|c|c|c|}
\hline Requerimientos & \multicolumn{3}{|c}{ Capacidad de usina } \\
\hline Requerimiento de biomasa verde (t/h) & $0,5 \mathrm{MW}$ & $1,0 \mathrm{MW}$ & $2,0 \mathrm{MW}$ \\
\hline Áreas de explotación (ha/mes) & 2,1 & 3,95 & 7,5 \\
\hline $\begin{array}{l}\text { Áreas de plantación / explotación para abastecimiento } \\
\text { sustentable (ha) }\end{array}$ & 8 & 16 & 30 \\
\hline
\end{tabular}

Fuente: Zaderenko, Constantino, sobre la base de datos de informantes calificados de la región. 
Cuadro 19. Balance energético en usinas de 0,5, 1,0 y 2,0 MW

\begin{tabular}{|c|c|c|c|c|}
\hline \multirow{2}{*}{$\begin{array}{l}\text { Balance energético } \\
\text { Detalle }\end{array}$} & \multicolumn{4}{|c|}{ Capacidad de usina } \\
\hline & $\begin{array}{l}0,5 \mathrm{MW} \\
\text { Térmica }\end{array}$ & $\begin{array}{l}1,0 \mathrm{MW} \\
\text { Eléctrica }\end{array}$ & $\begin{array}{l}1,0 \mathrm{MW} \\
\text { Eléctrica }\end{array}$ & $\begin{array}{l}2,0 \mathrm{MW} \\
\text { Eléctrica }\end{array}$ \\
\hline Aporte de biomasa verde $(\mathrm{t} / \mathrm{h})$ & 2,1 & 3,95 & 3,95 & 7,5 \\
\hline Aporte de biomasa (kcal/h) & 4217500 & 7940950 & 7940950 & 15060090 \\
\hline $\begin{array}{l}\text { Consumo energético (combustibles } \\
\text { lubricantes) (I/kWh) }\end{array}$ & 0,05 & 0,04 & 0,04 & 0,04 \\
\hline Energía generada $(\mathrm{kWh} / \mathrm{h})$ & 500 & 1000 & 1000 & 2000 \\
\hline $\begin{array}{l}\text { Energía utilizada (Consumos internos de } \\
\text { usina) }(\mathrm{kWh} / \mathrm{h})\end{array}$ & 53 & 100 & 100 & 195 \\
\hline Energía media de chipeado (kWh/h) & 12 & 21,4 & 21,4 & 40,6 \\
\hline Energía generada neta (kWh) & 434,2 & 877,7 & 1766,7 & 1766,7 \\
\hline Energía de cogeneración (kcal/h) & - & - & 5161541 & - \\
\hline
\end{tabular}

Fuente: Zaderenko, Constantino, sobre la base de datos de informantes calificados de la región.

Cuadro 20. Balance económico con precio de biomasa de 100 ARS/t

\begin{tabular}{|c|c|c|c|c|c|c|c|c|c|}
\hline & \multicolumn{2}{|c|}{$\begin{array}{l}\text { Capacidad de } \\
\text { usina: } 0,5 \mathrm{MW}\end{array}$} & \multirow[t]{2}{*}{$\begin{array}{c}\% \\
\text { costos }\end{array}$} & \multicolumn{2}{|c|}{$\begin{array}{l}\text { Capacidad de } \\
\text { usina: } 1,0 \mathrm{MW}\end{array}$} & \multirow[t]{2}{*}{$\begin{array}{c}\% \\
\text { costos }\end{array}$} & \multicolumn{2}{|c|}{$\begin{array}{l}\text { Capacidad de } \\
\text { usina: } 2 \mathrm{MW}\end{array}$} & \multirow[t]{2}{*}{$\begin{array}{l}\% \\
\text { costos }\end{array}$} \\
\hline & Térmicé & Eléctrica & & Térmica & Eléctrica & & Térmica & Eléctrica & \\
\hline $\begin{array}{l}\text { Amortización de } \\
\text { equipos, seguros y } \\
\text { mantenimiento } \\
\text { (ARS/kWh) }\end{array}$ & \multicolumn{2}{|c|}{0,84} & 21 & \multicolumn{2}{|c|}{0,77} & 25 & \multicolumn{2}{|c|}{0,63} & 26 \\
\hline $\begin{array}{l}\text { Costo de biomasa } \\
\text { (ARS/kWh) }\end{array}$ & \multicolumn{2}{|c|}{0,44} & 11 & \multicolumn{2}{|c|}{0,40} & 13 & \multicolumn{2}{|c|}{0,37} & 15 \\
\hline $\begin{array}{l}\text { Costos de transporte y } \\
\text { operativos (ARS/kWh) }\end{array}$ & \multicolumn{2}{|c|}{0,64} & 16 & \multicolumn{2}{|c|}{0,57} & 19 & \multicolumn{2}{|c|}{0,54} & 22 \\
\hline $\begin{array}{l}\text { Costos de mano de } \\
\text { obra (ARS/kWh) }\end{array}$ & \multicolumn{2}{|c|}{2,05} & 52 & \multicolumn{2}{|c|}{1,28} & 42 & \multicolumn{2}{|c|}{0,90} & 37 \\
\hline $\begin{array}{l}\text { Costos de energía } \\
\text { térmica (ARS/t vapor) }\end{array}$ & - & 1,48 & - & - & 1,17 & - & - & 1,11 & - \\
\hline $\begin{array}{l}\text { Costo de energía } \\
\text { generada (ARS/kWh) }\end{array}$ & 3,98 & 2,50 & - & 3,01 & 1,84 & - & 2,44 & 1,33 & - \\
\hline $\begin{array}{l}\text { Precio de energía } \\
\text { generada (con } \\
\text { subsidio) (ARS/kWh) }\end{array}$ & \multicolumn{8}{|c|}{2,34} & - \\
\hline
\end{tabular}

Nota: se considera que la biomasa tiene un $\mathrm{CHbs}$ de $80 \%$.

Fuente: Zaderenko, Constantino, sobre la base de datos de informantes calificados de la región. 
Potencial de desarrollo de plantaciones dendroenergéticas en la Argentina

para incrementar el precio de compra de la biomasa.

Debe tenerse en cuenta que el precio mínimo que surge del modelo de producción de biomasa correspondiente a Mesopotamia Tierras Coloradas es de $938 \mathrm{ARS} / \mathrm{t}$ en base seca, lo que corresponde aproximadamente a $625 \mathrm{ARS} / \mathrm{t}$ en base húmeda, siempre sin contar el costo de la tierra. Esto da la pauta de que ni 500 ARS/t de biomasa (valor sensiblemente mayor que los del mercado en la provincia de Misiones) compensan el costo de producción.

Se observa que aun proyectos que se muestran como viables ( $2 \mathrm{MW}$ con cogeneración), lo son considerando el precio de la energía para comercializar con el subsidio correspondiente a energías renovables. Para el caso de la alternativa técnica y económicamente más eficiente entre las consideradas (2 MW), el límite de su viabilidad acepta un precio de compra de biomasa menor a $400 \mathrm{ARS} / \mathrm{t}$ base húmeda. Como se indicó, este precio no llega a compensar el costo del modelo de producción de biomasa estimado para Mesopotamia Tierras Coloradas, consideración válida también para el resto de los siete modelos analizados.

Por lo tanto, en principio, con estas determinaciones técnicas, la producción de energía en base a biomasa forestal cultivada, en los términos planteados y con los precios vigentes en 2017, no parece mostrar viabilidad económica, incluso considerando los subsidios que aplican al caso.

Cuadro 21. Balance económico con precio de biomasa de 300 ARS/t

\begin{tabular}{|c|c|c|c|c|c|c|c|c|c|}
\hline & \multicolumn{2}{|c|}{$\begin{array}{l}\text { Capacidad de } \\
\text { usina: } 0,5 \mathrm{MW}\end{array}$} & \multirow[t]{2}{*}{$\begin{array}{c}\% \\
\text { costos }\end{array}$} & \multicolumn{2}{|c|}{$\begin{array}{l}\text { Capacidad de } \\
\text { usina: } 1,0 \mathrm{MW}\end{array}$} & \multirow[t]{2}{*}{$\begin{array}{c}\% \\
\text { costos }\end{array}$} & \multicolumn{2}{|c|}{$\begin{array}{l}\text { Capacidad de } \\
\text { usina: } \\
2,0 \mathrm{MW}\end{array}$} & \multirow[t]{2}{*}{$\begin{array}{c}\% \\
\text { costos }\end{array}$} \\
\hline & Térmice & Eléctrica & & Térmica & Eléctrica & & Térmica & Eléctrica & \\
\hline $\begin{array}{l}\text { Amortización de equipos, } \\
\text { seguros y mantenimiento } \\
\text { (ARS/kWh) }\end{array}$ & \multicolumn{2}{|c|}{0,84} & 17 & \multicolumn{2}{|c|}{0,77} & 20 & \multicolumn{2}{|c|}{0,63} & 20 \\
\hline $\begin{array}{l}\text { Costo de biomasa } \\
\text { (ARS/kWh) }\end{array}$ & \multicolumn{2}{|c|}{1,33} & 27 & \multicolumn{2}{|c|}{1,19} & 31 & \multicolumn{2}{|c|}{1,12} & 35 \\
\hline $\begin{array}{l}\text { Costos de transporte y } \\
\text { operativos (ARS/kWh) }\end{array}$ & \multicolumn{2}{|c|}{0,64} & 13 & \multicolumn{2}{|c|}{0,57} & 15 & \multicolumn{2}{|c|}{0,54} & 17 \\
\hline $\begin{array}{l}\text { Costos de mano de obra } \\
\text { (ARS/kWh) }\end{array}$ & \multicolumn{2}{|c|}{2,05} & 42 & \multicolumn{2}{|c|}{1,28} & 34 & \multicolumn{2}{|c|}{0,90} & 28 \\
\hline $\begin{array}{l}\text { Costos de energía térmica } \\
\text { (ARS/t vapor) }\end{array}$ & & 1,48 & - & - & 1,17 & - & - & 1,11 & - \\
\hline $\begin{array}{l}\text { Costo de energía } \\
\text { generada (ARS/kWh) }\end{array}$ & 4,86 & 3,38 & - & 3,80 & 2,63 & - & 3,19 & 2,08 & - \\
\hline $\begin{array}{l}\text { Precio de energía } \\
\text { generada } \\
\text { (con subsidio) (ARS/kWh) }\end{array}$ & \multicolumn{8}{|c|}{2,34} & - \\
\hline
\end{tabular}

Nota: se considera que la biomasa tiene un $\mathrm{CHbs}$ de $80 \%$.

Fuente: Zaderenko, Constantino, sobre la base de datos de informantes calificados de la región. 
Cuadro 22. Balance económico con precio de biomasa de 400 ARS/t

\begin{tabular}{|c|c|c|c|c|c|c|c|c|c|}
\hline & \multicolumn{2}{|c|}{$\begin{array}{l}\text { Capacidad de } \\
\text { usina: } 0,5 \mathrm{MW}\end{array}$} & \multirow[t]{2}{*}{$\begin{array}{c}\% \\
\text { costos }\end{array}$} & \multicolumn{2}{|c|}{$\begin{array}{l}\text { Capacidad de } \\
\text { usina: } 1,0 \mathrm{MW}\end{array}$} & \multirow[t]{2}{*}{$\begin{array}{c}\% \\
\text { costos }\end{array}$} & \multicolumn{2}{|c|}{$\begin{array}{l}\text { Capacidad de } \\
\text { usina: } 2,0 \mathrm{MW}\end{array}$} & \multirow[t]{2}{*}{$\begin{array}{c}\% \\
\text { costos }\end{array}$} \\
\hline & Térmica & Eléctrica & & Térmica & Eléctrica & & Térmica & Eléctrica & \\
\hline $\begin{array}{l}\text { Amortización de equipos, } \\
\text { seguros y mantenimiento } \\
\text { (ARS/kWh) }\end{array}$ & \multicolumn{2}{|c|}{0,84} & 16 & \multicolumn{2}{|c|}{0,77} & 18 & \multicolumn{2}{|c|}{0,63} & 18 \\
\hline Costo de biomasa (ARS/kWh) & \multicolumn{2}{|c|}{1,77} & 33 & \multicolumn{2}{|c|}{1,58} & 38 & \multicolumn{2}{|c|}{1,50} & 42 \\
\hline $\begin{array}{l}\text { Costos de transporte y } \\
\text { operativos (ARS/kWh) }\end{array}$ & \multicolumn{2}{|c|}{0,64} & 12 & \multicolumn{2}{|c|}{0,57} & 14 & \multicolumn{2}{|c|}{0,54} & 15 \\
\hline $\begin{array}{l}\text { Costos de mano de obra } \\
\text { (ARS/kWh) }\end{array}$ & \multicolumn{2}{|c|}{2,05} & 39 & \multicolumn{2}{|c|}{1,28} & 30 & \multicolumn{2}{|c|}{0,90} & 25 \\
\hline $\begin{array}{l}\text { Costos de energía térmica } \\
\text { (ARS/t vapor) }\end{array}$ & - & 1,48 & - & - & 1,17 & - & - & 1,11 & - \\
\hline $\begin{array}{l}\text { Costo de energía generada } \\
\text { (ARS/kWh) }\end{array}$ & 5,31 & 3,83 & - & 4,20 & 3,02 & - & 3,56 & 2,45 & - \\
\hline $\begin{array}{l}\text { Precio de energía generada } \\
\text { (con subsidio) (ARS/kWh) }\end{array}$ & \multicolumn{8}{|c|}{2,34} & \\
\hline
\end{tabular}

Nota: se considera que la biomasa tiene un $\mathrm{CHbs}$ de $80 \%$.

Fuente: Zaderenko, Constantino, sobre la base de datos de informantes calificados de la región.

Cuadro 23. Balance económico con precio de biomasa de 500 ARS/t

\begin{tabular}{|c|c|c|c|c|c|c|c|c|c|}
\hline & \multicolumn{2}{|c|}{$\begin{array}{l}\text { Capacidad de } \\
\text { usina: } 0,5 \mathrm{MW}\end{array}$} & \multirow[t]{2}{*}{$\begin{array}{l}\% \\
\text { costos }\end{array}$} & \multicolumn{2}{|c|}{$\begin{array}{l}\text { Capacidad de } \\
\text { usina: } 1,0 \mathrm{MW}\end{array}$} & \multirow[t]{2}{*}{$\begin{array}{l}\% \\
\text { costos }\end{array}$} & \multicolumn{2}{|c|}{$\begin{array}{l}\text { Capacidad de } \\
\text { usina: } 2,0 \mathrm{MW}\end{array}$} & \multirow[t]{2}{*}{$\begin{array}{c}\% \\
\text { costos }\end{array}$} \\
\hline & Térmica & Eléctrica & & Térmica & Eléctrica & & Térmica & Eléctrica & \\
\hline $\begin{array}{l}\text { Amortización de equipos, } \\
\text { seguros y mantenimiento } \\
\text { (ARS/kWh) }\end{array}$ & \multicolumn{2}{|c|}{0,84} & 15 & \multicolumn{2}{|c|}{0,77} & 17 & \multicolumn{2}{|c|}{0,63} & 16 \\
\hline $\begin{array}{l}\text { Costo de biomasa (ARS/ } \\
\text { kWh) }\end{array}$ & \multicolumn{2}{|c|}{2,22} & 39 & \multicolumn{2}{|c|}{1,98} & 43 & \multicolumn{2}{|c|}{1,87} & 48 \\
\hline $\begin{array}{l}\text { Costos de transporte y } \\
\text { operativos (ARS/kWh) }\end{array}$ & \multicolumn{2}{|c|}{0,64} & 11 & \multicolumn{2}{|c|}{0,57} & 12 & \multicolumn{2}{|c|}{0,54} & 14 \\
\hline $\begin{array}{l}\text { Costos de mano de obra } \\
\text { (ARS/kWh) }\end{array}$ & \multicolumn{2}{|c|}{2,05} & 36 & \multicolumn{2}{|c|}{1,28} & 28 & \multicolumn{2}{|c|}{0,90} & 23 \\
\hline $\begin{array}{l}\text { Costos de energía térmica } \\
\text { (ARS/t vapor) }\end{array}$ & - & 1,48 & - & - & 1,17 & - & - & 1,11 & - \\
\hline $\begin{array}{l}\text { Costo de energía generada } \\
\text { (ARS/kWh) }\end{array}$ & 5,75 & 4,27 & - & 4,59 & 3,42 & - & 3,94 & 2,83 & - \\
\hline $\begin{array}{l}\text { Precio de energía generada } \\
\text { (con subsidio) (ARS/kWh) }\end{array}$ & \multicolumn{8}{|c|}{2,34} & - \\
\hline
\end{tabular}

Nota: se considera que la biomasa tiene un $\mathrm{CHbs}$ de $80 \%$.

Fuente: Zaderenko, Constantino, sobre la base de datos de informantes calificados de la región. 
6. CONCLUSIONES
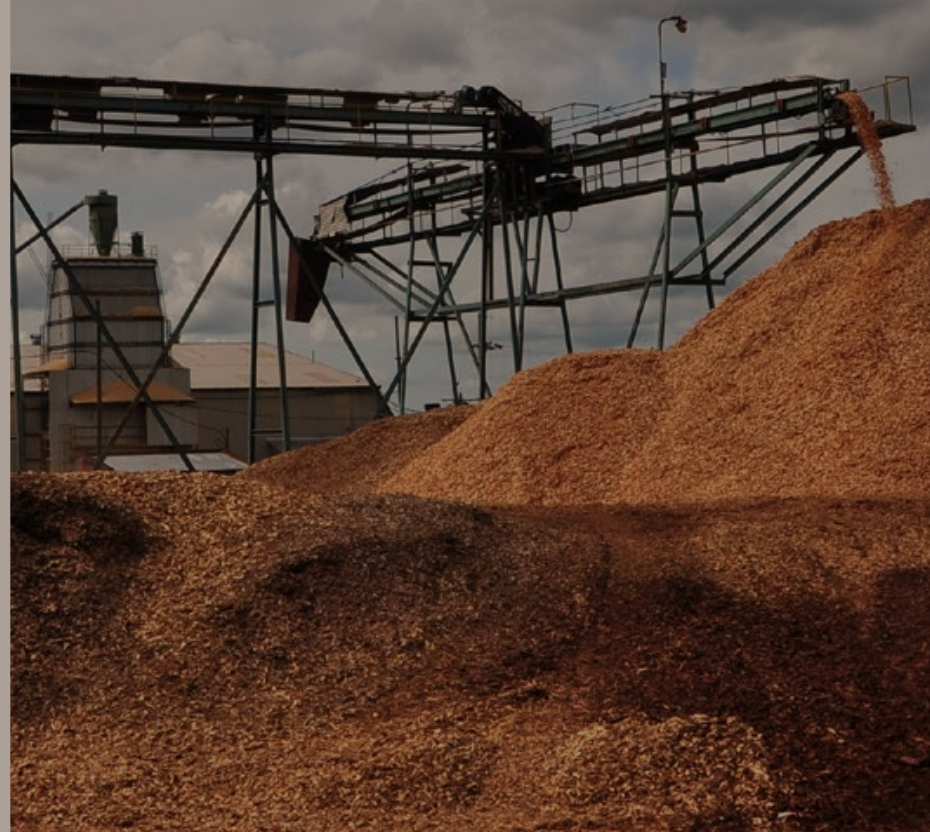

207.

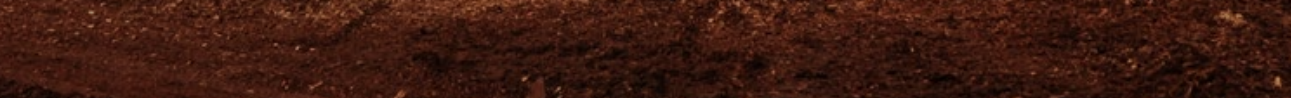


La actividad forestal en la República Argentina se estableció en regiones con suelos de diferentes potenciales productivos, donde las especies cultivadas permiten generar productos y subproductos, así como provisión de servicios.

En este documento, como resultado de un análisis integral que tomó en cuenta no sólo lo productivo sino también los aspectos ambientales y los servicios ecosistémicos, se analizaron cuatro regiones con potencial de producción de biomasa para energía: Mesopotamia, Pampeana, Central y Noroeste, con Eucalyptus, Salicáceas y Pinus.

De la cartografía de las áreas aptas y moderadamente aptas para cada una de las especies y regiones, se desprende que existen a nivel nacional unas 15252878 de hectáreas potencialmente aptas para plantaciones dendroenergéticas. De ellas, 2544057 se encuentran en la región Central; 5375463 en la Mesopotamia; 325104 en el NOA y 7008254 en la región Pampeana.

Por la casi inexistencia de información, el trabajo se basó en el conocimiento generado respecto de plantaciones comerciales destinadas a la producción de madera de calidad o para la industria celulósica.

Del análisis regulatorio efectuado cabe destacar que el elemento de tracción para la expansión de las plantaciones forestales con destino energético radica en el marco normativo de estímulo a la generación en base a ERNC y, una vez afianzado éste, en la configuración de un sistema que instaure y promocione la figura del "prosumidor", que conlleva la necesidad de un régimen de generación distribuida moderno y adecuado a las características del país.

El análisis económico mostró (para valores de 2017) que el precio mínimo esperado va de los 762 ARS/t, en la región Pampeana subregión 2 (E. dunnii), a los 1902 ARS/t en la región Chaco-Formosa. Esta variación obedece a factores que van desde las duraciones de cada proyecto modelizado hasta los rendimientos esperables, además de las estructuras de costo en cada modelo. Los modelos desarrollados son intensivos en mano de obra, por lo cual este rubro constituye uno de los componentes clave de la estructura de costos. En segundo lugar, influye fuertemente el costo del combustible. Por ello, los precios de la tonelada seca son muy sensibles a las variaciones de ambos costos.

La construcción de un modelo de generación dendroenergética, desarrollado para el noroeste de Misiones a partir de rollos de eucaliptus y en base a usinas de 0,5, 1,0 y 2,0 MW, permitió observar que el máximo precio de compra de materia prima, aun para el proyecto de menor costo de transformación de energía (2 MW con cogeneración de electricidad y vapor), no llegó a compensar el costo de producción de biomasa estimado para esa especie en suelos rojos.

Cabe resaltar el impacto positivo de la cogeneración de energía, que brinda a los proyectos dendroenergéticos una alta complementariedad en regiones del país donde deben satisfacerse los requerimientos de calor y/o vapor de la industria. Bajo las condiciones técnico-económicas analizadas para el modelo completo de generación de energía a partir de biomasa forestal, en todos los casos el proyecto muestra una viabilidad que depende económicamente de los precios relativos del sistema, y que siempre resulta más probablemente viable con cogeneración.

Frente a los impactos que puede tener la aplicación de estos modelos productivos altamente intensivos, se recomienda la implementación de buenas prácticas de manejo de suelos, del agua y de conservación de la biodiversidad, así como incorporar el monitoreo de la continua provisión de servicios ecosistémicos a diferentes escalas.

Por otro lado, los cultivos forestales con fines energéticos, monoespecíficos y de alta densidad, resultan sistemas altamente vulnerables a las actuales plagas y enfermedades exóticas invasoras, lo que puede convertirlos, a su vez, en fuentes-sumideros y generar serios problemas en el manejo sanitario de plantaciones aledañas con otros fines comerciales, entre ellos, las industrias de transformación mecánica. Es por ello que los temas de manejo sanitario resultan de gran relevancia. 


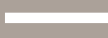

Bibliografía

Aguilar, S. 2014. "La promoción de energías renovables en Argentina: el caso GENREN", en Puentes Vol. 15 N. ${ }^{\circ}$. Ginebra. ICTSD.

Altomonte, H. (coord.). 2016. Las energías renovables no convencionales en la matriz de generación eléctrica. Santiago de Chile. CEPAL.

Bertero, R. 2015. Relevamiento y fortalecimiento del marco normativo de la producción y aprovechamiento de la biomasa destinada a la generación de energía. Buenos Aires. CEARE.

Bianchi, A.R. y S.A.C. Cravero. 2010. Atlas climático digital de la República Argentina. Estación Experimental Salta del Instituto Nacional de Tecnología Agropecuaria. Salta (Argentina). INTA.

Broto Cartagena, M. 2015. La biomasa para uso energético como negocio sostenible. Cuaderno Técnico N. ${ }^{\circ} 21$. Buenos Aires. INTI.

Comité Argentino del Consejo Mundial de Energía (CACME). 2016. Hacia la generación distribuida en la Argentina. Informes Anuales CAMMESA. Buenos Aires.

Crosara Benelli, A. (2001). Identificación de indicadores de sustentabilidad en plantaciones de Eucalyptus Globulus en el litoral del país. Montevideo, Universidad de la República.

FAO. 2004a. Perspectivas del sector forestal en Argentina. Roma.

FAO. 2004b. Tendencias y perspectivas del sector forestal al año 2020 en Argentina. Roma.

FAO. 2005. Situación de los bosques en el mundo. Roma.

FAO. 2006. Tendencias y perspectivas del sector forestal en América Latina y el Caribe al 2020. Roma.
FAO. 2007. Bosques y energía. Roma.

FAO. 2008. Bosques y energía: cuestiones clave. Roma.

FAO. 2009. Análisis del balance de energía derivada de biomasa en Argentina - WISDOM Argentina. Informe Final. Buenos Aires. Departamento Forestal Dendroenergía de FAO.

FAO. 2014. Poplars and willows: trees for society and the environment. Edited by J.G. Isebrands and J. Richardson. Roma.

FAO. 2016. Datos y cifras globales de productos forestales 2015, Roma, FAO.

Federico, J. 2012. Prospectiva tecnológica: complejo madera y muebles. Buenos Aires. MINCYT.

García Pizarro, R. 2016. “La generación eléctrica a partir de energías renovables no convencionales en Chile", en Altomonte, H. (coord.). Las energías renovables no convencionales en la matriz de generación eléctrica. Santiago de Chile. CEPAL.

Gomel, D. 2016. "El mapa de la generación distribuida de energías de fuentes renovables", en Clean Energy New, 15 de noviembre de 2016. Buenos Aires.

Instituto para la Diversificación y Ahorro de la Energía (IDAE). 2007a. Biomasa: cultivos energéticos. Madrid, Ministerio de Industria, Turismo y Comercio de España.

IDAE. 2007b. Energía de la biomasa. Manuales de Energías Renovables 2. Madrid. Ministerio de Industria, Turismo y Comercio de España.

IDEAR Desarrollo. 2016. Efectos de la implementación de la nueva ley de energías renovables. Buenos Aires.

Instituto Nacional de Tecnología Agropecuaria (INTA). 1990. Atlas de suelos de la República Argentina. Escala 1:500.000 y 1:1.000.000. Proyecto PNUD ARG 85/019. Centro de Investigaciones de Recursos Naturales. Castelar. Secretaría de Agricultura, Ganadería y Pesca.

INTA. 2016. Potencial de desarrollo de plantaciones dendroenergéticas en Argentina. Buenos Aires. INTA.

Klingebiel, A.A. y P.H. Montgomery. 1961. Land-capability classification. Soil conservation serive. Washington D.C. United States Departament of Agriculture (USDA). 
Lozanoff, J., S. Heinichen, G. Marchi y E. Risso. 2007. Bioenergía. Revisión de tecnologías emergentes. Buenos Aires. Jefatura de Gabinete de la Nación.

Marco, L., E. Goldstein y B. Griffa. 2017. Generación de energía eléctrica a partir de biomasa. Experiencias y actualidad en Argentina. Buenos Aires. USAM.

MINCYT. 2015a. Plan operativo: biorrefinerías. Buenos Aires.

MINCYT. 2015b. Plan Operativo: producción y procesamiento de recursos forestales. Buenos Aires. MINEM. 2016. Balance Energético Nacional (disponible en: http://www.energia.gob.ar/contenidos/ verpagina.php?idpagina=3366).

Morrone, M. 2016. Programa RenovAr. Energías renovables en la Argentina. Buenos Aires. Dirección Nacional de Promoción de Energías Renovables.

Patiño Díez, J. y R. Smith. 2008. "Consideraciones sobre la dendroenergía bajo un enfoque sistémico", en Revista Energética N. ${ }^{\circ}$ 39. Medellín (Colombia). Universidad Nacional de Colombia.
Secretaría de Energía de la Nación. 2009. Energías renovables en la Argentina. Buenos Aires.

Sharry, S. 2013. Producción y procesamiento de recursos forestales. Buenos Aires, MINCYT .

Uasuf, A. y J. Hilbert. 2012. El uso de la biomasa de origen forestal con destino a bioenergía en la Argentina. Buenos Aires. INTA.

Unidad para el Cambio Rural (UCAR). 2015. Argentina: plantaciones forestales y gestión sostenible. Buenos Aires. Ministerio de Agricultura, Ganadería y Pesca.

Villalonga, J. 2013. Energías renovables. Buenos Aires. Grupo de Energías Renovables.

Zoratti, A. y O. Guzmán. 2015a. Energías renovables. Análisis de la situación institucional sectorial. Buenos Aires. Documento de proyecto CEPAL-Secretaría de Energía.

Zoratti, A. y O. Guzmán. 2015b. Energías renovables. Evolución del contexto legal. Buenos Aires. Documento de proyecto CEPAL-Secretaría de Energía. 

POTENCIAL DE DESARROLLO

DE PLANTACIONES DENDROENERGÉTICAS

EN LA ARGENTINA

$N^{\circ} 18$

COLECCIÓN DOCUMENTOS TÉCNICOS

Organización de las Naciones Unidas

para la Alimentación y la Agricultura (FAO)

www.fao.org

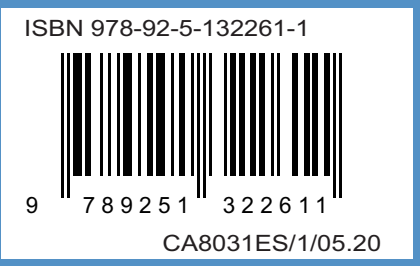

